$$
\begin{aligned}
& \text { UNIVERSIDADE DE SÃO PAULO } \\
& \text { ESCOLA DE ENGENHARIA DE SÃO CARLOS } \\
& \text { INSTITUTO DE FÍSICA DE SÃO CARLOS } \\
& \text { INSTITUTO DE QUÍMICA DE SÃO CARLOS }
\end{aligned}
$$

RONALDO SOARES TEIXEIRA

\title{
Utilização de resíduos sucro-alcooleiros na fabricação de fibrocimento pelo processo de extrusão
}

São Carlos

2010 



\section{RONALDO SOARES TEIXEIRA}

\section{Utilização de resíduos sucro-alcooleiros na fabricação de fibrocimento pelo processo de extrusão}

Dissertação apresentada ao Programa de Pós-Graduação Interunidades em Ciência e Engenharia de Materiais, da Universidade de São Paulo para obtenção do título de Mestre em Ciência e Engenharia de Materiais.

Área de Concentração: Desenvolvimento, Caracterização e Aplicação de Materiais.

Orientador: Prof. Dr. Francisco Antonio Rocco Lahr

São Carlos 


\begin{abstract}
AUTORIZO A REPRODUÇÃO E DIVULGAÇÃO TOTAL OU PARCIAL DESTE TRABALHO, POR QUALQUER MEIO CONVENCIONAL OU ELETRÔNICO, PARA FINS DE ESTUDO E PESQUISA, DESDE QUE CITADA A FONTE.
\end{abstract}

Ficha catalográfica elaborada pelo Serviço de Biblioteca e Informação IFSC/USP

Teixeira, Ronaldo Soares

Utilização de resíduos sucro-alcooleiros na fabricação de fibrocimento pelo processo de extrusão./ Ronaldo Soares Teixeira; orientador Francisco Antonio Rocco Lahr. -- São Carlos, 2010.

$133 p$.

Dissertação (Mestrado em Ciência e Engenharia dos Materiais Área de concentração: Desenvolvimento, Caracterização e Aplicação de Materiais) - Escola de Engenharia de São Carlos, Instituto de Física de São Carlos, Instituto de Química de São Carlos da Universidade de São Paulo.

1. Fibras de bagaço de cana-de-açúcar. 2. Cinzas de bagaço de cana-de-açúcar. 3. Processo de extrusão. 4. Tratamento químico. 5. Compósitos cimentício. I. Título. 


\section{FOLHA DE APROVAÇÃO}

Ronaldo Soares Teixeira

Dissertação apresentada ao Programa de Pós-Graduação em Ciência e Engenharia de Materiais da Universidade de São Paulo para obtenção do título de Mestre em Ciência e Engenharia de Materiais.

Área de Concentração: Desenvolvimento, Caracterização e Aplicação de Materiais.

Aprovado(a) em 14.10.2010

Comissão Julgadora

Prof(a). Dr(a). Francisco Antonio Rocco Lahr

Instituição: EESC/USP

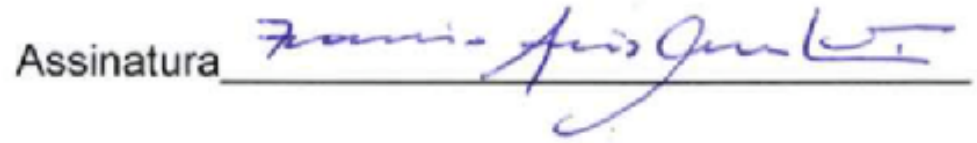

Prof(a). Dr(a). Holmer Savastano Junior

Instituição: FZEA/USP

Assinatura

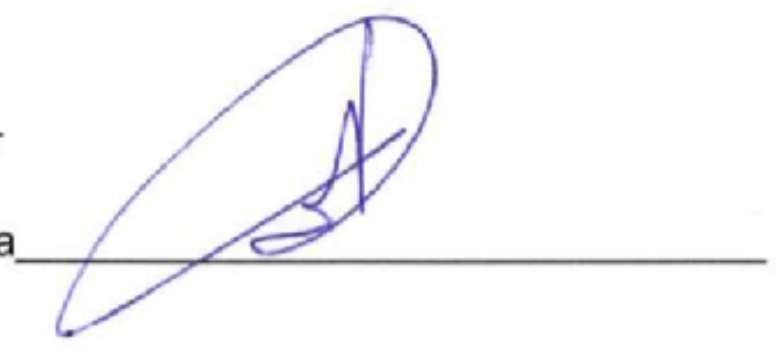

Prof(a). Dr(a). Raquel Gonçalves

Instituição: UNICAMP

Assinatura_ R.mm 



\section{DEDICATÓRIA}

Aos meus pais Valter e Conceição, minha namorada Gisele, pela paciência, compreensão e pelo amor e principalmente meu irmão Rodrigo (in memorian), pelo anos vividos em sua companhia que serão eternos por toda minha 



\section{AGRADECIMENTOS}

Principalmente agradeço a Deus pela vida, pela minha família e pelos meus amigos.

Aos Profs. Dr. Francisco A. Rocco Lahr e Holmer Savastano Junior pelo contínuo incentivo, orientação e supervisão.

Ao Prof. Dr. Gustavo Henrique Denzin Tonoli e ao Dr. Sergio Francisco dos Santos que colaboraram diretamente na execução deste trabalho.

A Profa. Dr. Catharina Gomide da FZEA/USP pelo apoio na realização do ensaio de Bromatologia.

Ao grupo de Construções \& Ambiência (C\&A) da FZEA/USP: Zaqueu, Humberto, Viviane, Priscila, Débora, Alessandra, Camila, Melissa, Tiago, Aline, Mariane Marcos, Yatsen e Prof. Dr. Juliano e do laboratório de Madeiras e Estruturas de Madeira (LAMEM) da EESC/USP: Fátima, Marcio e Aparecido pelo coleguismo e aprendizagem.

Aos colegas Rui, Brunoro, Cesar do laboratório de microestrutura do Departamento de Engenharia Civil da Escola Politécnica da USP pelo apoio na realização dos ensaios mecânicos e do desenvolvimento deste trabalho.

À Fundação de Amparo à Pesquisa do Estado de São Paulo pela concessão da bolsa de Mestrado.

A colega Michelle da FEAGRI (UNICAMP) pela troca de experiência e auxilio na execução do trabalho.

A todos os familiares e amigos que incentivaram este período de dedicação exclusiva à ciência. 

"Eu mantenho o tema dos meus estudos sempre diante de mim, e espero até o amanhecer iniciar gradualmente, pouco a pouco, numa luz clara e completa."

Isaac Newton 



\section{RESUMO}

TEIXEIRA, R. S. Utilização de resíduos sucro-alcooleiros na fabricação de fibrocimento pelo processo de extrusão. 2010. 133p. Dissertação (Mestrado) Escola de Engenharia de São Carlos, Instituto de Física de São Carlos, Instituto de Química de São Carlos da Universidade de São Paulo, São Carlos, 2010.

Este trabalho avalia a utilização de fibras e cinzas de bagaço de cana-de-açúcar em compósitos cimentícios extrudados. Este trabalho visa ao estudo da potencialidade do emprego da fibra e cinza do bagaço da cana-de-açúcar na construção civil, a fibra e a cinza uma vez que o aproveitamento deste produto em matrizes cimentícias representa uma boa alternativa para diminuição de gastos com locais para deposição do resíduo, evita a degradação do meio ambiente. A cinza de bagaço de cana-de-açúcar apresenta características pozolânicas, além de garantir uma redução do consumo de cimento. Fibras de bagaço de cana-de-açúcar (FBC) foram classificadas por peneiramento, lavadas em água fervente para reduzir o açúcar residual e foi tratado quimicamente com silicato de sódio e sulfato de alumino com finalidade de proteger as fibras contra a agressão do meio alcalino proporcionado pelo cimento, imobilizar a matéria orgânica e reduzir a absorção de água, diminuindo as variações dimensionais e proporcionar melhor qualidade no compósito, tais como durabilidade e evitar o ataque de microorganismo. As cinzas de bagaço de cana-de-açúcar ( $\mathrm{CBC}$ ) foram queimadas com temperatura e tempo controlado para ter um ótimo grau de amorficidade e conseqüentemente maior reatividade. A moagem também foi efetuada a fim de melhorar a reatividade da cinza. Foi realizada uma série de ensaios de caracterização da CBC. A atividade pozolânica foi averiguada por ensaio condutividade elétrica. $O$ desempenho mecânico e físico e na microestrutura dos compósitos de fibrocimento foram avaliados. Os compósitos foram avaliados antes e após ciclos de envelhecimento acelerado. A extrusão foi utilizada como uma alternativa ao processo Hatschek na produção de compósitos cimentícios com geometrias diferenciadas e na produção em pequena escala. Os resultados apresentam que a fervura da FBC reduz o açúcar residual e o tratamento químico mineralizou as $\mathrm{FBC}$ de forma rápida. As CBC apresentaram o valor de sílica elevada. Os resultados mecânicos e físicos apresentaram resultados satisfatórios. Foram produzidos placas com 0,5\%, 1,0\% 
1,5\%, 3,0\% e 5,0\% de níveis de reforço de FBC. Compósitos extrudados com $5 \%$ de reforço de FBC com 28 dias de cura apresentaram melhores resultados em tenacidade (TE), devido à maior introdução de FBC no compósito, mas não apresentou diferença entre o tratamento químico. Compósitos extrudados com $5 \%$ de reforço de FBC tratada 200 ciclos de envelhecimento apresentaram maior absorção de água (AA) e porosidade aparente (PA). Esse fato se deve a explicado com a maior hidratação do cimento que ocasionou mineralização drástica da FBC e descolagem da fibra na interface fibra e matriz. Compósito extrudado com $5 \%$ de FBC tratada com 28 dias e 200 ciclos com a substituição de cimento por $30 \%$ de CBC apresentou diminuição de módulo de ruptura (MOR) e maior absorção de água (AA). Este fato deve ser explicado pela substituição do matriz (agregado) e maior relação água/cimento da mistura ocasionado pela sua superfície específica. Novos estudos devem ser realizados para a melhor adequação das fibras e cinzas e do processo de extrusão para viabilizar futuramente seu uso em escala industrial.

Palavras-chave: Fibras de bagaço de cana-de-açúcar, Cinzas de bagaço de canade-açúcar, Processo de extrusão, Tratamento químico, Compósitos cimentícios. 
ABSTRACT

TEIXEIRA, R. S. Use residual of sugar and alcohol in the manufacture of cement by the extrusion process. 2010. 133p. Dissertação (Mestrado) - Escola de Engenharia de São Carlos, Instituto de Física de São Carlos, Instituto de Química de São Carlos da Universidade de São Paulo, São Carlos, 2010.

This study evaluates the use of fibre and ash from sugar cane bagasse in extruded cementitious composites. This work aims to study the potential of the use of fibre and ash from sugarcane bagasse in construction, fibre and ash since the use of this product in cementitious matrices represents a good alternative to reduce expenses with local deposition of the waste, prevents the degradation of the environment. The ash sugar cane bagasse has pozzolanic characteristics, and ensures a reduction in cement consumption. Fibres from sugar cane bagasse (FSB) were classified by sieving, washed in boiling water to reduce the residual sugar and has been chemically treated with sodium silicate and aluminium sulphate in order to protect the fibres against the aggression of alkaline provided by the cement, immobilize the organic material and reduce the absorption of water, reducing size variations and provide better quality in the composite, such as durability and prevent the attack of microorganisms. The ashes of sugar cane bagasse (ASB) were burned with controlled temperature and time to have a great degree of amorphous and consequently higher reactivity. The grinding was also performed to improve the reactivity of the ashes. We performed a series of tests to characterize the ASB. The pozzolanic activity was determined by electrical conductivity test. The physical and mechanical performance and microstructure of cement composites were evaluated. The composites were evaluated before and after cycles of accelerated ageing. Extrusion was used as an alternative to the Hatschek process in the production of cementitious composites with different geometries and small scale production. The results show that boiling FSB reduces the residual sugar and chemically treated to mineralized FSB quickly. The ASB showed the value of high silica. The mechanical and physical results showed satisfactory results. Plates were produced with $0.5 \%$ $1.0 \% 1.5 \% 3.0 \%$ and $5.0 \%$ of enhanced levels of FSB. Composites extruded with $5 \%$ increase of FSB with 28 days of healing showed better results in toughness (TE) due to introduction of increased FSB in the composite, but no difference between the chemical treatments. Composites extruded with $5 \%$ strengthening of FSB treated 
200 ageing cycles had higher water absorption (AA) and apparent porosity (AP). This fact can be explained with the higher hydration of cement which caused drastic mineralization FSB and off the fibre and fibre-matrix interface. Extruded composite with 5\% FSB treated with 28 days and 200 cycles with replacement of cement by $30 \%$ of $A S B$ showed low modulus of rupture (MOR) and higher water absorption (AA). This fact must be explained by replacing the matrix (aggregate) and higher water/cement ratio of the mixture caused by its specific surface. Further studies should be conducted to better match the fibre and ash and the extrusion process to enable its future use in industrial scale.

Keywords: Fibre sugar cane bagasse, Ash sugar cane bagasse, Extrusion process, Chemical treatment, Cementitious composites. 


\section{LISTA DE FIGURAS}

Figura 1 - llustração do modelo de parede celular com complexo lignocelulolítico (33).

Figura 2 - Representação esquemática do comportamento à flexão de um compósito sem fibras e um reforçado com fibras (35)

Figura 3 - Diagramas tensão $x$ deformação. (a) Comportamento frágil; (b) comportamento dúctil: 1 - limite de proporcionalidade e 2 módulo de ruptura; (c) área hachurada sob a curva indica a energia específica do material (25)

Figura 4 - Representação esquemática do caminhamento da fissura através da matriz reforçada com fibras: (1) e (2) descolamento da fibra; (3) arrancamento da fibra; (4) rompimento da fibra (53)

Figura 5 -

Detalhes do mecanismo de funcionamento do processo de extrusão. Adaptado (80).

Figura 6Fluxograma detalhadas das fases dos experimentos do projeto

Figura 7 (a) Agitador de peneiras, (b) peneira de 16 mesh (abertura $1,18 \mathrm{~mm}$ ) e (c) fibra retida e utilizada nos experimentos.

Figura 8 -

Câmara climática marca Thermotron utilizada na determinação de absorção de água

Figura 9 - Multipicnômetro a gás hélio Quantachrome, Ultrapycnometer 1000

Figura 10 - Vista geral de um espectrofotômetro de infravermelho (FTIR)...

Figura 11 - Esquema da curva de queima e calcinação do bagaço de cana-de-açúcar.

Figura 12 - Fotos das montagens de bandejas refratárias com bagaço de cana-de-açúcar, dentro das câmaras das muflas.

Figura 13 - Foto do moinho de bolas com jarro de porcelana

Figura 14 - llustração do condutivímetro DM-32 da Digimed.

Figura 15 - Sistema de medida de condutividade elétrica com controle de temperatura. (a) Detalha a disposição do condensador Allihn, agitador magnético com aquecimento e controlador digital de temperatura. (b) Indica a disposição da célula de condutividade e do balão volumétrico de três bocas na base do agitador.

Figura 16 - Ilustração da janela de identificação do programa de aquisição de dados do condutivímetro DM-32 da Digimed...... 
Figura 17 - Foto da extrusora do Laboratório de Construções e Ambiência, da FZEA da Universidade de São Paulo..................

Figura 18 - (a) Vista frontal da máquina extrusora à vácuo. (b) Vista lateral ilustrando a saída de massa pela boquilha. (c) Colocação de um corpo extrudado sobre uma placa metálica.

Figura 19 - Dimensões do corpo-de-prova usado nos experimentos.

Figura 20 - (a) Vista geral da máquina de ensaios mecânicos da marca Instron, modelo 5569; (b) Dispositivo de flexão com quatro cutelos.

Figura 21 - Definição dos parâmetros mecânicos em uma curva típica de tensão vs deflexão específica (108).

Figura 22 - Visão geral do microscópio eletrônico de varredura (MEV)......... 77

Figura 23 - (a) Vista geral do Permeâmetro; (b) Dispositivo de coleta de pressões de ar de entrada (Pe) e pressão de saída (Ps).

Figura 24 - (a) Estufa automática de operação dos ciclos de imersãosecagem; (b) Disposição das placas no interior do equipamento.

Figura 25 - Distribuição do diâmetro de partículas: (a) cimento Portland (CPV-ARI); (b) sílica cristalina \#500.

Figura 26 - Dimensões nominais das fibras de bagaço de cana-de-açúcar:

(a) comprimento ( $\mathrm{mm}$ ); (b) espessura $(\mathrm{mm})$.

Figura 27 - Determinação de absorção de água por variação em massa (\%) das FBC natural, não-tratada e tratada em relação à porcentagem de umidade

Figura 28 - Difratômetro de raios-X da FBC natural com sua intensidade em relação ao ângulo de difração $(2 \Theta)$

Figura 29 - Espectro na região de infravermelho da FBC natural, não tratada e tratada.

Figura 30 - Características morfológicas da FBC observadas por microscopia eletrônica de varredura (MEV).

Figura 31 - Micrografia eletrônica de varredura (MEV): (a) fibra natural; (b) fibra não tratada (fervida); (c) fibra tratada com seus respectivos pontos de análise em EDS.

Figura 32 - Distribuição do diâmetro de partículas da cinza de bagaço de cana-de-açúcar

Figura 33 - Difratograma de raios $X$ das cinzas de bagaço..........................

Figura 34 - Características morfológicas das partículas observadas por microscopias eletrônicas de varredura: (a) e (b) cinza de bagaço. 
Figura 35 - Condutividade elétrica de CBC e sílica cristalina do sistema de hidróxido de cálcio, em temperatura constante de $60^{\circ} \mathrm{C}$

Figura 36 - Efeito dos níveis de reforço nos resultados físicos e mecânicos de fibras de bagaço de cana-de-açúcar tratadas e não tratadas: (a) módulo de ruptura (MOR); (b) tenacidade (TE); (c) densidade aparente (DA) e (d) porosidade aparente (PA) em compósitos cimentícios extrudados com 28 dias de idade..

Figura 37 - (a) Micrografia de superfície de fratura de elétrons secundários de compósito cimentício extrudado com $5 \%$ de fibra de bagaço de cana-de-açúcar tratada com 28 dias; (b) alinhamento das fibras na direção do fluxo do compósito (127)

Figura 38 - Efeito dos níveis de reforço os resultados físicos e mecânicos de fibras de bagaço de cana-de-açúcar tratadas e não tratadas: (a) módulo de ruptura (MOR); (b) módulo elástico (MOE); (c) absorção de água (AA) e (d) porosidade aparente (PA) em compósitos cimentícios extrudados com 200 ciclos de envelhecimento.

Figura 39 - Micrografias de superfície de fratura de compósitos cimentícios extrudados com $5 \%$ de fibra de bagaço de cana tratada com 200 ciclos de envelhecimento

Figura 40 - Efeito dos níveis de reforço nos resultados físicos e mecânicos de fibras de bagaço de cana-de-açúcar não tratadas: (a) módulo elástico (MOE); (b) tenacidade; (c) densidade aparente (DA) e (d) porosidade aparente (PA) em compósitos cimentícios extrudados de 28 dias VS. 200 ciclos de envelhecimento.

Figura 41 - Curvas tensão-deformação para compósitos cimentícios extrudados com fibras de bagaço de cana-de-açúcar não tratada e tratada com diferentes níveis de reforço: (a) 28 dias; (b) 200 ciclos de envelhecimento.

Figura 42 - Micrografias de superfície de fratura de compósitos cimentícios extrudados com $5 \%$ de fibra de bagaço de cana tratada com 200 ciclos de envelhecimento.

Figura 43 - Efeito dos níveis de reforço nos resultados físicos e mecânicos de fibras de bagaço de cana-de-açúcar não tratadas e tratadas com substituição de cimento por $30 \%$ de cinza de bagaço de cana-de-açúcar com 28 dias e 200 ciclos de envelhecimento: $(\mathrm{a}, \mathrm{b})$ módulo de ruptura (MOR) VS absorção de água (AA).

Figura 44 - Imagens em microscopia eletrônica de varredura (MEV-BSE) de superfícies polidas de compósitos reforçados com: (a) 0\% de reforço com 28 dias; (b) $5 \%$ de reforço com 28 dias; (c) $5 \%$ de reforço tratada com 28 dias; (d) $5 \%$ de reforço com 200 ciclos de envelhecimento e $(e, f) 5 \%$ de reforço tratado com $30 \%$ de substituição de cinzas com 28 dias. Pontos de análises de EDS estão sinalizados nas imagens (pontos 1 a 14). 
Figura 45 - Porosimetria por intrusão de mercúrio (PIM) acumulativa em compósitos extrudados com $0,0 \%, 1,5 \%$ e $5,0 \%$ de reforço em fibra de bagaço de cana-de-açúcar............................................

Figura 46 - Influência da permeabilidade ao ar nos compósitos cimentícios extrudados com 28 dias. 


\section{LISTA DE TABELAS}

Tabela 1 - Propriedades físicas e mecânicas das fibras de bagaço de cana-de-açúcar.

Tabela 2 - Características físicas da polpa de eucalipto não-branqueada* (94)

Tabela 3 - Formulações utilizadas nas moldagens (Valores \% em volume de matéria prima).

Tabela 4 - Composição química (\% em massa de óxidos) dos cimentos Portland (CPV-ARI) e sílica cristalina.

Tabela 5 - Área superficial específica determinada pelo método BET a densidade real pelo método de deslocamento de hélio do cimento Portland CPV-ARI e da sílica cristalina utilizadas

Tabela 6 - Resultado da determinação de teor de açúcar residual............... 83

Tabela 7 - Resultado da densidade da FBC 86

Tabela 8 - Resultado da análise bromatológica em porcentagem em massa utilizando como base a massa seca em 100\% da FBC natural e não tratada (fervida)

Tabela 9 - Resultado do índice de cristalinidade da FBC

Tabela 10 - Composição química (em \% em massa de óxidos) da cinza de bagaço utilizada.

Tabela 11 - Área de superfície específica das cinzas de bagaço de cana......

Tabela 12 - Resultado da densidade real da CBC

Tabela 13 - Comparação de custo de matérias-primas por produção de compósito cimentício. 


\section{LISTA DE ABREVIATURAS}

AA - $\quad$ Absorção de Água;

ABNT - $\quad$ Associação Brasileira de Normas Técnicas;

ADVA - $\quad$ Adivitivo Poliéter carboxílico;

ASTM - $\quad$ American Society for Testing and Materials;

BSE - $\quad$ Backscattering Eletrons (Elétrons Retroespalhados);

CBC- Cinza de bagaço de cana-de-açúcar;

CPV-ARI - Cimento Portland tipo V de Alta Resistência Inicial;

CSF - $\quad$ Canadian Standard Freeness;

CONAB - Companhia nacional de abastecimento;

DA - $\quad$ Densidade Aparente;

EDS - $\quad$ Energy Dispersive Spectroscopy (espectroscopia de raios-X por energia dispersiva);

EN - $\quad$ European Standard;

FBC - $\quad$ Fibra de bagaço de cana-de-açúcar;

FTIR Fourier transform infrared spectroscopy

HPMC - Hidroxipropilmetilcelulose;

LOP - $\quad$ Limite de Proporcionalidade;

MEV - Microscopia Eletrônica de Varredura;

MOE - Módulo Elástico;

MOR - Módulo de Ruptura;

$\mathrm{OH}-\quad$ Hidroxila;

PIM - $\quad$ Porosimetria por Intrusão de Mercúrio;

OPC - $\quad$ Ordinary Portland Cement (Cimento Portland Comum);

RILEM - $\quad$ Reunion Internationale Des Laboratoires D'Essais Et Des Recheches

Sr lex Materiaux Et Les Constructions;

SE - $\quad$ Secondary Electrons (Elétrons Secundários);

RPM - Rotação por minuto;

PA - $\quad$ Porosidade Aparente;

TE - $\quad$ Tenacidade;

VS - Versus; 


\section{LISTA DE SÍMBOLOS}

b - $\quad$ Largura do compósito;

$\delta$ - $\quad$ Deflexão Específica;

$\rho$ - $\quad$ Densidade da água;

h - $\quad$ Espessura do compósito;

$\mathrm{I}_{\mathrm{C}}-\quad$ Índice de crstalinidade

L - $\quad$ Espessura da amostra;

$\mathrm{L}_{1}$ - $\quad$ Intensidade de difração mínima, referente à região não cristalina;

$\mathrm{L}_{2}-\quad$ Intensidade de difração mínima, referente à região cristalina;

$\mathrm{L}_{v}$ - $\quad$ Medida do maior vão do aparato de ensaio mecânico;

$\mathrm{L}_{0}-\quad$ Comprimento longitudinal do compósito seco (inicial);

$\mathrm{L}_{\mathrm{t}}$ - $\quad$ Comprimento longitudinal do compósito após t min dentro de câmara climática em diferentes condições de umidade;

$\mathrm{k}_{1}$ - Constantes de permeabilidade;

$k_{2}-\quad$ Constantes de permeabilidade;

m - $\quad$ Tangente do ângulo de inclinação da curva força vs deflexão durante a deformação elástica;

$\mathrm{M}_{\mathrm{sss}}$ - $\quad$ Massa do compósito saturado em água, mas com a superfície seca;

$\mathrm{M}_{\mathrm{seca}}$ - $\quad$ Massa do compósito seco em estufa;

$\mathrm{M}_{\mathrm{i}}-\quad \quad \quad$ Massa do compósito saturado imerso em água;

$\mathrm{P}$ - $\quad$ Força;

$P^{2}-\quad$ Pressões de entrada de ar;

$\mathrm{Po}^{2}{ }_{-} \quad$ Pressões de saída do ar;

$\mu-\quad$ Viscosidade do fluido;

$\rho-\quad$ Densidade do fluido;

$\mathrm{P}_{\text {lop }}-\quad$ Força no ponto da parte linear da curva força vs deflexão;

$\mathrm{P}_{\max }-\quad$ Força máxima atingida durante o ensaio mecânico;

$\mathrm{R}^{2}$ - Coeficiente de correlação;

$\mathrm{t}$ - $\quad$ Tempo;

$\sigma-\quad$ Tensão;

$2 \theta$ - $\quad$ Ângulo de Bragg;

v - Velocidade do fluido;

$z-\quad$ Eixo z; 



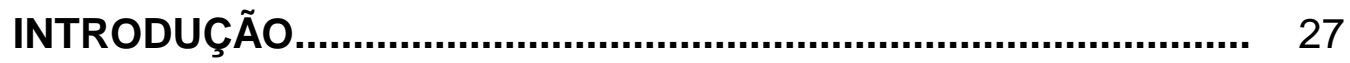

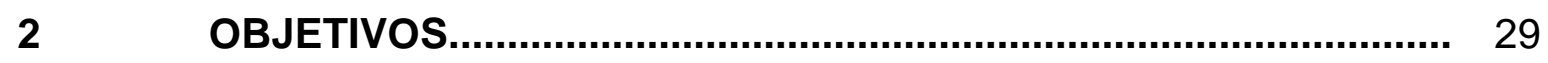

$3 \quad$ REVISÃO BIBLIOGRÁFICA..................................................... 31

3.1 3.1 Breve histórico da utilização das fibras de cana-de-açúcar como reforço.............................................................................

3.2 A utilização de fibras vegetais em fibrocimentos......................... 32

3.3 Fibras lignocelulósicos e sua composição.................................. 33

3.4 O papel das fibras na matriz cimentícia........................................ 34

3.5 Produção de cana-de-açúcar...................................................... 35

3.5.1 Fibra de bagaço de cana-de-açúcar............................................ 36

3.5.2 Tratamento químico nas fibras de cana-de-açúcar.......................... 37

3.5.3 Utilização do bagaço de cana-de-açúcar como pozolana................. 38

3.6 Mecanismos de tenacificação proporcionados pelas fibras....... 39

3.7 Cimento Portland e principais forças de adesão entre as fases do compósito..

3.8 Durabilidade dos compósitos..................................................... 42

3.9 Processo de Produção por extrusão............................................. 44

3.9.1 Características do processo de extrusão...................................... 46

3.9.2 Modificadores reológicos...................................................... 46

3.10 Comentários finais sobre a revisão bibliográfica Materiais........ 47

$4 \quad$ MATERIAIS E MÉTODOS.......................................................... 49

4.1 Planejamento dos experimentos ......................................................... 49

4.2 Fibras de bagaço de cana-de-açúcar (FBC)........................................ 51

4.2.1 Classificação das fibras (peneiramento).................................................. 51

4.2.2 Lavagem das fibras.................................................................... 52

4.3 4.3 Métodos do estudo da FBC...................................................... 52

4.3.1 Determinação do teor de extrativos de açúcares residuais da FBC........... 52

4.3.2 Tratamento químico das FBC....................................................... 53

4.3.3 Determinação das dimensões nominais das FBC............................ 54 
4.3.4 Determinação de absorção de água nas FBC................................ 54

4.3.5 Determinação da densidade das FBC............................................ 55

4.3.6 Análise Bromatológica das fibras................................................ 56

4.4 Caracterizações microestruturais das FBC................................ 56

4.4.1 Difração de raios-X (DRX) das FBC............................................ 56

4.4.2 Espectroscopia na região do Infravermelho (FTIR) das FBC............ 57

4.4.3 Microscopia eletrônica de varredura (MEV) das FBC...................... 58

4.5 Obtenção das cinzas de bagaço de cana-de-açúcar (CBC)......... 59

4.5.1 Procedimento de queima......................................................... 59

4.6 Métodos do estudo da CBC.................................................... 61

4.6.1 Espectroscopia de fluorescência de Raios-X das CBC.................... 61

4.6.2 Distribuição granulométrica das CBC............................................ 62

4.6.3 Área de superfície específica das CBC....................................... 62

4.6.4 Determinação da densidade das CBC........................................ 62

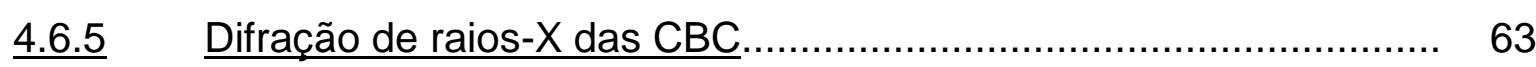

4.6.6 Microscopia eletrônica de varredura (MEV) das CBC...................... 63

4.6.7 Avaliação das reações pozolânicas das CBC através de condutividade elétrica............................................................... 64

4.7 Caracterização e preparação das matérias-primas cimentícias. 66

4.7.1 Preparação das matrizes de compósitos cimentícios........................ 67

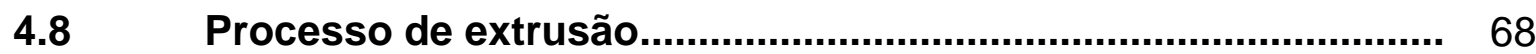

4.9 Caracterizações dos compósitos................................................. 73

4.9.1 Caracterização mecânica dos compósitos....................................... 73

4.9.2 Caracterização física dos compósitos............................................. 75

4.9.3 Microscopia eletrônica de varredura dos compósitos (MEV)............ 76

4.9.4 Distribuição do tamanho de poros dos compósitos (PIM)................ 77

4.9.5 Permeabilidade ao ar dos compósitos........................................... 78

4.10 Envelhecimento acelerado (imersão-secagem)........................... 79

$5 \quad$ RESULTADOS E DISCUSSÃO................................................. 81

5.1 Caracterização das matérias-primas............................................ 81

5.2 Resultados do estudo da FBC 83

5.2.1 Resultado da determinação do teor de extrativos de açúcares residuais

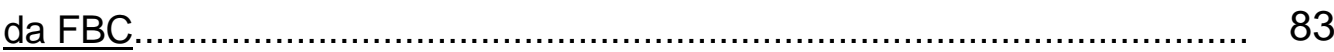


5.2.2 Resultado da determinação das dimensões nominais das FBC....... 84

5.2.3 Resultados da determinação de absorção de água nas FBC........... 84

5.2.4 Resultados da determinação da densidade das FBC...................... 85

5.2.5 Resultado da análise Bromatológica das fibras............................... 86

5.3 Resultado das Caracterizações microestruturais das FBC......... 87

5.3.1 Resultado da difração de raios-X (DRX) das FBC............................ 87

5.3.2 Resultado da espectroscopia na região do Infravermelho (FTIR)

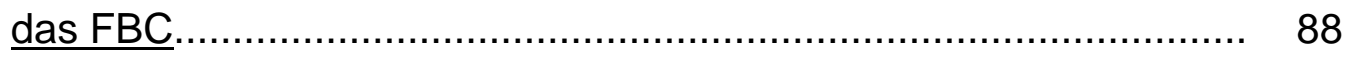

5.3.3 Resultado da microscopia eletrônica de varredura (MEV) das FBC. 89

5.3.4 Considerações parciais dos resultados da FBC............................. 92

5.4 Resultado do estudo da caracterização das cinzas de bagaço de cana-de-açúcar (CBC)........................................................... 92

5.4.1 Resultado da espectroscopia de fluorescência de Raios-X das CBC

5.4.2 Resultado da distribuição granulométrica das CBC......................... 93

5.4.3 Resultado da área de superfície específica das CBC...................... 94

5.4.4 Resultado da determinação da densidade das CBC......................... 94

5.4.5 Resultado da difração de raios-X das CBC.................................... 95

5.4.6 Resultado microscopia eletrônica de varredura (MEV) das CBC...... 96

5.4.7 Resultado da avaliação das reações pozolânicas das CBC através de condutividade elétrica........................................................... 97

5.4.8 Considerações parciais dos resultados das CBC............................ 98

5.5 Resultados da caracterização microestruturais dos compósitos cimentícios extrudados.......................................... 98

5.5.1 Resultados físicos e mecânicos dos compósitos cimentícios extrudados .................................................................... 98

5.5.2 Resultado da microscopia eletrônica de varredura (MEV) em compósitos cimentícios extrudados............................................ 106

5.5.3 Resultado da porosimetria por intrusão de mercúrio nos compósitos (PIM) .......................................................... 110

5.5.4 Resultado da permeabilidade ao ar dos compósitos........................ 112

5.5.5 Resultado do custo de produção por matéria prima 113 
6.1 Sugestões para trabalhos futuros ............................................. 117

REFERÊNCIAS..................................................................................... 118

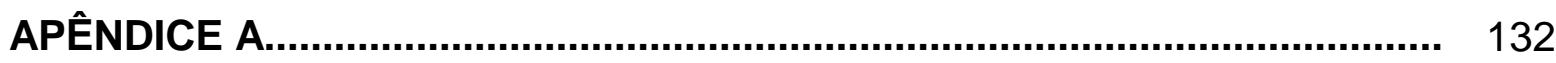

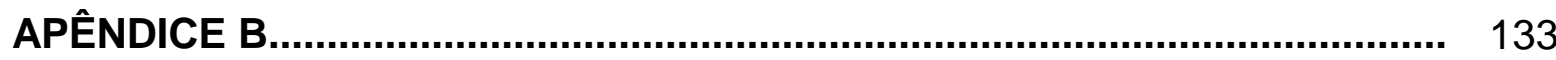




\section{INTRODUÇÃO}

Milhares de toneladas de resíduos industriais e agrícolas gerados no processo de transformação de matérias-primas de diferentes segmentos são produzidas anualmente, sendo que atualmente a maioria destes materiais não possui aplicação específica e gera problemas de contaminação do meio ambiente devido a sua deposição desordenada. Nos países desenvolvidos existe uma tendência muito forte de regulamentar a questão da deposição dos resíduos no meio ambiente. As atividades da engenharia civil são grandes consumidoras de materiais de construção e, conseqüentemente, potenciais fontes de emprego de resíduos. Nos últimos anos, tem-se verificado um crescente número de trabalhos voltados para a utilização e o aproveitamento de resíduos industriais e agrícolas na produção de diversos materiais voltados para o setor da construção civil, como argamassas, blocos, painéis e concretos (1).

A estimativa da produção brasileira de cana-de-açúcar na safra de 2010 é superar a marca de 664 milhões de toneladas segundo dados do Conab (2).

A utilização de fibras naturais como reforços em pastas, concretos tem-se relevado de grande importância, pois permite a obtenção de produtos chamados de compósitos que, alem de apresentarem menor massa específica aparente, apresentam também valores satisfatórios de resistência a tração e ao impacto, maior controle da fissuração, alem de comportamento dúctil na ruptura.

Freqüentemente as áreas de engenharia e ciências dos materiais são pressionadas a oferecerem ao mercado materiais baratos mais do que materiais resistentes. (3).

A co-geração de energia a partir do bagaço da cana-de-açúcar origina um resíduo, a cinza do bagaço, que tem papel importante no contexto da reciclagem.

Grande parte destas cinzas apresenta características pozolânicas, ou seja, mesmo sem ter, isoladamente, valor aglomerante, reagem, quando finamente moídas e em presença de água, com o hidróxido de cálcio $\mathrm{Ca}(\mathrm{OH})_{2}$ para formar compostos aglomerantes (4).

A reciclagem pode contribuir bastante com a diminuição das áreas destinadas à deposição de resíduos e dos custos que isto acarreta. A incorporação de resíduos 
na produção de materiais pode reduzir o consumo de energia para a produção do mesmo produto sem resíduos e, dependendo de onde esteja localizado o resíduo e seu mercado consumidor potencial, reduzir distâncias de transporte e contribuir para a redução da poluição gerada (5).

Com o objetivo de reduzir a geração de resíduos nos processos industriais e agrícolas, principalmente os poluentes, bem como melhor reaproveitá-los, seja no próprio processo produtivo ou como matéria-prima na elaboração de outros materiais, tem-se investido cada vez mais em pesquisas para a transformação destes, até então considerados apenas resíduos, em co-produtos de interesse comercial (6).

A fabricação de produtos de fibrocimento em escala industrial é realizada principalmente pelo processo Hatschek. Estudos recentes apresentam o processo de extrusão como alternativa econômica de manufatura com a produção de elementos construtivos com características mecânicas e físicas semelhantes ou ainda melhores que os oriundos do processo Hatschek (7-12). Segundo Horst (13), as extrusoras utilizadas na indústria de cerâmica são adaptáveis para o processo de extrusão de materiais de fibrocimento, por conseguinte assume-se que os valores de investimento para a implementação de uma linha de produção de fibrocimento por extrusão sejam valores próximos ao de uma linha de materiais cerâmicos e com capacidade de produção instalada semelhante.

A proposta desse trabalho tem como objetivo estudar dois resíduos sólidos da indústria sucro-alcooleira, a saber, fibras e cinzas de bagaço de cana-de-açúcar, para fins de obtenção de fibrocimento pelo processo de extrusão, avaliar sua adequação como compósito cimentício, determinado pelas suas características físicas e mecânicas e comparando-as como material projetados para o mesmo fim. 


\section{OBJETIVOS}

O objetivo deste trabalho é avaliar o desempenho de compósitos cimentícios por processo de extrusão reforçado com fibra de bagaço de cana-de-açúcar e substituição parcial do cimento por cinza de bagaço de cana-de-açúcar.

Os objetivos específicos são:

- Utilização de fibra de bagaço de cana-de-açúcar tratada quimicamente como reforço em compósitos cimentícios extrudados;

- Substituição parcial do cimento pela cinza de bagaço de cana-de-açúcar em compósitos extrudados; 


\section{REVISÃO BIBLIOGRÁFICA}

Neste item são abordadas as informações bibliográficas consideradas mais relevantes a respeito das fibras de bagaço de cana-de-açúcar e cinzas provenientes da queima do bagaço, abordados nas condições de reforço e de substituição parcial do cimento em compósitos cimentícios respectivamente. Estão também apresentadas as principais causas da degradação das fibras na matriz cimentícia, o tratamento químico e a produção de compósitos cimentícios por extrusão.

\subsection{Breve histórico da utilização das fibras de cana-de-açúcar como reforço}

Noticias sobre o emprego do bagaço de cana-de-açúcar para fins de obtenção de materiais de construção remontam à primeira metade do século XX (14).

Cuba foi o primeiro país do mundo a produzir industrialmente chapas de fibras de bagaço de cana-de-açúcar, em 1929. Na construção civil, as chapas isolantes são empregadas no revestimento e acabamentos de interiores (15).

Hesch (16) reportou a instalação de uma indústria para a transformação de bagaço de cana-de-açúcar em placas destinadas à fabricação de móveis e componentes da edificação. Essa fábrica foi instalada no Paquistão e se destinava a produzir placas de três camadas, de grande resistência mecânica e superfície de excelente qualidade. Embora as fibras de bagaço de cana-de-açúcar não tenham sido utilizadas com absoluto sucesso como reforço de chapas de cimento, devido à sua baixa resistência em meio alcalino, se adequadamente tratadas com aditivos químicos ou protegidas superficialmente com asfalto aluminizado, são duráveis e podem ser usadas como elemento de cobertura.

Bourlin (17) relatou um processo de fabricação de concreto leve pela incorporação de fibras de bagaço de cana-de-açúcar, neutralizadas quimicamente, a uma pasta de cimento. Após moldagem e cura de 21 dias, a $82^{\circ} \mathrm{C}$, os corpos-deprova de concreto apresentaram massa especifica de $1,2 \mathrm{~kg} / \mathrm{dm}^{3}$ e resistência à 
compressão de 8,08 MPa. Com esses resultados apresentados há possibilidades do emprego desse produto na construção civil.

Como componente de material de construção, o bagaço tem sido usado de várias formas, como as relatadas por Paturau (18), que se referiu a produtos patenteados, feitos à base de bagaço de cana-de-açúcar aglomerado com cimento Portland. Ainda de acordo com Paturau (18), embora o material apresente vantagens associadas ao alto índice de enfeltramento e à baixa massa especifica aparente, sua fibra, com alta capacidade de absorção de água, podem restringir o uso em compósitos. Além disso, açúcar residual (sacarose) e microorganismos (levedura, actinomicetos e fungos), eventualmente presentes no início do processo fermentativo, podem levar a significativas mudanças na quantidade e qualidade da matéria prima fibrosa, pois alguns organismos termofílicos têm a capacidade de decompor o material celular.

\subsection{A utilização de fibras vegetais em fibrocimentos}

Atualmente, compósitos de fibrocimento podem ser encontrados em produtos como caixas d'água e materiais de construção não estruturais, principalmente produtos de baixa espessura como telhas e placas planas, para forros e divisórias. As fibras têm sido empregadas em materiais cimentícios para promover o aumento da ductilidade e tenacidade (19-22).

As fibras lignocelulósicas vêm recebendo considerável atenção no desenvolvimento dos compósitos sem o uso do amianto, por apresentarem vantagens como disponibilidade, baixo custo e aspectos favoráveis quanto às questões ambientais (biodegradabilidade), dentre outros (23). Durante as últimas três décadas, várias pesquisas foram desenvolvidas no intuito de encontrar substitutos para a fibra de amianto em produtos de fibrocimento largamente utilizados em construções (22,24-29). Pesquisas indicam que o desempenho mecânico dos compósitos estudados foi satisfatório, mas salientam que ajustes da formulação e dos parâmetros de processo devem ser investigados para melhorar a durabilidade. 


\subsection{Fibras lignocelulósicos e sua composição}

A biomassa vegetal é fonte inesgotável de recursos naturais, renováveis e disponíveis, apresentando-se na forma de resíduos industriais (serragem, maravalhas, cavacos, talos de frutas, etc.), agroindustriais (bagaço de cana-deaçúcar, casca e palha de cereais), ou partículas obtidas no meio rural através da desintegração mecânica de colmo (bambu) (30).

De acordo com Ramos (31) os resíduos agro-florestais, subprodutos decorrentes dos desdobros primário e secundário da exploração da madeira, e os resíduos agrícolas, materiais oriundos de atividades associadas ao ciclo produtivo de culturas como a cana-de-açúcar, o arroz, entre outros, são parcialmente utilizados como fonte de energia. A geração e acúmulo de resíduos não só representam um sério problema econômico como um problema ambiental de grandes proporções. De modo aproximado, estima-se que no Brasil sejam gerados anualmente cerca de 2,2 milhões de toneladas de casca de arroz, 23 milhões de toneladas de resíduos florestais (serrarias) e mais de 60 milhões de toneladas de bagaço de cana-de-açúcar, com teor de umidade variado. Contudo, nem todo este resíduo, somado aos derivados de outras atividades agroindustriais, tem sido desperdiçado. O setor agrícola já utiliza boa parte destes materiais para a produção de energia sob a forma de vapor. No entanto, o percentual não utilizado ainda representa um problema sócio-econômico complexo, agravado pela heterogeneidade destes materiais de natureza lignocelulósica (31).

As células vegetais apresentam parede celular formada por microfibrilas de celulose, imersas em uma matriz contendo polissacarídeos não celulósicos, os hemicelulósicos e pectinas (Figura 1). A microfibrila de celulose tem diâmetro entre de 10 a $25 \mathrm{~nm}$ de comprimento correspondente a até 100 moléculas que se unem por meio de pontes de hidrogênio, e mostra um arranjo ordenado, responsável por sua cristalinidade e birrefringência. A lignina é uma macromolécula tridimensional amorfa, associada à celulose na parede celular cuja função é de conferir rigidez, impermeabilidade e resistência (32). 


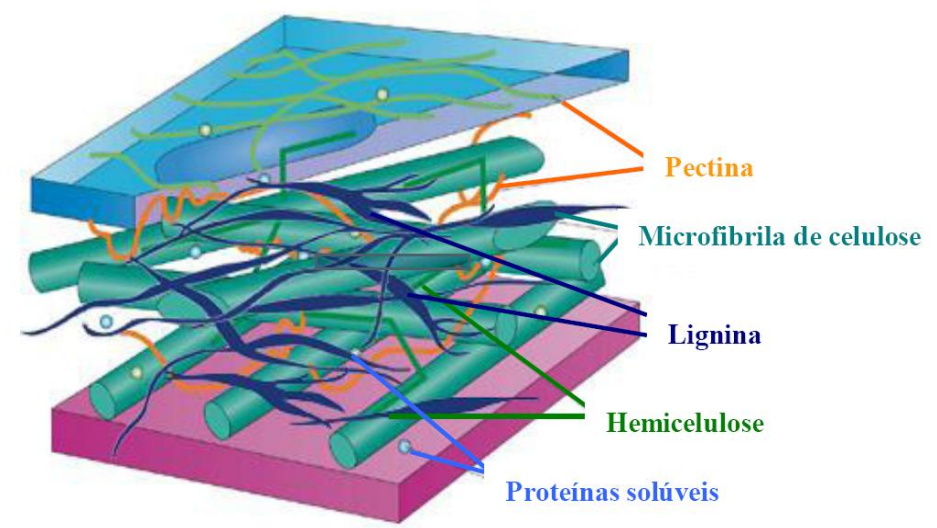

Figura 1 - Ilustração do modelo de parede celular com complexo lignocelulolítico (33).

\subsection{O papel das fibras na matriz cimentícia}

Normalmente, o concreto contém numerosas fissuras. Sua rápida propagação sob tensão é conseqüência da baixa resistência à tração do material.

De início, considerou-se que a resistência à tração na flexão do concreto podia ser aumentadas pela introdução de fibras próximas umas das outras, as quais poderiam obstruir a propagação de microfissuras. Com isto, seria retardado o início das fissuras e aumentada à resistência à tração do material. Estudos experimentais, porém, mostraram que determinadas argamassas ou concretos convencionais reforçados com fibras não proporcionam aumento substancial na resistência mecânica, em comparação às correspondentes misturas sem fibras. Entretanto, pesquisadores obtiveram considerável melhora na energia específica, criando possibilidade de trabalho no estágio pós-fissurado (Figura 2) e conferindo isolamento termo-acústico aceitável (34). Fica claro que o advento do reforço com fibras aumenta a versatilidade da argamassa como um material, propiciando um método efetivo para superar suas características de fragilidade (35). 


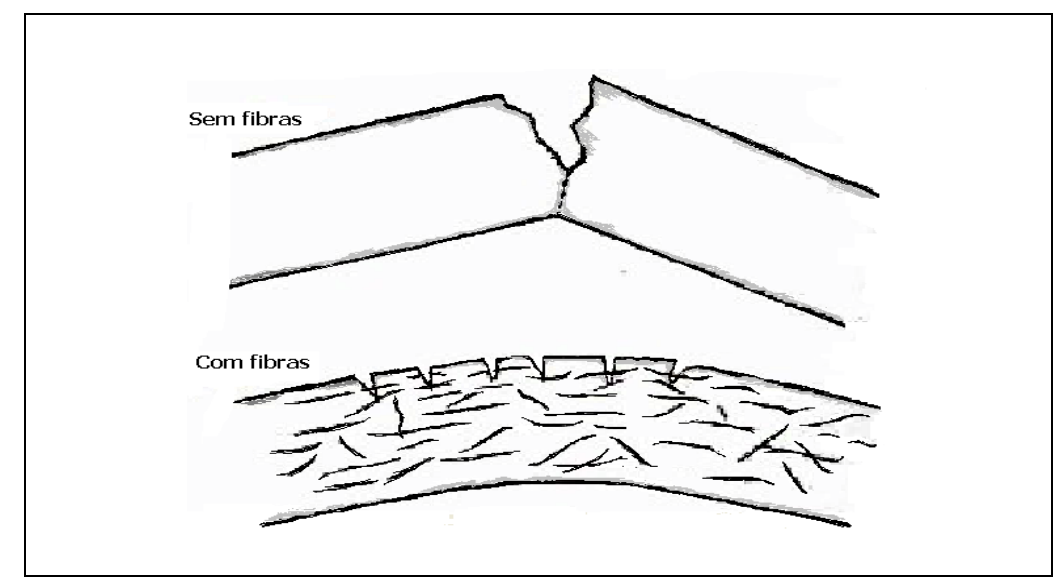

Figura 2 - Representação esquemática do comportamento à flexão de um compósito sem fibras e um reforçado com fibras (35).

Mangat e Azari (36), e Balaguru e Shah (37) ressaltaram o reforço de matrizes à base de cimento com fibras para combater a retração plástica por secagem. Esta ocorre nas primeiras horas após a moldagem em função da evaporação diferenciada, ao longo do produto, da água usada na produção. Efeitos desse tipo de retração são mais evidentes em componentes com grandes áreas de exposição.

Compósitos de fibrocimento apresentam valores mais elevados para energia específica, ductilidade, capacidade de flexão e resistência à fratura quando comparados a materiais não fibro-reforçados. Fibras são o único material de reforço que oferece vantagens como não toxicidade, renovabilidade e disponibilidade a relativo relativamente baixo custo. (38).

\subsection{Produção de cana-de-açúcar}

A agroindústria açucareira é a mais antiga atividade econômica do Brasil e está relacionada aos principais eventos históricos do país. O Brasil é atualmente o maior produtor mundial de cana-de-açúcar, maior produtor de açúcar e álcool e maior exportador mundial de açúcar. A estimativa da safra 2010/2011 é aproximadamente 8 milhões de hectares com uma produção de 664 milhões de toneladas de cana, 38 milhões de toneladas de açúcar e 28 milhões de litros de álcool (2). 
O bagaço, gerado durante a extração do caldo por meio da moagem da canade-açúcar, se constitui em material fibroso com muitas possibilidades de industrialização (39). Cerca de $95 \%$ de todo o bagaço produzido no Brasil são calcinados em caldeiras para geração de vapor, formando a cinza de bagaço. Todavia, é necessário dar um destino final à cinza residual proveniente da calcinação do bagaço usado como combustível. O bagaço da cana-de-açúcar é composto aproximadamente por $50 \%$ de celulose, $25 \%$ de hemicelulose e $25 \%$ de lignina. Após a queima, a parte remanescente é um material cuja composição química revela a presença predominante de dióxido de silício no qual, devido às características de queima e granulometria, pode se desenvolver atividade pozolânica (40).

\subsubsection{Fibra de bagaço de cana-de-açúcar}

Bagaço é o resíduo fibroso obtido da produção do açúcar após a extração do suco do caule da cana. Tem grande valor como fonte de energia, sendo utilizado como combustível, o que pode restringir a utilização dessa fibra no fibrocimento, além da dificuldade em retirar todo o açúcar contido nas fibras, que interfere na pega do cimento (41). A Tabela 1 contém valores de propriedades físicas e mecânicas das fibras de bagaço de cana-de-açúcar.

Aggarwal (42) encontrou parâmetros otimizadores das propriedades em compósitos de pasta de cimento reforçada com partículas de bagaço, tais como, o teor de bagaço entre $12 \%$ e 16\% em massa, pressão na moldagem de 2 a $3 \mathrm{MPa}$ e tempo de desmoldagem mínimo de 6 horas. O compósito assim preparado atingiu resistência à tração entre 1,58 e 1,71 $\mathrm{MPa}$, resistência à flexão entre 8,85 e 9,60 $\mathrm{MPa}$, densidade entre 1550 e $1650 \mathrm{~kg} / \mathrm{m}^{3}$ e absorção de água entre $12,5 \%$ e 14,5\%. Apresentou bom desempenho quando imerso em água ou submetido a ciclos de molhagem e secagem, sendo recomendado para aplicações internas e externas em construções.

Bilba et al. (43) analisaram a influência dos componentes botânicos das fibras de bagaço no processo de pega do cimento, concluindo que os açúcares solúveis em água, a hemicelulose e a lignina respondem pelo retardo e diminuição da 
temperatura máxima na hidratação do cimento. $\mathrm{O}$ bagaço que recebeu tratamento térmico a $200^{\circ} \mathrm{C}$ produziu compósitos com comportamento similar ao da matriz sem reforço.

Tabela 1 - Propriedades físicas e mecânicas das fibras de bagaço de cana-de-açúcar.

\begin{tabular}{ccccccc}
\hline $\begin{array}{c}\text { Fontes dos } \\
\text { dados }\end{array}$ & $\begin{array}{c}\text { Resistência a } \\
\text { tração }(\mathrm{MPa})\end{array}$ & $\begin{array}{c}\text { Módulo de } \\
\text { elasticidade } \\
(\mathrm{GPa})\end{array}$ & $\begin{array}{c}\text { Deformação } \\
\text { na ruptura }^{(\mathrm{c})} \\
(\%)\end{array}$ & $\begin{array}{c}\text { Diâmetro } \\
(\mathrm{mm})\end{array}$ & $\begin{array}{c}\text { Densidade } \\
\left(\mathrm{Kg} / \mathrm{m}^{3}\right)\end{array}$ & $\begin{array}{c}\text { Absorção } \\
\text { de água } \\
(\%)\end{array}$ \\
\hline $\begin{array}{c}\text { Aziz et al. } \\
(44)\end{array}$ & $170-290$ & $15-19$ & - & $0,2-0,4$ & $1200-1300$ & $70-75$ \\
$\begin{array}{c}\text { Guimarães } \\
(45)\end{array}$ & 177 & 4,9 & 5,11 & - & - & - \\
$\begin{array}{c}\text { CEPED } \\
(41)\end{array}$ & 181,1 & 5,0 & 5,11 & 0,0257 & 750,9 & 562 \\
$\begin{array}{c}\text { Aggarwal } \\
(42)\end{array}$ & - & - & - & - & - & $250-280$ \\
\hline
\end{tabular}

\subsubsection{Tratamento químico nas fibras de cana-de-açúcar}

Devido à agressão em meio alcalino do cimento nas fibras, Sarmiento e Freire (46), submeteram as fibras de cana-de-açúcar, previamente classificadas e lavadas em água fervente, a um tratamento químico à base de silicato de sódio e sulfato de alumínio, com finalidades de: (a) "mineralizar" as fibras, protegendo-as contra a agressão do meio alcalino; (b) imobilizar a matéria orgânica constituinte e diminuir sua capacidade de absorção de água, de modo a evitar possíveis variações dimensionais; (c) reduzir ao mínimo a incompatibilidade química com o cimento; e (d) proporcionar melhores qualidades ao compósito produzido, tais como: durabilidade, resistência ao fogo e ao ataque de microrganismos.

Em seu trabalho, descreveram todo o processo de preparação das fibras, concluindo que suas características são muito variáveis em função do comprimento e espessura; além de se tratar de um material que apresenta grandes vantagens associadas ao seu alto índice de enfeltramento e baixa massa específica aparente.

Para tal, os autores aplicaram o diffusion-penetrating-process proposto por Furuno et al. (47), originalmente desenvolvido para o tratamento de partículas de 
madeira. Ao final, Sarmiento e Freire (46) concluíram que a pré-lavagem do bagaço de cana-de-açúcar com água quente diminuiu consideravelmente o teor de açúcar residual, a "mineralização" das fibras reduziu a capacidade de absorção de água em até $50 \%$ a $60 \%$. Dentre as técnicas experimentadas, aquela que melhor resultado apresentou foi a de "mineralização" das fibras de bagaço, após lavagem, com silicato de sódio a $5 \%$ e sulfato de alumínio $30 \%$ em condições saturadas.

\subsubsection{Utilização do bagaço de cana-de-açúcar como pozolana}

Da calcinação nas caldeiras do bagaço de cana-de-açúcar, para fins de geração de energia nas indústrias sucro-alcooleiras, produzem-se cinzas como material residual. Do total de bagaço calcinado, cerca de $10 \%$ se transformam em cinzas. A aplicação do bagaço da cana-de-açúcar como fonte de cinza para adição mineral leva em conta dois fatores: o rendimento da cinza (em torno de 15\%) e a sua constituição química (em torno de $80 \%$ de $\mathrm{SiO}_{2}$ ). Além da sílica, a cinza contém álcalis e traços de óxido de ferro, alumínio, cálcio e magnésio (48).

Cincotto (49) analisou a atividade pozolânica da cinza de bagaço de cana-deaçúcar e concluiu que ela se comporta como um cimento pozolânica, muito embora a viabilidade de seu uso dependa ainda de outras verificações e novos estudos como, por exemplo, a condição de queima e moagem da cinza. A finura e a área específica da cinza são outros requisitos importantes.

Em primeiro lugar, a área de contato do sólido com o meio aquoso é fundamental na taxa de reação e na precipitação de produtos hidratados, ou seja, o aumento da área de superfície resulta em um aumento na velocidade de ganho de resistência mecânica.

No entanto, a eficiência do aumento da finura decresce devido ao fato de as partículas menores, de elevada área superficial, tenderem à aglomeração ainda no estado seco, exigindo energia de mistura elevada, incompatível com os equipamentos hoje existentes, ou o emprego de aditivos para aumentar a dispersão e, conseqüentemente, a superfície de reação.

A finura é também importante no manuseio do aglomerante ainda no estado fresco: é ela que proporciona coesão à pasta, controla fenômenos como exsudação 
da água e garante a trabalhabilidade ao sistema, condições sem as quais o produto não pode ser facilmente empregado com os procedimentos usuais de construção (50).

\subsection{Mecanismos de tenacificação proporcionados pelas fibras}

Compósitos convencionais sem fibras rompem repentinamente, com um comportamento frágil (Figura 3a), quando a deformação correspondente à resistência à tração na flexão for superada.

Por outro lado, um material reforçado com fibras continua a resistir a cargas consideráveis (Figura 3b), mesmo com deformações bastante superiores à deformação de fratura do compósito convencional (35), originando grandes energias específicas (Figura 3c).

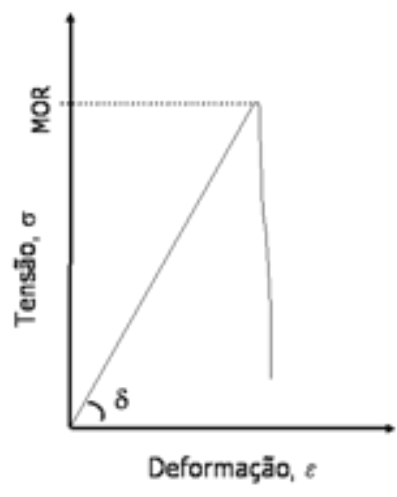

(a)

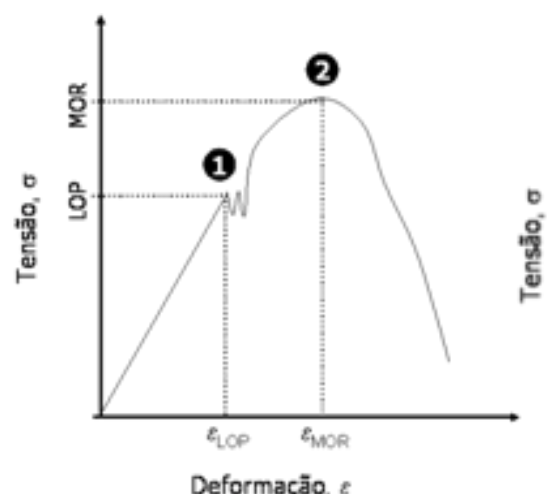

(b)

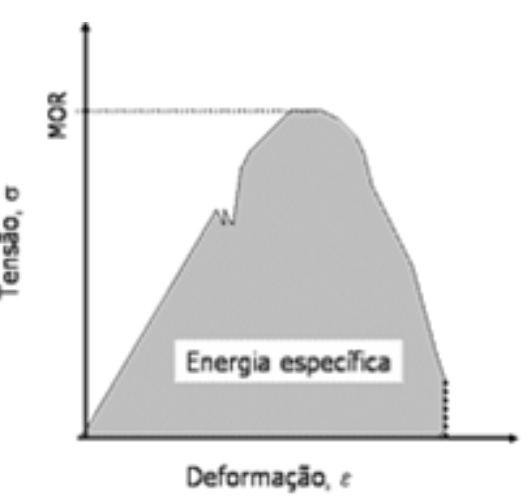

(c)

Figura 3 - Diagramas tensão x deformação. (a) Comportamento frágil; (b) comportamento dúctil: 1 - limite de proporcionalidade e 2 - módulo de ruptura; (c) área hachurada sob a curva indica a energia específica do material (35).

Durante 0 carregamento do material, a tensão necessária para 0 aparecimento da primeira fissura (final da fase elástica - Figura 3b - ponto 1) costuma aumentar com a aderência e, ainda, com a relação comprimento/diâmetro e concentração de fibras (51). O compósito suportará forças cada vez maiores, após o limite de proporcionalidade (LOP), se a resistência das fibras ao arrancamento na primeira fissura for maior do que a carga na primeira fissuração (módulo de ruptura Figura $3 b$ - ponto 2); em uma seção fissurada, a matriz não resiste a nenhum 
esforço de tração e as fibras suportam todo o carregamento do compósito (após MOR). Com um aumento de carga no compósito, as fibras tendem a transferir a tensão adicional para a matriz, por meio das tensões de aderência. Se estas não excedem a resistência de aderência, pode haver um descolamento fibra-matriz e fissurações adicionais na matriz (Figura 4 - pontos 1 e 2). Este processo de fissuração múltipla continuará até que haja o seu arrancamento (Figura 4 - ponto 3), devido à perda de aderência local acumulada; caso contrário, a partir do momento em que o escorregamento da fibra é substituído pela sua ruptura (Figura 4 - ponto 4), ocorre a redução da ductilidade (52).

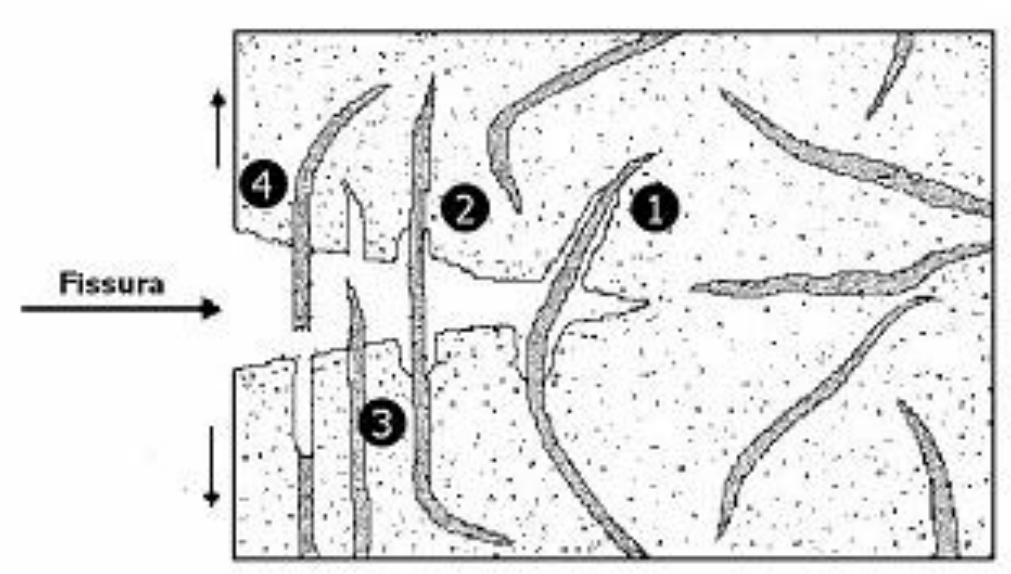

Figura 4 - Representação esquemática do caminhamento da fissura através da matriz reforçada com fibras: (1) e (2) descolamento da fibra; (3) arrancamento da fibra; (4) rompimento da fibra (53).

O tipo, a distribuição, a relação comprimento-diâmetro, a durabilidade da fibra e a umidade assim como o seu grau de aderência com a matriz determinam o comportamento mecânico do compósito e o desempenho do componente fabricado (54-56).

A energia específica ou tenacidade é uma propriedade importante, pois é a avaliação da resistência ao impacto, o que evitaria a ruptura frágil durante o transporte ou durante a instalação devido aos esforços dinâmicos envolvidos (57).

Busca-se, assim, a situação ótima em que se compatibilizam energias específicas elevadas e resistências aceitáveis. 


\subsection{Cimento Portland e principais forças de adesão entre as fases do compósito}

O cimento Portland é um aglomerante hidráulico constituído basicamente por silicatos e aluminatos de cálcio (58). Logo que o grão de cimento anidro entra em contato com a água inicia-se a dissolução dos íons $\mathrm{Ca}^{2+} \mathrm{e} \mathrm{Si}^{4+}$, oriundos dos principais componentes do cimento Portland: os silicatos tricálcico $\left(\mathrm{C}_{3} \mathrm{~S}\right)$ e bicálcico $\left(\mathrm{C}_{2} \mathrm{~S}\right)$, respectivamente, que juntos representam $75-80 \%$ do cimento Portland (59). O mesmo ocorre a outro componente importante, o aluminato tricálcico $\left(\mathrm{C}_{3} \mathrm{~A}\right)$ que, por sua vez, contribui com os íons $\mathrm{Ca}^{2+}$ e $\mathrm{Al}(\mathrm{OH})_{4}^{-}$em solução. Com isso, formam-se os chamados embriões das fases hidratadas de silicatos e aluminatos de cálcio, produtos de hidratação do cimento, graças à diferença de solubilidades em relação à do grão ainda anidro (60).

Para passarem à condição de núcleos estáveis, tais embriões precisam superar a chamada energia de ativação (Ea) conforme descrito por Rossetto (60). De acordo com este autor, em termos práticos, isso representa uma redução na relação entre a área de superfície e o volume que satisfaça a redução da energia livre Gibbs. Mais detalhes sobre as teorias dos estágios iniciais de hidratação do cimento Portland se encontram nas referências $(61,62)$.

A hidratação prossegue até que a pressão osmótica do sistema não seja suficiente para romper a superfície dos grãos anidros. Na seqüência, dois são os mecanismos responsáveis pela redução da energia livre de Gibbs: o crescimento das fases hidratadas e a densificação (60). A contínua disponibilidade de água favorece o crescimento dos hidratados de silicatos e aluminatos de cálcio, enquanto o maior empacotamento das partículas favorece a densificação. Em uma pasta de cimento já hidratada, os produtos de hidratação formados são principalmente o silicato de cálcio hidratado (C-S-H), o hidróxido de cálcio $\mathrm{Ca}(\mathrm{OH})_{2}$, a etringita (fases $\mathrm{AFt}$ ), o monosulfato (fases $\mathrm{AFm}$ ) e possivelmente fases amorfas ricas em íons $\mathrm{Al}^{3+} \mathrm{e}$ $\mathrm{SO}_{4}$ (46). Outro processo importante que ocorre pela difusão do $\mathrm{CO}_{2}$ presente na atmosfera através dos poros insaturados da matriz cimentícia é a carbonatação. Nela, $\mathrm{o} \mathrm{CO}_{2}$ sofre dissolução na fase aquosa presente nos poros transformando-se em ácido carbônico $\left(\mathrm{H}_{2} \mathrm{CO}_{3}\right)$ que, por sua vez, sofre dissociação como íons $\mathrm{HCO}^{3-}$ e $\mathrm{CO}^{3-}$, juntamente com a dissolução do $\mathrm{Ca}(\mathrm{OH})_{2}$ que libera íons $\mathrm{Ca}^{2+} \mathrm{e} \mathrm{OH}^{-}$, os quais precipitam e formam o carbonato de cálcio $\left(\mathrm{CaCO}_{3}\right)$. Um estudo paramétrico e 
aprofundado sobre a reação do $\mathrm{CO}_{2}$ em cada constituinte do cimento foi realizado por Peter et al. (63). O Ca(OH $)_{2}$ é o composto com maior grau de dissolubilidade e, portanto, o que reage mais rapidamente com $\mathrm{CO}_{2}$ para a formação do $\mathrm{CaCO}_{3}$ (64).

O processo de hidratação é responsável por reduzir a separação das superfícies cimentícias, pelo crescimento das fases hidratadas que confinam moléculas de água em nanocamadas ao redor dos grãos. Segundo Rossetto et al. (65), a configuração das superfícies hidratadas, em escala nanométrica, proporciona adesão ao material em função de pontos discretos de contato. De acordo com esses autores, a água confinada permite aderir duas superfícies que com ela possam realizar ligações hidrogênio. As ligações de hidrogênio são formadas quando a eletronegatividade do elemento covalente ao hidrogênio for suficiente para mantê-lo susceptível à interação com o outro elemento que disponibilize um par de elétrons não-conjugados (66). Portanto, a água, além de provocar a hidratação do cimento, também apresenta uma função importante na adesão das partículas hidratadas de cimento, pois esta é capaz de doar duas ligações hidrogênio e de aceitar outras duas $(60,65)$.

Enquanto existe água disponível para a hidratação dos grãos anidros de cimento e a estabilidade entre a área superficial e o volume dos núcleos ou embriões não é atingida, os íons são dissociados e transportados por osmose para regiões onde a água dos poros está menos saturada. A formação e a precipitação dos núcleos ou embriões naturalmente aproximam as superfícies dos grãos adjacentes. A secagem ou 0 consumo da água dos poros da matriz cimentícia cessa o processo de dissolução dos íons dos componentes do cimento e, a partir daí, a água confinada atua somente na adesão das fases cimentícias.

\subsection{Durabilidade dos compósitos}

Há evidências de que as fibras sofrem alterações no seu desempenho mecânico, em conjunto com a matriz, dependendo da idade do compósito e das condições de exposição. A degradação dos compósitos pode ser estudada por 
envelhecimento natural, mais confiável, ou por ensaios acelerados, cuja vantagem é a de fornecerem resultados em menor intervalo de tempo (67).

Muitas tentativas de produção de argamassas ou pastas de cimento Portland comum reforçadas com fibras vegetais fracassaram, por apresentarem vida útil entre 2 a 4 anos (68). Uma das principais razões para essa rápida degradação é a elevada alcalinidade da água presente nos poros da matriz de cimento Portland, com $\mathrm{pH}$ aproximadamente igual a 13 , que leva à rápida decomposição da lignina e da hemicelulose presentes nas fibras. A região da matriz em torno da fibra (zona de transição) é caracterizada pela porosidade elevada, permitindo acúmulo de água, e pela maior concentração de hidróxido de cálcio, propiciando elevada alcalinidade (69).

A zona ou auréola de transição é a região da pasta de cimento próxima à fibra, com espessura que varia de 10 a $100 \mu \mathrm{m}$, e suas propriedades são diferenciadas do restante da matriz (70). Por sua maior porosidade, apresenta concentração de macrocristais de portlandita e microfissuras, características que podem se apresentar com diferentes intensidades estão diretamente ligadas à aderência fibra-matriz e, por decorrência, ao desempenho mecânico do compósito. $O$ aumento da aderência faz com que se torne maior a resistência à tração do compósito e, também, a sua ductilidade, desde que não haja redução excessiva do comprimento critico de ancoragem da fibra (68).

Gram (71) estudou a durabilidade das fibras em materiais à base de cimento e concluiu que a primeira causa de mudança das características da fibra refere-se à decomposição química da lignina e da hemicelulose, presentes na lamela intercelular. Essa lamela é dissolvida pela ação da água capilar bastante alcalina $(\mathrm{pH}=12)$ da matriz e as células individuais perdem sua capacidade de reforço. Em seguida, os lumens das células são preenchidos por hidróxido de cálcio, que as torna menos flexíveis.

A durabilidade é diminuída, como uma conseqüência da redução da resistência e tenacidade (72). Esse comportamento está associado com o aumento da resistência da fratura da fibra e redução do arrancamento devida à combinação do enfraquecimento das fibras pelo ataque alcalino, mineralização da fibra e variação do volume devido à sua alta absorção de água (73). O aumento da durabilidade das fibras vegetais como reforço em cimento tem sido avaliado por vários pesquisadores incluindo estudos com impregnação das fibras com agentes 
bloqueadores e repelentes à água, selando os poros da matriz; redução da alcalinidade da matriz; combinação da impregnação das fibras e modificação da matriz para prevenir a fibra da mineralização $(74,75)$.

Soroushian e Marikunte (76) testaram, por meio de 120 ciclos de umedecimento e secagem acelerados, a durabilidade de argamassas reforçadas com fibras. Constataram a redução da tenacidade dos compósitos, provavelmente pela "petrificação" das fibras. Sabe-se, também, que a alternância entre molhagem e secagem é favorável à degradação e posterior lixiviação da lignina, presente na estrutura das fibras vegetais, o que pode reduzir ainda mais a atuação dessas fibras como reforço no interior da matriz.

\subsection{Processo de Produção por extrusão}

Quase $85 \%$ dos produtos de fibrocimento vendidos no mundo são produzidos pelo processo Hatschek (77), o processo mais empregado na produção de fibrocimento. Por outro lado, a composição do fibrocimento vem sofrendo constantes mudanças pela incorporação de novos aditivos químicos e minerais, diferentes fibras e cimentos com novas características (78).

Estudos recentes apresentam o processo de extrusão como alternativa econômica de manufatura para produzir elementos construtivos com características mecânicas e físicas semelhantes ou melhores que os oriundos do processo Hatschek (7-12). Segundo Horst (13), as extrusoras utilizadas na indústria de cerâmica são adaptáveis para o processo de extrusão de materiais de fibrocimento. Assim, assume-se que o investimento para implantá-la uma linha de produção de fibrocimento por extrusão seja próximo ao de uma linha de materiais cerâmicos e com capacidade de produção instalada semelhante.

Os altos custos de implementação e a grande capacidade de produção de uma linha de processo Hatschek fazem com que as plantas industriais sejam instaladas próximas de um mercado capaz de amortizar os altos investimentos e de absorver esta capacidade de produção. Isto pode ser observado na distribuição das plantas industriais no território nacional. Verifica-se que elas estão próximas ou dentro de uma região de alta densidade demográfica. Esta distribuição estratégica 
de fábricas faz com que regiões de baixa densidade não possam desfrutar em plenitude as vantagens de um produto barato, devido à logística necessária para disponibilizá-lo.

Assim, o setor do fibrocimento encontra-se, segundo as cinco forças competitivas de Porter (79), protegido de novos competidores devido aos altos custos de implantação de uma linha de produção baseada no processo Hatschek, reduzindo o número de fornecedores de produtos de fibrocimento num mercado de alta demanda. Observa-se isto também no mercado nacional, atendido por apenas 13 plantas industriais de fibrocimento. Como faltam opções para o consumidor, esta situação leva a melhores rendimentos aos fornecedores.

Em trabalhos anteriores Soto et al. (80) estudaram adições de fibras vegetais em fibrocimento pelo processo de extrusão. Observaram que a fibra de bagaço de cana-de-açúcar não apresentou bons resultados e sugeriram estudos futuros para uma otimização desses resultados.

Implantar o processo de extrusão de materiais de fibrocimento no setor produtivo permitirá a instalação de fábricas em regiões de baixa densidade demográfica, pois é baixo o custo da linha de produção. Além disso, o processo de extrusão possibilita a flexibilidade de adequar essa linha de produção com objetivo de atender os pequenos mercados. Como efeito, a barreira de altos investimentos para a implementação de indústria de fibrocimento seria quebrada com a viabilização do processo de extrusão, permitindo o surgimento de novos fornecedores no mercado, tornando-o mais competitivo. Tal panorama beneficiaria os consumidores em função da competição mais acirrada, com melhores e diversificados produtos.

Adicionalmente, aumenta a probabilidade de uso de matérias-primas alternativas, tais como resíduos do setor produtivo primário ou secundário, com o objetivo de minimizar seus custos.

Neste contexto, observa-se pela literatura que a implantação do processo de extrusão de compósitos de fibrocimento em países em desenvolvimento, como o Brasil, pode gerar benefícios sociais, econômicos e ambientais (79). 


\subsubsection{Características do processo de extrusão}

As características relevantes da máquina extrusora são: a geometria da rosca, o comprimento das secções de alimentação, de desaeração e de compactação, a velocidade da rosca e as pressões de vácuo exercido na seção de desaeração (7).

O propósito da boquilha é promover a compactação final da mistura cimentícia e formar a desejada geometria do produto. Para garantir a saída de produtos extrudados com bom acabamento devem-se evitar gradientes de velocidade para as misturas de formulações cimentícias fluírem uniformemente através da boquilha. Caso as misturas fluam com taxas de velocidade diferentes, geram-se gradientes de tensões durante o processo e o produto extrudado não sairá da boquilha com a geometria desejada.

As partes de uma extrusora de vácuo são apresentadas na Figura 5, sendo salientada a câmara de mistura, câmara de vácuo e a câmara de compactação.

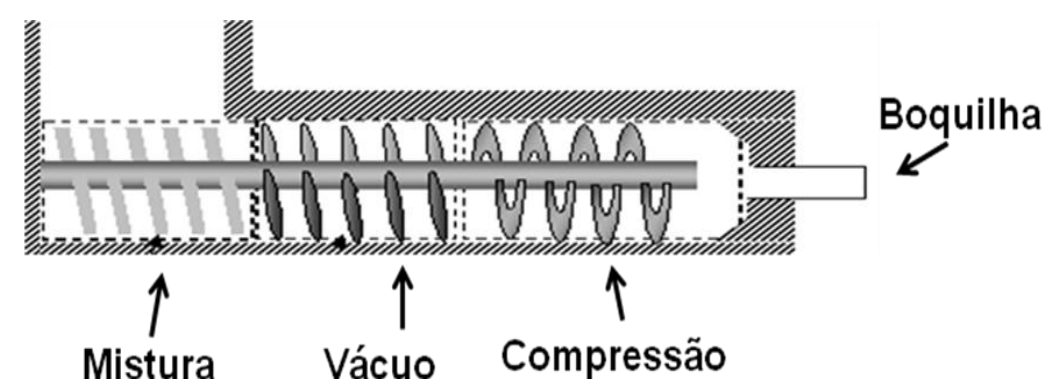

Figura 5 - Detalhes do mecanismo de funcionamento do processo de extrusão. Adaptado (80).

\subsubsection{Modificadores reológicos}

Braun e Rosen (81) classificam os modificadores reológicos em orgânicos e inorgânicos, mencionando que os modificadores reológicos orgânicos conseguem influenciar, fortemente, com pequenas quantidades, o comportamento reológico de uma mistura, enquanto que os inorgânicos necessitam de grandes quantidades. 
Com isso, os orgânicos são os modificadores mais utilizados em compósito de fibrocimento.

O modificador hidroxipropilmetilcelulose é o que tem apresentado uma maior eficiência na produção de extrudados de fibrocimento (9).

Shen (82) menciona a necessidade de estudos com a finalidade de encontrar modificadores reológicos alternativos de valor econômico inferior ao do hidroxipropilmetilcelulose para a extrusão de fibrocimento. A utilização deste modificador reológico é uma opção de alto custo, daí a necessidade de se encontrar um produto substituto eficiente e com menor preço.

\subsection{Comentários finais sobre a revisão bibliográfica}

Esta revisão bibliográfica apresentou as informações essenciais ao entendimento do processo de produção do fibrocimento por extrusão, dos mecanismos de hidratação e cura do cimento, das forças de adesão entre as partículas do compósito e dos mecanismos de ruptura dos compósitos reforçados com fibras. Mecanismos de degradação das fibras nos compósitos cimentícios, reportados em literatura, também constam desta revisão.

A avaliação dos tópicos apresentados nestas seções serviu de base para definição dos experimentos adotados na presente pesquisa. Ficou clara a necessidade de verificar as propriedades das fibras e os seus efeitos no desempenho dos compósitos. Entre as avaliações necessárias, destaca-se a importância da avaliação dos efeitos das propriedades de superfície das fibras na aderência entre elas e a matriz cimentícia.

Observou-se a necessidade de avaliar a durabilidade dos compósitos, ou seja, o seu desempenho após exposição a intempéries. Por isso, neste trabalho adotou-se a interpretação dos resultados daqueles ensaios mecânicos, físicos e de análise microestrutural tanto nas idades iniciais (28 dias de cura) como após ciclos de envelhecimento acelerado (imersão em água e secagem).

A pesquisa pretendeu-se, portanto, contribuir para o entendimento dos mecanismos de aderência entre fibras e matriz, e de degradação das fibras e dos compósitos de fibrocimento expostos à umidade. 


\section{MATERIAIS E MÉTODOS}

Esta seção aborda o planejamento dos experimentos, composto por três fases. A primeira fase visou verificar o estudo da fibra, como o tratamento químico e análises microestruturais, a segunda fase foi estudado a introdução de fibras como reforço em compósitos cimentícios, o processo de extrusão e a verificação do desempenho mecânico. Na terceira fase, o estudo dos parâmetros da queima da cinza, a substituição parcial do cimento, além disso, foram realizados ensaios de durabilidade como envelhecimento acelerado.

\subsection{Planejamento dos experimentos}

A Figura 6 mostra um fluxograma com a descrição das fases dos experimentos, que envolveu o tratamento químico, a produção de corpos-de-prova e as seqüências de envelhecimento; 


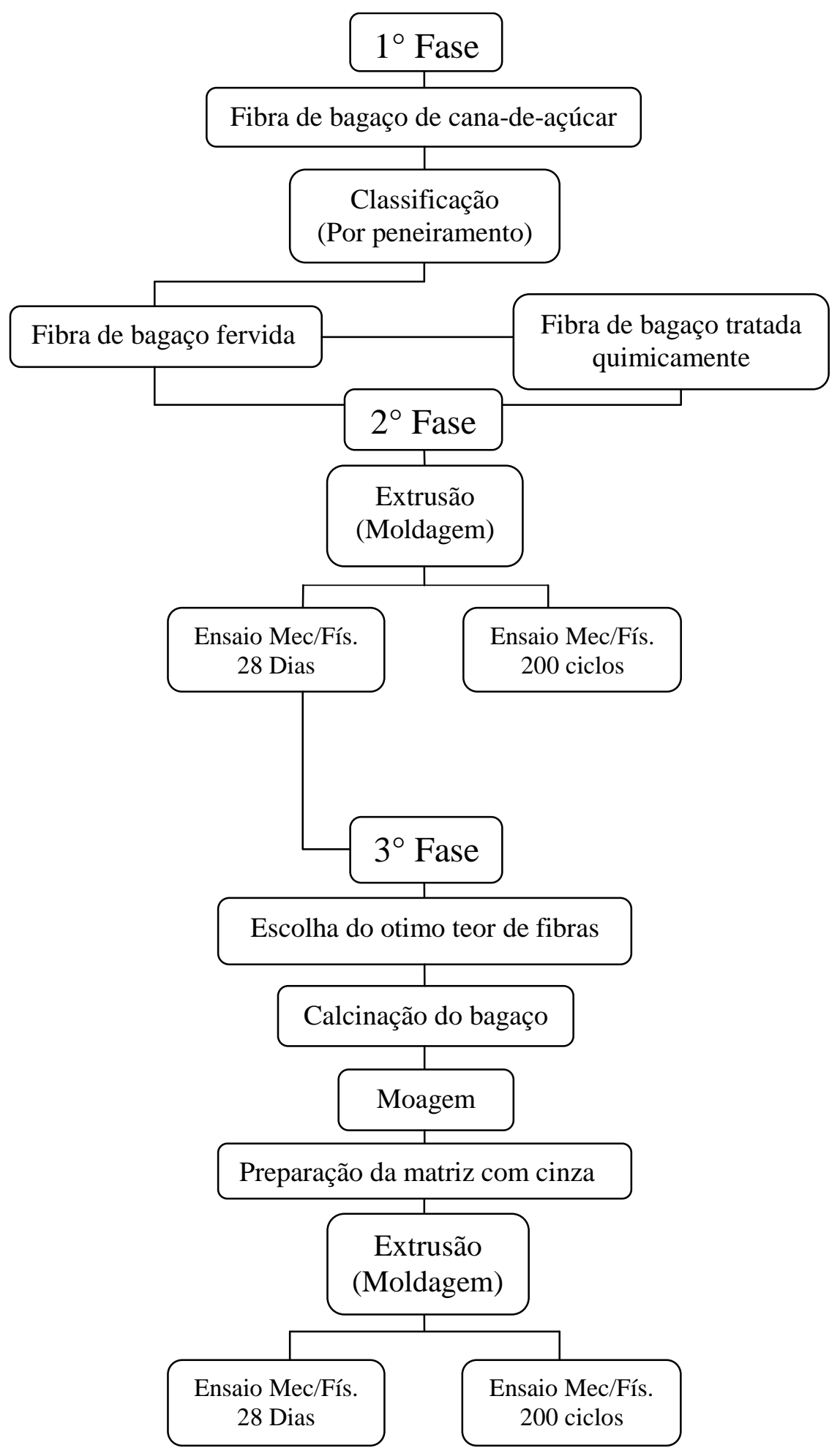

Figura 6 - Fluxograma detalhadas das fases dos experimentos do projeto. 


\subsection{Fibras de bagaço de cana-de-açúcar (FBC)}

O bagaço de cana-de-açúcar usado neste trabalho foi fornecido pela Usina Baldin Agroenergia localizada em Pirassununga, SP, sendo colhidas na safra 2009/2010. O material fornecido originalmente composto por uma mistura de fibras e medulas passou por secagem ao ar livre por $48 \mathrm{~h}$ e em estufa com circulação de ar Marconi, modelo MA 35 com temperatura de $60^{\circ} \mathrm{C}$ por $24 \mathrm{~h}$.

\subsubsection{Classificação das fibras (peneiramento)}

Procurou-se separar a fração utilizável baseado no principio que seria mais adequado seria aquela que apresentasse maior volume de fibras do bagaço.

Sendo assim, foi utilizado um agitador de peneiras (Figura 7a) e escolhida a fibra passante na peneira de 16 mesh (abertura 1,18 mm) (Figura 7b), onde apresentou dimensões nominais entre 10 a $30 \mathrm{~mm}$ para a utilização em fibrocimento. Aproximadamente $20 \%$ das fibras foram usadas de todo o bagaço coletado pela Usina (Figura 7c).
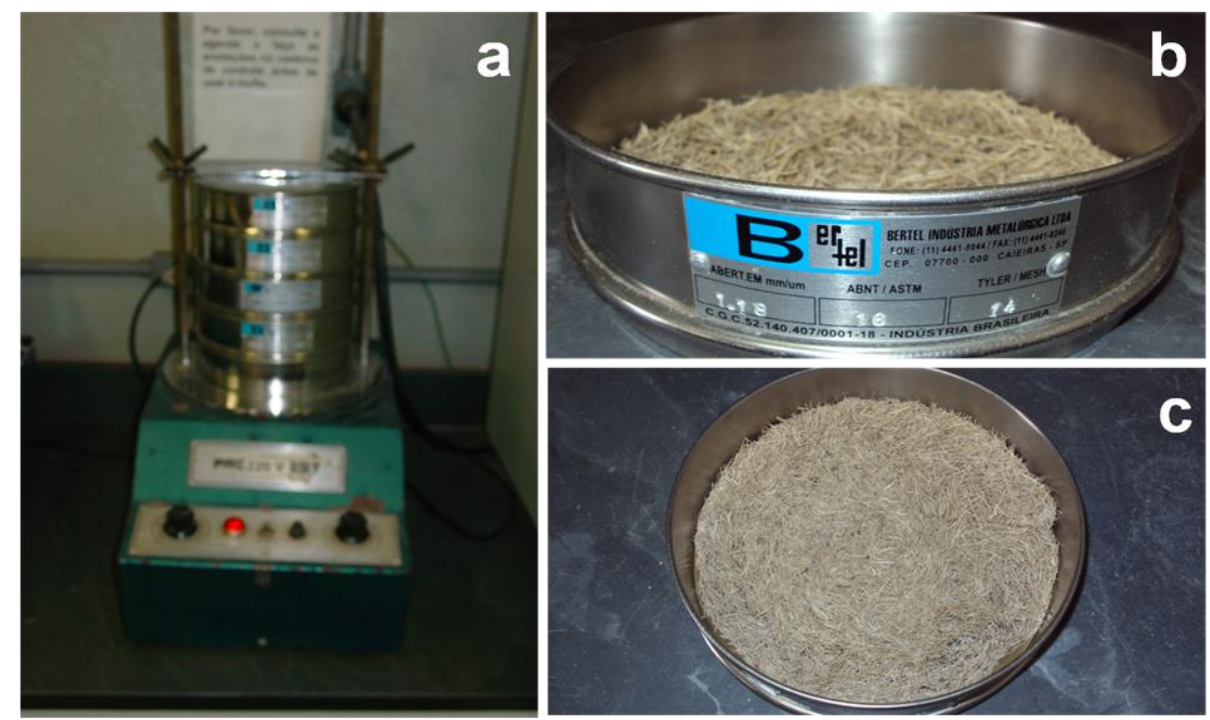

Figura 7 - (a) Agitador de peneiras, (b) peneira de 16 mesh (abertura 1,18 mm) e (c) fibra retida e utilizada nos experimentos. 


\subsubsection{Lavagem das fibras}

Geralmente o bagaço apresenta certa quantidade de impurezas como terra, fuligem e constituintes indesejáveis como o açúcar residual que produz um efeito inibidor sobre o tempo de pega do cimento. Para remover essas impurezas o bagaço passou por um banho, sendo imersas em água fervente por 30 min para remover as impurezas e reduzir o açúcar residual, seguido de lavagem em água corrente e posto a secar novamente em ar livre por $48 \mathrm{~h}$ e em estufa a $60^{\circ} \mathrm{C}$ por $24 \mathrm{~h}$ (46). Desse processo foram obtidas as fibras utilizadas nos experimentos.

\subsection{Métodos do estudo da FBC}

\subsubsection{Determinação do teor de extrativos de açúcares residuais da FBC}

Após o procedimento inicial, foram tomadas 3 amostras de fibra natural e fervida para a determinação do teor de açúcar residual. O método foi realizado no laboratório de bromatologia da FZEA/USP. Foi utilizado $1 \mathrm{~g}$ de fibra em cadinhos postos a queimar em mufla utilizando temperatura de $550^{\circ} \mathrm{C}$ por 1 hora. A cinza da FBC obtida não é necessariamente da mesma composição que a matéria mineral, pois pode haver perda por volatilização ou alguma interação entre os constituintes da amostra.

A diferença da composição final das fibras após a queima será dos carboidratos existentes nas fibras e são divididos em: monossacarídeos (glicose, frutose), dissacarídeos (sacarose, lactose, galactose, maltose), polissacarídeos (maltodextrinas, amidos, gomas, pectinas e celuloses) (83). 


\subsubsection{Tratamento químico das FBC}

As FBC passaram por um tratamento químico a base de silicato de sódio $30 \%$ em combinação com o sulfato de alumínio $5 \%$ com a finalidade:

- "Mineralizar" as fibras, protegendo-as contra a agressão do meio alcalino proporcionado pelo cimento;

- Imobilizar a matéria orgânica constituinte e diminuir sua capacidade de absorção de água, de modo a evitar possíveis variações dimensionais;

- Reduzir ao mínimo nas reações de pega e endurecimento do cimento;

- Proporcionar melhores qualidades do compósito produzido, tais como resistência mecânica, durabilidade e ao ataque de microorganismo.

Aplicou-se as fibras o "diffusion-penetrating-process", proposto por Furuno et al. (47) desenvolvido inicialmente para o tratamento de partículas de madeira e utilizado posteriormente por Sarmiento (84) com FBC utilizado em argamassa. Do tratamento original foram feitas algumas modificações para atender as características próprias das FBC.

Preparou-se uma solução de silicato de sódio a 5\%, com água destilada em um agitador mecânico de eixo vertical com auxilio de um becker de $5 \mathrm{~L}$ a $700 \mathrm{RPM}$ durante $1 \mathrm{~h}$, após as fibras foram imersas em agitação por mais $1 \mathrm{~h}$ em solução (concentração solução/fibra 20:1), em seguida, lavadas em água corrente por $5 \mathrm{~min}$, enxugadas através de uma centrifuga de roupas por $5 \mathrm{~min}$, e deixadas a secar ao ar livre por mais $40 \mathrm{~min}$. Em seguida as fibras passaram pelo mesmo processo, agora com o sulfato de alumínio 30\%. Após todo o procedimento, as fibras foram levadas em estufa com circulação de ar Marconi, modelo MA 35 com temperatura de $60 \pm$ $5^{\circ} \mathrm{C}$ por $24 \mathrm{~h}$, em seguida elas foram colocadas em dessecador com sílica gel hermeticamente fechado por $24 \mathrm{~h}$. 


\subsubsection{Determinação das dimensões nominais das FBC}

As dimensões das FBC foram medidas com o auxilio de um estereoscópico da marca Zeiss, modelo Stemi 2000 com aumento de 10x e de um paquímetro digital.

Foram feitas 100 medições para a determinação do diâmetro e do comprimento das fibras.

\subsubsection{Determinação de absorção de água nas FBC}

As FBC foram previamente secas em estufa com circulação de ar marca Marconi, modelo MA $35 \mathrm{com}$ temperatura de $60 \pm 5^{\circ} \mathrm{C}$. Após foram transferidas para uma câmara climática da marca Thermotron, modelo SM-3.5S, (Figura 8), com temperatura fixada em $25 \pm 2^{\circ} \mathrm{C}$, variando a umidade relativa de 30 a $90 \% \mathrm{com}$ intervalos de $20 \%$. Cada umidade relativa $(30,50,70$ e 90\%) foi mantida por 24 horas. Cada curva é a média de pelo menos duas determinações para cada amostra. Foram analisadas às $\mathrm{FBC}$ natural, não tratada e tratada.

A determinação da absorção de umidade em câmara climática foi adotada por Motta (85) por ser considerada mais precisa do que a absorção determinada pela imersão das fibras em água. A principal dificuldade da determinação da massa saturada é a secagem da superfície das fibras, que poderia ser uma fonte de variação nos resultados difícil de ser quantificada. A análise de absorção de água foi realizada no Laboratório de Construções e Ambiência FZEA/USP. 


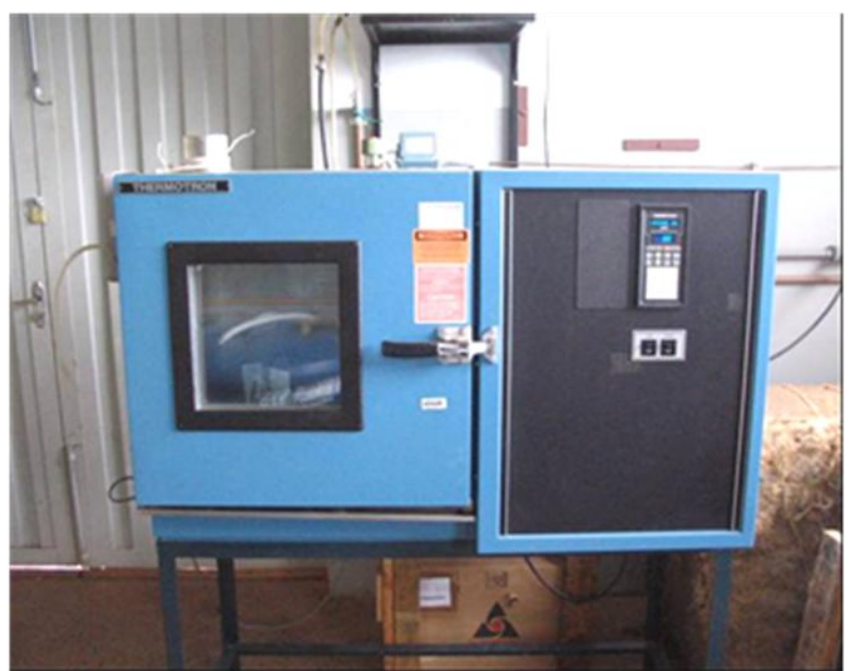

Figura 8 - Câmara climática marca Thermotron utilizada na determinação de absorção de água.

\subsubsection{Determinação da densidade das FBC}

A massa específica é a relação existente entre a massa de uma amostra e o volume ocupado pelas suas partículas sólidas. Para a determinação é necessário obter-se o valor da massa da amostra e depois o volume dos sólidos presentes (86).

A massa específica da fibra foi determinada em multipicnômetro a gás hélio, marca Quantachrome, Ultrapycnometer 1000, no Laboratório de Construções e Ambiência FZEA/USP (fig. 9). 


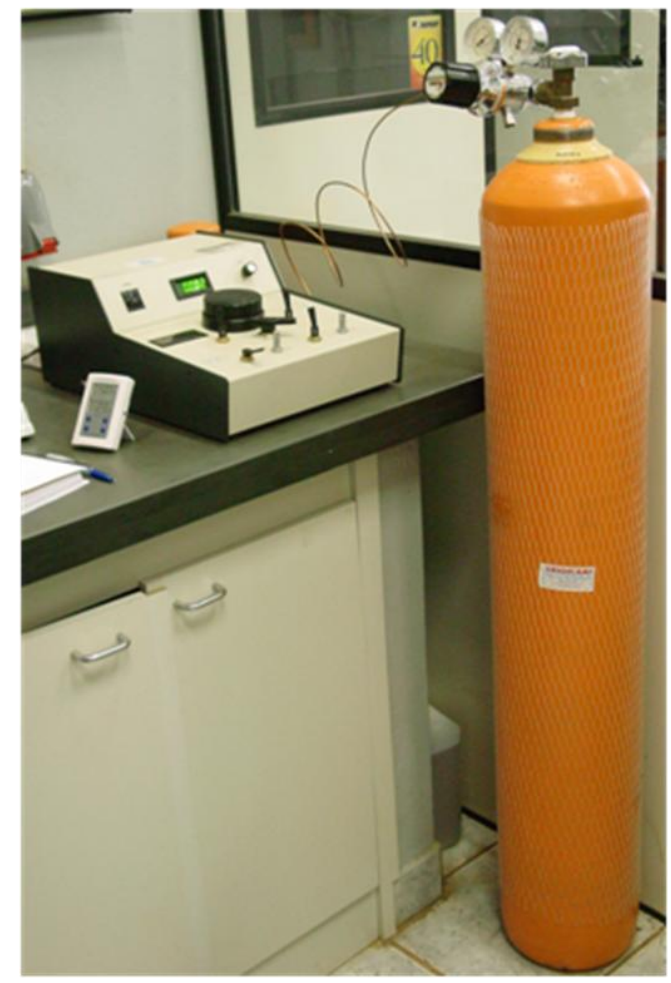

Figura 9 - Multipicnômetro a gás hélio Quantachrome, Ultrapycnometer 1000

\subsubsection{Análise Bromatológica das fibras}

Foi realizada a análise bromatológica da FBC, no laboratório de bromatologia da FZEA/USP, para determinação da composição do material estudado (87). As análises foram: matéria seca (MS), matéria mineral $(M M)$, proteína bruta $(P B)$, fibra bruta (FB).

\subsection{Caracterizações microestruturais das FBC}

\subsubsection{Difração de raios-X (DRX) das FBC}

O índice de cristalinidade da fibra informa sobre a proporção de regiões cristalinas com relação às regiões não cristalinas presentes na amostra. Este dado é 
importante, pois na região cristalina o acesso dos reagentes é dificultado pela região não cristalina (amorfas), (88).

O índice de cristalinidade (ICR) foi determinada por difração de raios-X em pó utilizando uma URD-6, VEB CARL difratômetro operacional Zeiss-Jena a $40 \mathrm{kV}, 20$ $m A$ e radiação $C u K a=1,5406 \AA$. $O$ índice de cristalinidade foi calculado utilizando-se a equação 1, descrita por Busche-Diller e Zeronian (89).

$$
I_{c}=1-\frac{I_{1}}{I_{2}}
$$

sendo:

$\mathrm{I}_{C}=$ índice de cristalinidade;

$\mathrm{I}_{1}=$ Intensidade de difração mínima, referente à região não cristalina;

$\mathrm{I}_{2}=$ Intensidade de difração máxima, referente à região cristalina.

O índice de cristalinidade foi obtido pelos valores de intensidade (eixo y) observados na figura de intensidade $x$ ângulo de difração e relacionando-se a equação 2, sem a utilização de métodos de integração e deconvolução. As principais características que diferem cada forma da região cristalina das fibras

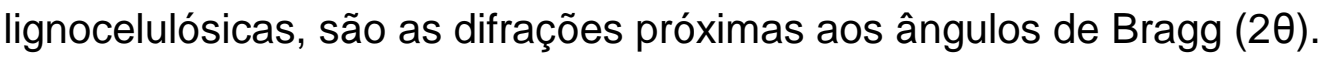

Assim:

$$
\% I_{c r}=1-\frac{\left[\left(I_{22^{\circ}-} I_{18^{\circ}}\right)\right] \times 100}{I_{22^{\circ}}}
$$

\subsubsection{Espectroscopia na região do Infravermelho (FTIR) das FBC}

A espectroscopia na região do infravermelho (FTIR) e uma técnica de identificação estrutural, também utilizado na determinação da pureza e quantificação de substâncias orgânicas, bem como o controle e acompanhamento de reações e processos de separação. A técnica é usada como ferramenta para compreender a 
estrutura isolada e a remoção ou a adição de grupos químicos durante os processos.

Foram analisadas a fibra natural, fervida e tratada por espectroscopia na região do infravermelho médio com transformação de Fourier no laboratório de tecnologia de alimentos da FZEA/USP.

Foi utilizado um espectrofotômetro Spectrum-One da marca Perkin-Elmer, no intervalo da região de infravermelho de 4000 a $500 \mathrm{~cm}^{1}$. Esse aparelho possui um acessório UATR (atenuador de reflectância total universal), que permite a análise por simples aplicação do material sobre o "porta-amostra" (cristal) (Figura 10).

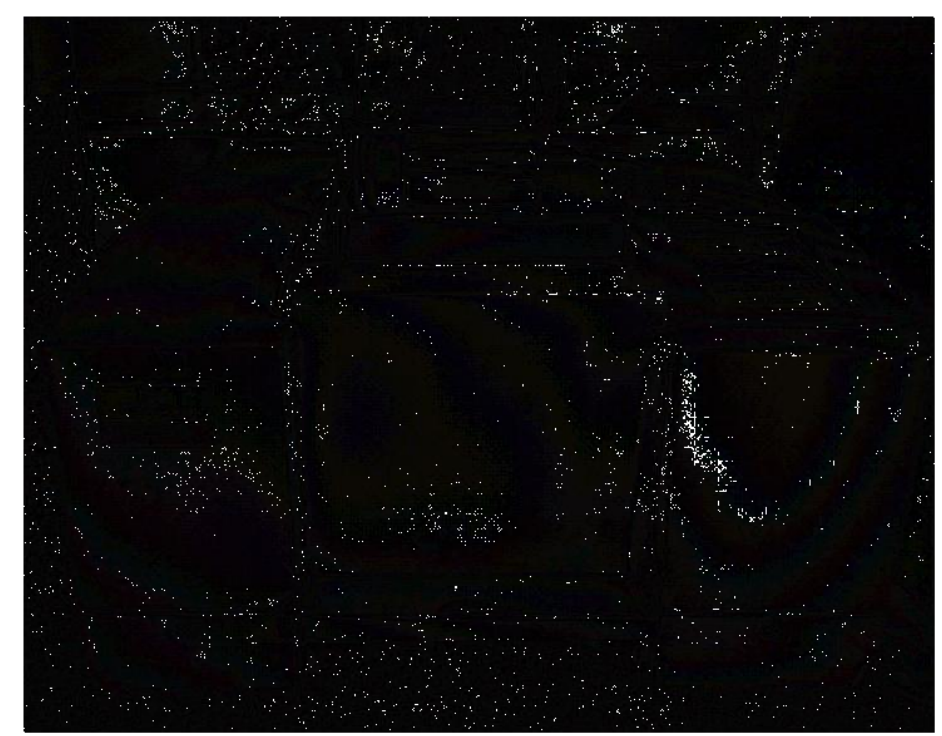

Figura 10 - Vista geral de um espectrofotômetro de infravermelho (FTIR).

\subsubsection{Microscopia eletrônica de varredura (MEV) das FBC}

A microscopia eletrônica de varredura (MEV) foi utilizada para o estudo das superfícies das fibras. O microscópio eletrônico utiliza elétrons para a formação de imagem. As imagens têm alta profundidade de foco, o que obtém vários relevos diferentes o que facilita a interpretação (90).

Análises com microscopia eletrônica de varredura (MEV) foram feitas nas fibras naturais, fervida e tratada. As imagens foram realizadas em um microscópio da marca Zeiss $\mathrm{P}^{\circledR}$ LEO 440, para visualização da superfície das fibras. As 
micrografias com imagem de elétrons secundários foram também utilizadas para avaliar as características morfológicas das fibras.

\subsection{Obtenção das cinzas de bagaço de cana-de-açúcar (CBC)}

Para a produção e avaliação das cinzas de bagaço de cana-de-açúcar (CBC) optou-se em queimar o bagaço de cana-de-açúcar em condições controlada de temperatura e tempo, em mufla, no Laboratório de Construções e Ambiência da FZEA/USP de acordo com a sugestão de Villar-Cociña et al. (91). No entanto, a definição da curva de queima foi baseada nos parâmetros típicos de queima de uma usina açucareira.

\subsubsection{Procedimento de queima da $\mathrm{CBC}$}

O bagaço foi submetido a uma taxa de aquecimento de $10^{\circ} \mathrm{C} / \mathrm{min}$, até atingir o patamar de $400^{\circ} \mathrm{C}$, permanecendo nessa temperatura por 20 min. Após essa etapa, usando a mesma taxa de aquecimento da pré-queima, as cinzas foram calcinadas a $800^{\circ} \mathrm{C}$ por $1 \mathrm{~h}$, como ilustra o esquema da Figura 11. Foram usadas bandejas refratárias marca Estiva e duas muflas, modelos LF10010 e LF 10013, da Jung.

A Figura 12 ilustra a montagem com as bandejas refratárias, contendo bagaço de cana-de-açúcar, dentro das muflas. É importante ressaltar que os bagaços foram secos naturalmente sob o sol antes de serem queimados. 


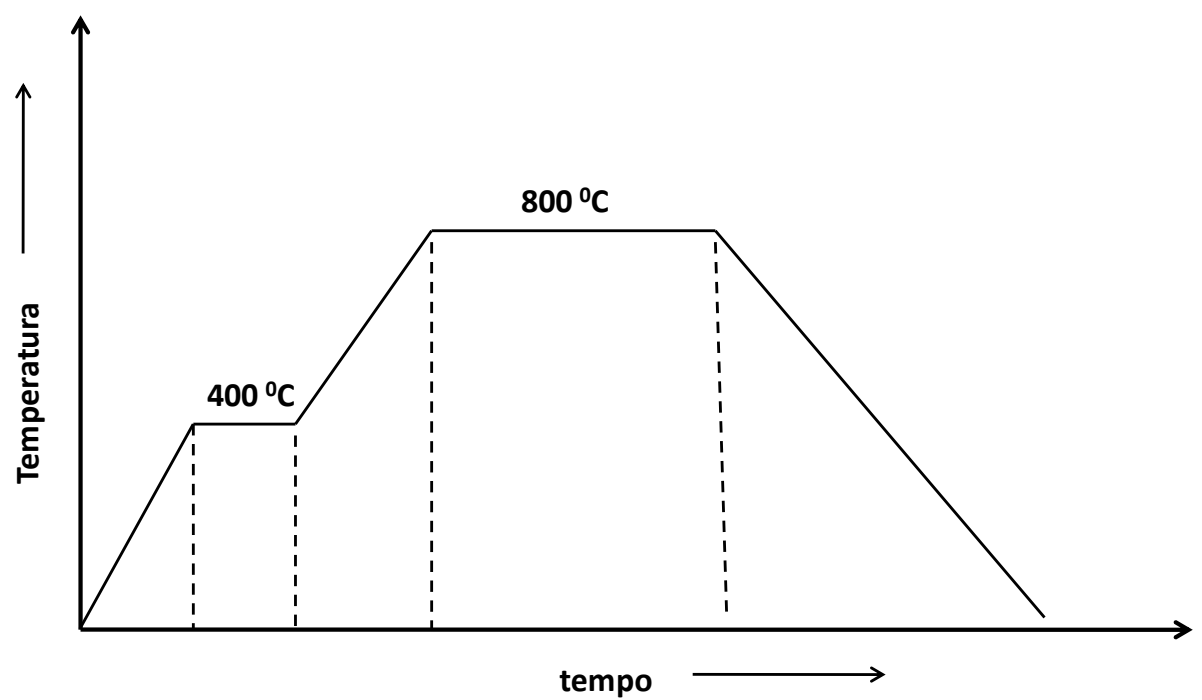

Figura 11 - Esquema da curva de queima e calcinação do bagaço de cana-de-açúcar.

Outro aspecto importante da queima foi o baixo rendimento de produção de cinzas de bagaço de cana-de-açúcar, na faixa de 50 a 80 g para cada $1 \mathrm{~kg}$ de bagaço. Desse modo, sabendo-se que todo o processo de queima e de calcinação completo dura em torno de 1 dia, para se obter $1 \mathrm{~kg}$ de cinza de bagaço de cana-deaçúcar necessita-se de no mínimo 13 dias.

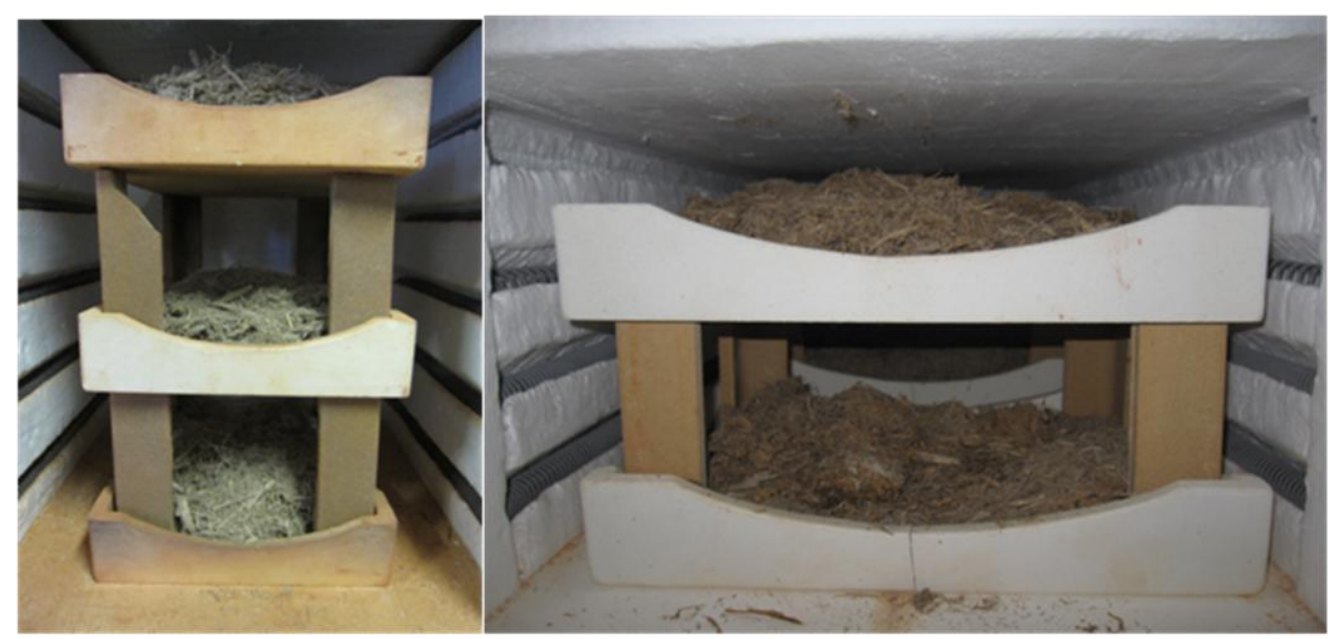

Figura 12 - Fotos das montagens de bandejas refratárias com bagaço de cana-deaçúcar, dentro das câmaras das muflas.

Após a etapa de queima, as cinzas de bagaço de cana-de-açúcar calcinadas foram beneficiadas em moinhos de bolas. As cinzas foram moídas em moinho rotativo de bolas, em jarro de porcelana de 7,5 L, da marca Tecnal, modelo TE500/2 (Figura 13). 


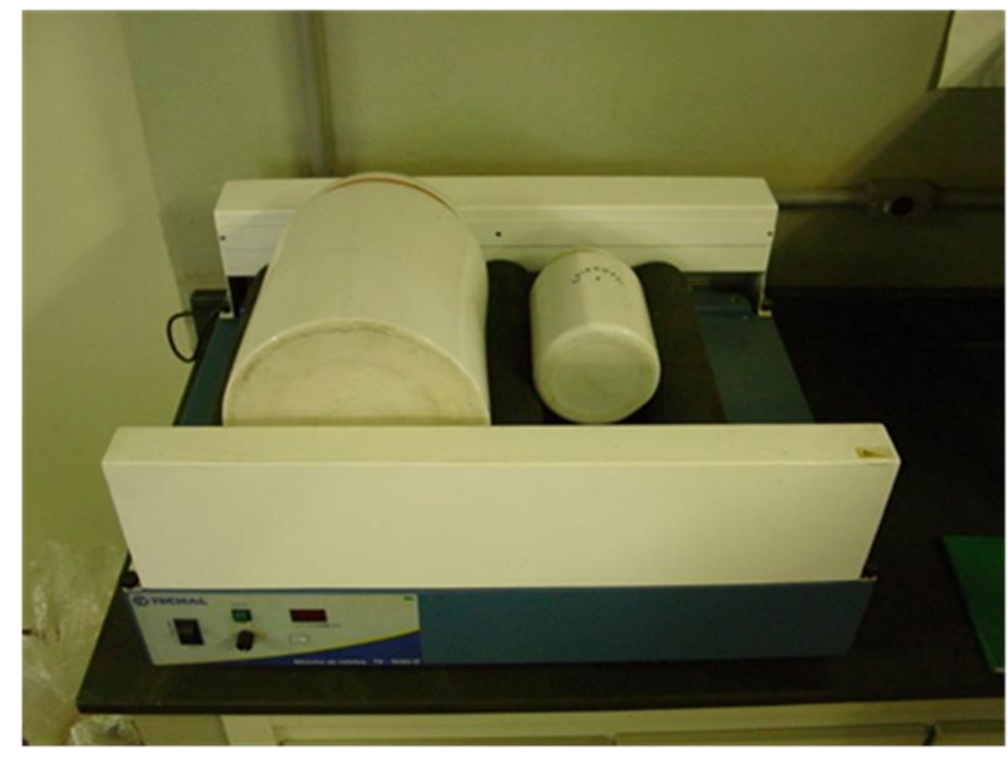

Figura 13 - Foto do moinho de bolas com jarro de porcelana.

A velocidade de moagem utilizada foi de 200 RPM. Dentro do jarro foram utilizados $3,8 \mathrm{~kg}$ de corpos moedores (bolas de alumina com diâmetros na faixa de 5 a $40 \mathrm{~mm}$ ) para cada $1,5 \mathrm{~kg}$ de cinzas. O tempo de moagem foi de 60 minutos.

\subsection{Métodos do estudo da CBC}

\subsubsection{Espectroscopia de fluorescência de Raios-X das CBC}

A composição da CBC foi avaliada por meio de análises por fluorescência de raios-X. Esta técnica é adequada para análise de elementos de tamanhos variados, metálicos ou não metálicos, em amostras sólidas e líquidas. É sensível à grande parte dos elementos da Tabela Periódica, do Sódio ao Urânio. As vantagens principais são: alta velocidade analítica, alta resolução gráfica, sendo um método não-destrutivo, multielementar e simultâneo. O ensaio foi determinado em um equipamento Malvern Mastersizer S long bed versão 2.19. 


\subsubsection{Distribuição granulométrica das CBC}

O ensaio de granulometria por difração a laser vem sendo utilizado devido sua facilidade de operação, rapidez de análise e ampla faixa de tamanhos, para caracterizar distribuições de tamanho de partículas, dispersas em meio líquido ou em forma de pó seco. A difração a laser baseia-se no princípio (difração Fraunhöffer) de que, quanto menor o tamanho da partícula, maior o ângulo de difração de um feixe luminoso que atravessa uma população de partículas. As distribuições do diâmetro de partículas do CBC foi determinada em um equipamento Malvern Mastersizer S long bed versão 2.19,

\subsection{3 Área de superfície específica das CBC}

A área de superfície específica expressa, para uma dada quantidade de material, a área total superficial de suas partículas. Quanto maior a área de superfície específica, maior o contato entre as partículas da cinza de bagaço com o cimento. Portanto maior a reatividade.

Os equipamentos utilizados para a preparação das amostras e para análise foram, respectivamente, o VacPrep 061 e o Gemini III 2375 . O gás usado na adsorção foi o nitrogênio e os ensaios foram efetuados na temperatura de 77K. A amostra foi tratada em vácuo $(100 \mu \mathrm{m}$ de $\mathrm{Hg})$ com tratamento térmico de 15 horas, após continuou o tratamento térmico sem vácuo por mais 6 horas sempre na temperatura de $110^{\circ} \mathrm{C}$.

\subsubsection{Determinação da densidade das CBC}

Foi usado um multipicnômetro da Quantachrome, pela técnica de deslocamento de hélio. As $\mathrm{CBC}$ foram caracterizadas quanto à densidade real, visto 
que as formulações dos compósitos foram feitas por teores em volume. Esta análise foi realizada no Laboratório de Construções e Ambiência da FZEA/USP.

\subsubsection{Difração de raios-X das CBC}

O ensaio de difração raios-X é uma técnica que responde à cristalinidade da substância permitindo identificação de materiais quanto às suas características cristalinas e a quantificação de elementos de constituição desde que em faixa adequada de concentração. Para identificação de fases por difração de raios- $X$, alguns materiais foram moídos usando pulverizador rotativo, modelo MA-590, da Marconi. No entanto, para todas as amostras foi usada uma granulometria passante na peneira padrão U.S. Tyler \# 325 mesh. Foi utilizado equipamento Philips, modelo MPD 1880. A identificação de fases cristalinas foi obtida por comparação do difratograma da amostras com os bancos de dados PDF2 do ICDD - International Centre for Diffraction Data e PAN-ICSD Panalytical Inorganic Crystal Structure Database (2007).

\subsubsection{Microscopia eletrônica de varredura (MEV) das CBC}

As análises por microscopia eletrônica de varredura (MEV) foi realizada no microscópio ZEISS modelo LEO 440. O feixe de elétrons principal foi gerado por um filamento de tungstênio cuja tensão e corrente de operação foi respectivamente 10 $15 \mathrm{kV}$ e $50 \mu \mathrm{A}$.

As cinzas foram secas em estufa a $110^{\circ} \mathrm{C}$ por um período de $24 \mathrm{~h} \mathrm{e}$, posteriormente foram depositadas sobre um porta amostra com o auxilio de uma fita dupla face de carbono. Em seguida, o porta amostra foi submetido a uma deposição de ouro, sendo mantido em estufa até o momento da visualização no microscópio. 
4.6.7 Avaliação das reações pozolânicas das CBC através de condutividade elétrica

A variação da condutividade elétrica de uma solução saturada de hidróxido de cálcio pode indicar rapidamente a capacidade de a adição mineral promover uma reação pozolânica. Esta medida se baseia no conceito de que os constituintes ativos da adição mineral reagirão com o hidróxido de cálcio levando a um decréscimo de concentração de $\mathrm{Ca}^{2+}$ e, portanto, a diminuição da condutividade elétrica no sistema adição mineral e hidróxido de cálcio. Esta técnica é útil para obter dados que podem ser aplicados em modelos cinéticos-difusivos para descrever reações pozolânicas em solução com hidróxido de cálcio (91-92).

Para tanto, o sistema de medida de condutividade elétrica foi concebido para minimizar a interação da solução, adição mineral e hidróxido de cálcio, com o ambiente externo e mantê-lo em temperatura constante. Os equipamentos utilizados no sistema são: condutivímetro elétrico, modelo DM-32, da Digimed (Figura 14), agitador magnético com aquecimento, modelo RCT Basic, controlador digital de temperatura, modelo ETS-D5, ambos da Ika (Figura 15a), célula de condutividade utilizada foi modelo DMC-001TXT, da Digimed (Figura 15b) e um computador acoplado ao condutivímetro com o programa de aquisição de dados, desenvolvido pela Digimed (Figura 16).

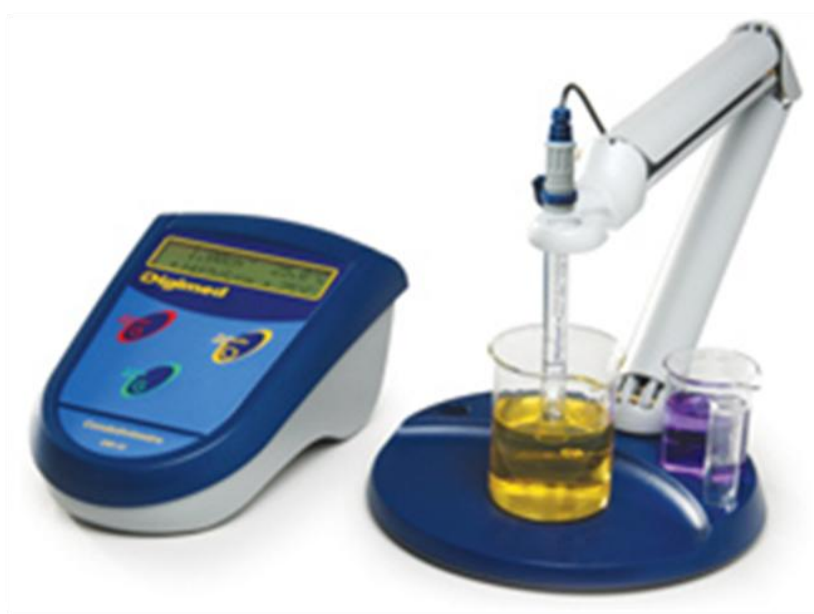

Figura 14 - Ilustração do condutivímetro DM-32 da Digimed.

Outros acessórios do sistema de medida de condutividade elétrica consistem em balão volumétrico de $250 \mathrm{~mL}$ com três bocas (Figura 16b) e condensador tipo Allihn (Figura 16a). 

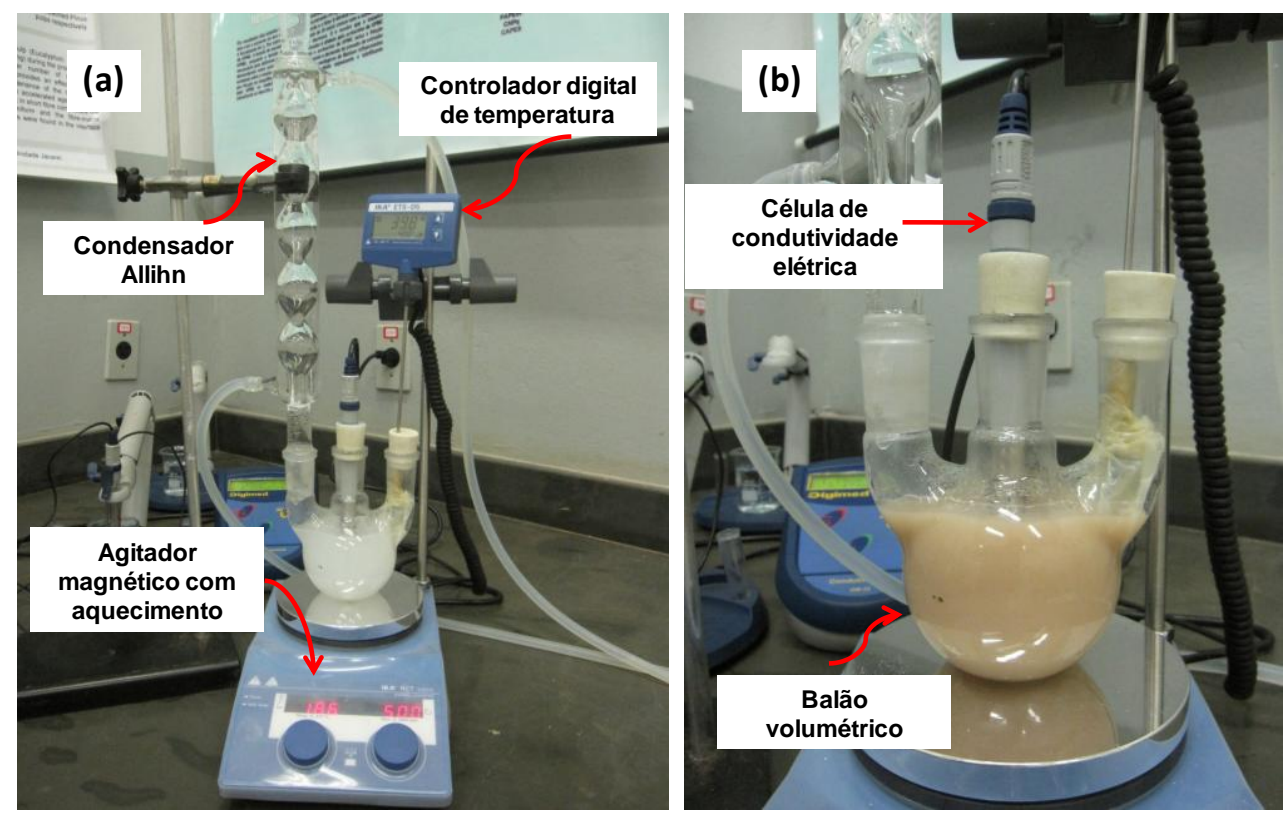

Figura 15 - Sistema de medida de condutividade elétrica com controle de temperatura. (a) Detalha a disposição do condensador Allihn, agitador magnético com aquecimento e controlador digital de temperatura. (b) Indica a disposição da célula de condutividade e do balão volumétrico de três bocas na base do agitador.

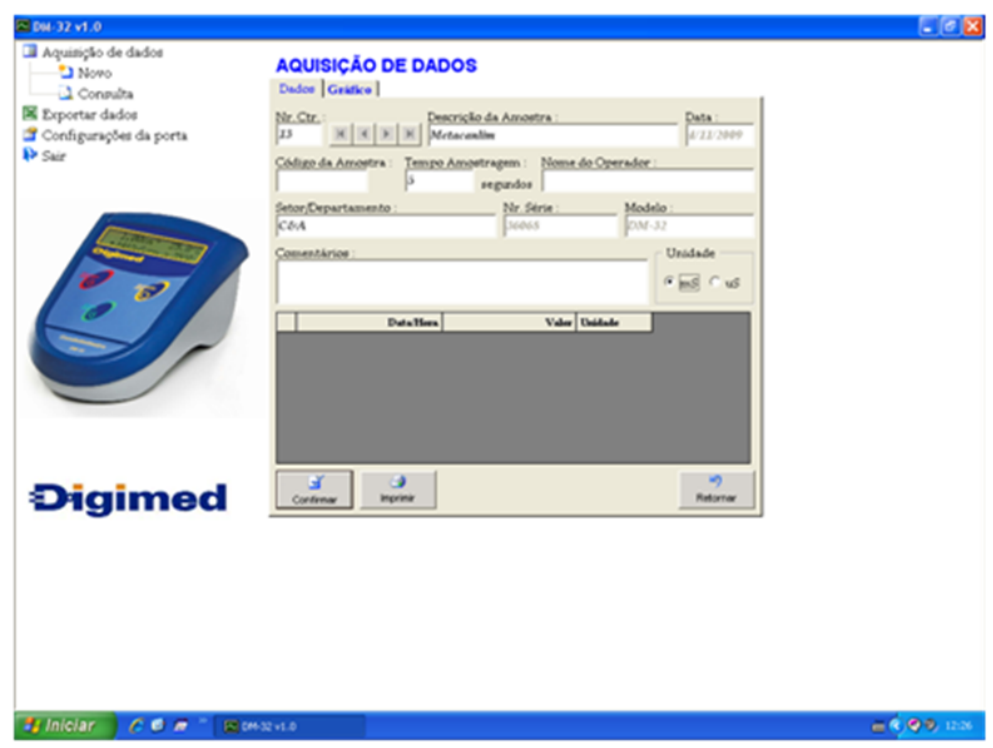

Figura 16 - llustração da janela de identificação do programa de aquisição de dados do condutivímetro DM-32 da Digimed.

As etapas de preparação da solução alcalina e medida da condutividade elétrica foram às seguintes: 
- Coletar $250 \mathrm{~mL}$ de água deionizada em becker de vidro graduado e verter no balão volumétrico. A água deionizada foi utilizada para minimizar a influência de sais dissolvidos, dando-Ihes uma pureza iônica. A água foi retirada do deionizador, modelo DE1800, da Permution;

- Aquecer a água no balão em cima da base do agitador magnético, sob agitação com velocidade de 900 RPM, até atingir a temperatura estipulada no controlador digital e deixá-la se estabilizar;

- Pesar 500 mg de hidróxido de cálcio $\mathrm{Ca}(\mathrm{OH})_{2}$ (procedência: Sigma-Aldrich, com pureza maior ou igual a 95\%) na balança de precisão $(0,0001 \mathrm{~g})$, marca Shimadzu;

- Adicionar $\mathrm{Ca}(\mathrm{OH})_{2}$ no balão sobre o agitador magnético com aquecimento (velocidade 900 RPM). O valor inicial da condutividade do sistema dependerá da temperatura definida de ensaio. $O$ acompanhamento desse valor deve ser feito observando diretamente no leitor do condutivímetro até estabilizar a medida de condutividade;

- Pesar 5,25 g de adição mineral na balança de precisão Shimadzu (precisão $0,0001 \mathrm{~g}$ );

- Caso a solução estiver nos requisitos estabelecidos previamente, temperatura e valor condutividade estabilizados, acionar o programa de aquisição de dados (preencher os campos da janela de identificação, Figura 16). Determinar no programa que coleta de pontos seja a cada $20 \mathrm{~s}$;

- Acrescentar a adição mineral na solução;

- A duração do ensaio definida neste trabalho foi de no mínimo $24 \mathrm{~h}$.

\subsection{Caracterização e preparação das matérias-primas cimentícias}

Para formular o compósito foram necessárias várias etapas de classificação e de análise das matérias-primas.

Para tanto, as matérias-primas foram classificadas quanto à distribuição granulométrica usando o principio de difração à laser e dispersando as partículas 
em álcool isopropílico, com o equipamento Malvern Mastersize S long bed versão 2.19.

As matérias-primas foram caracterizadas também quanto à densidade real, visto que esta informação foi importante para formular os compósitos por teores em volume. Para isto, foi usado um multipicnômetro da Quantachrome, pela técnica de deslocamento de hélio. A análise química quantitativa foi por fluorescência de raios$X$ no equipamento Axios Advanced da marca Panalytical.

O cálculo da área superficial das matérias-primas que compõem a matriz dos compósitos foi pelo método BET. Os equipamentos utilizados para a preparação das amostras e para análise foram, respectivamente, o VacPrep 061 e o Gemini III 2375, ambos da Micromeritics. O gás usado na adsorção foi o nitrogênio e os ensaios foram efetuados na temperatura de 77K. A amostra foi tratada em vácuo (100 $\mu \mathrm{m}$ de $\mathrm{Hg}$ ) com tratamento térmico de 15 horas, após continuou o tratamento térmico sem vácuo por mais 6 horas sempre na temperatura de $110^{\circ} \mathrm{C}$.

Para identificação de fases por difração de raios- $X$, alguns materiais foram moídos usando pulverizador rotativo, modelo MA-590, da Marconi. No entanto, para todas as amostras foi usada uma granulometria passante na peneira padrão U.S. Tyler \# 325 mesh. Foi utilizado equipamento Philips, modelo MPD 1880. A identificação de fases cristalinas foi obtida por comparação do difratograma da amostras com os bancos de dados PDF2 do ICDD - International Centre for Diffraction Data e PAN-ICSD Panalytical Inorganic Crystal Structure Database (2007).

A morfologia das partículas foi analisada por meio de microscopia eletrônica de varredura. O estudo da granulometria e do formato das partículas será útil para análise do empacotamento das mesmas na matriz cimentícia.

\subsubsection{Preparação das matrizes de compósitos cimentícios}

Os materiais que compõem o compósito estão classificados em dois tipos: matriz e reforço. O material matriz é o que confere estrutura ao compósito, preenchendo os espaços vazios que ficam entre os materiais reforços e mantendoos em suas posições relativas. 
Os teores das matérias-primas e da fibra foram definidos em volume com base no conceito de empacotamento (volume ocupado pelo material), que é condição básica para o desenvolvimento de materiais cimentícios em geral, inclusive fibrocimento, visto ser determinante de uma série de propriedades desses materiais.

Entre elas, destaca-se o controle do comportamento reológico de suspensões e argamassa, bem como da resistência mecânica final do compósito.

Foi adotado o cimento Portland CPV-ARI por ser, comercialmente, o cimento disponível com menor teor de adições, nesse caso, sílica cristalina, e sem adições pozolânicas, evitando-se, assim, efeitos combinados de diferentes pozolanas (adições minerais). Outra importante característica do CPV ARI está na distribuição granulométrica (diâmetro médio equivalente de partículas, $D(50)$, igual a 10,98 $\mu \mathrm{m}$ ).

Quanto mais fino o cimento, mais rápida será sua reação de hidratação e maior sua reatividade. Adicionalmente, o cimento CPV ARI contém teores mais elevados de $\mathrm{C}_{3} \mathrm{~S}$ e $\mathrm{C}_{2} \mathrm{~S}$ para formação de C-S-H.

A polpa de eucalipto não-braqueada foi usada porque, segundo TONOLI (93), as fibras branqueadas são menos resistentes mecanicamente devido às reações de polimerização ocorridas durante o processo de branqueamento (retirada de lignina).

A Tabela 2 mostra as características da polpa de eucalipto não-branqueada e não-refinada.

Tabela 2 - Características físicas da polpa de eucalipto não-branqueada* (94).

\begin{tabular}{cccccc}
\hline $\begin{array}{c}\text { Polpa } \\
\operatorname{CSF}(\mathrm{mL})\end{array}$ & $\begin{array}{c}\text { Comprimento } \\
\text { médio }(\mathrm{mm})\end{array}$ & $\begin{array}{c}\text { Largura média } \\
(\mu \mathrm{m})\end{array}$ & $\begin{array}{c}\text { Razão de } \\
\text { Aspecto }\end{array}$ & $\begin{array}{c}\text { Material fibroso } \\
\left(10^{6} \text { fibras } / \mathrm{g}\right)\end{array}$ & $\begin{array}{c}\text { Conteúdo de finos } \\
(\%)\end{array}$ \\
\hline 664 & $0.83 \pm 0.05$ & $16.4 \pm 0.2$ & 51 & $18.17 \pm 1.11$ & $25.7 \pm 0.6$ \\
\hline
\end{tabular}

* Doada pela empresa Fibria (Fusão das empresas Aracruz e Votorantim Celulose e Papel).

\subsection{Processo de extrusão}

O êxito do processo de extrusão depende do comportamento reológico da formulação, e da boa homogeneização das misturas. O comportamento reológico da mistura cimentícia é um dos aspectos de fundamental importância fundamental no processo de extrusão. As características reológicas da mistura são influenciadas 
principalmente pela quantidade de cimento, material de enchimento (material carbonático e outras adições minerais, por exemplo), fibra, surfactante, água e modificador reológico, bem como pelas características físicas, químicas e morfológicas desses componentes a serem utilizados na mistura $(95,12)$.

Desse modo, para viabilizar o processo de extrusão foram usados modificadores reológicos à base de celulose (hidroxipropilmetilcelulose, HPMC) da linha Celotex, da empresa Aditex indústria e comércio, e um redutor de água (ADVA 190), da empresa Grace, a fim de garantir que a formulação seja extrudável. Esses tipos de modificadores, na literatura, são mencionados como os que têm apresentado uma maior eficiência na produção de extrudados de fibrocimento, segundo Shen (82). Em todas as formulações foi usado o teor de $1 \%$ em massa de modificadores reológicos sobre a massa total de particulados. Um importante aspecto dos modificadores é a capacidade de impedir separação das fases durante a homogeneização da mistura.

Os corpos-de-prova prismáticos das matrizes extrudadas foram produzidas na máquina extrusora à vácuo com rosca helicoidal (tipo Auger), com diâmetro e comprimento de $75 \mathrm{~mm}$ e $500 \mathrm{~mm}$, respectivamente. O equipamento, modelo MVIG05, da marca Gelenski, contém um regulador de velocidades. A velocidade média utilizada foi de 25 RPM. Foi usada uma boquilha com $100 \mathrm{~mm}$ de comprimento.

Esse equipamento e acessórios encontram-se disponíveis e em operação no Laboratório de Construções e Ambiência da FZEA USP (Figura 17). 


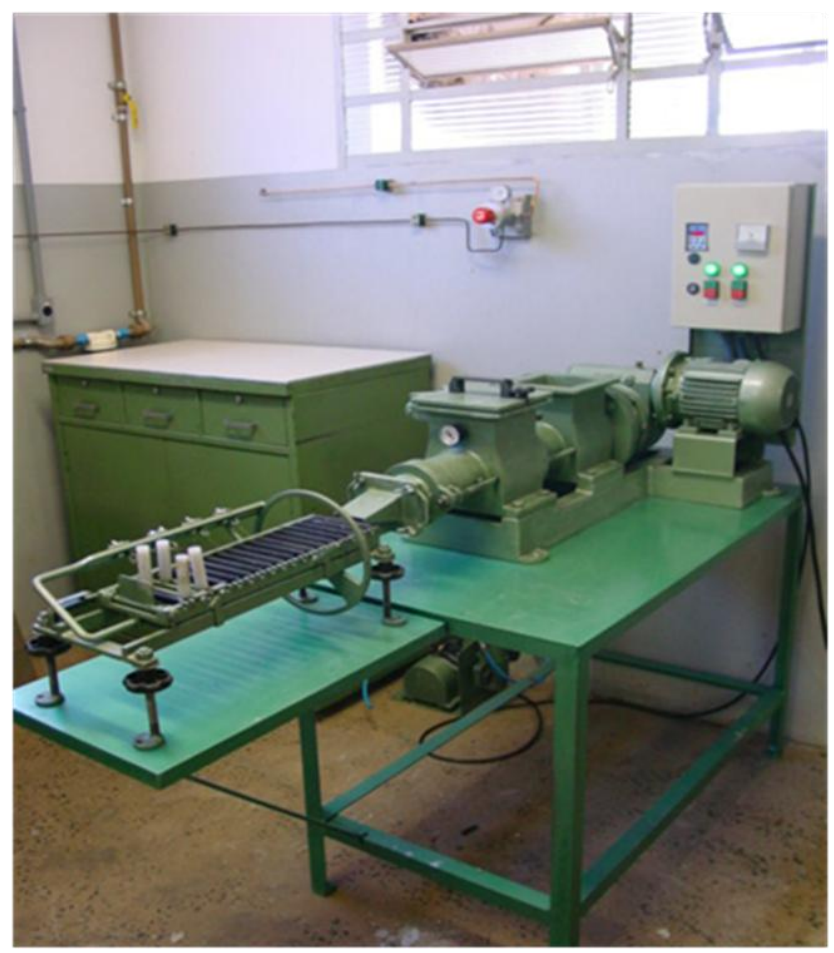

Figura 17 - Foto da extrusora do Laboratório de Construções e Ambiência, da FZEA da Universidade de São Paulo.

As formulações utilizadas na produção das placas estão descritas na tabela 3 e foram baseadas em estudos anteriores Aldea et al.(96) e Tonoli (97) que fabricou placas pelo processo de Hatschek (processo de produção industrial de placas de fibrocimento) e foram adaptadas para o processo de extrusão. A quantidade de polpa foi escolhida através de estudos anteriores pelo processo de extrusão onde 0 melhor resultado mecânico foi apresentado por $3 \%$ de polpa utilizada como reforço secundário. Foram utilizadas $\mathrm{FBC}$ não tratada e tratada $\left(2^{\circ}\right.$ fase), onde a relação água/cimento foi de 0,28. Com 3 e $5 \%$ de reforço a relação foi de 0,29 . A substituição do cimento por $30 \%$ de CBC ( $3^{\circ}$ fase) foi baseada em estudos anteriores Paula (98), onde a relação água/cimento foi de 0,32.

A escolha da formulação para a substituição do cimento por CBC será avaliada pelo resultado mecânico de 28 dias, onde o melhor resultado será à formulação escolhida. Outro dado importante para a produção é o custo e quantidade de matéria-prima utilizada. Será realizado um estudo quanto ao custo em relação ao processo mais utilizado para a produção de fibrocimento.

A Tabela 3 apresenta as formulações utilizadas nas moldagens em valores de volume das matérias-primas. 
Tabela 3 - Formulações utilizadas nas moldagens (Valores \% em volume de matéria prima).

\begin{tabular}{|c|c|c|c|c|c|c|c|c|}
\hline & \multicolumn{6}{|c|}{$2^{\circ}$ Fase } & \multirow{2}{*}{$\begin{array}{c}3^{\circ} \text { Fase } \\
\text { FBC } 5,0 \% \\
+30 \% \\
\text { CBC }^{(c)}\end{array}$} \\
\hline & & $0,0 \%$ & $\begin{array}{c}\mathrm{FBC}^{(\mathrm{a})} \\
0,5 \%\end{array}$ & $\begin{array}{l}\text { FBC } \\
1,0 \%\end{array}$ & $\begin{array}{l}\text { FBC } \\
1,5 \%\end{array}$ & $\begin{array}{l}\text { FBC } \\
3,0 \%\end{array}$ & $\begin{array}{l}\text { FBC } \\
5,0 \%\end{array}$ & \\
\hline $\begin{array}{l}\text { Cimento } \\
\text { ARI }\end{array}$ & CPV- & 70 & 70 & 70 & 70 & 70 & 70 & 40 \\
\hline $\begin{array}{l}\text { Sílica } \\
\# 500^{(b)}\end{array}$ & Moída & 27 & 26,5 & 26 & 25,5 & 24 & 22 & 22 \\
\hline \multicolumn{2}{|c|}{$\begin{array}{l}\text { Polpa Celulósica } \\
\text { não branqueada }\end{array}$} & 3 & 3 & 3 & 3 & 3 & 3 & 3 \\
\hline \multicolumn{2}{|c|}{$\begin{array}{l}\text { Fibra de bagaço } \\
\text { de cana }\end{array}$} & - & 0,5 & 1 & 1,5 & 3 & 5 & 5 \\
\hline \multicolumn{2}{|c|}{ Cinza de bagaço } & - & - & - & - & - & - & 30 \\
\hline
\end{tabular}

(a) Fibra de bagaço de cana; (b) mesh \#500 (abertura 0,025mm); (C) Cinza de bagaço de cana.

Antes de iniciar a extrusão, a mistura cimentícia e redutor de água (ADVA 190) foram colocados na argamassadeira, modelo 20LA, da Amadio, e homogeneizada a seco em baixa rotação (mistura distributiva, com velocidade de rotação 01), o tempo total de mistura foi em torno de 10 min. Após essa etapa, a polpa de eucalipto não-branqueada e dispersa foi adicionada e misturada por 3 min.

Posteriormente se procedeu à introdução lenta do HPMC com a água, continuando-se com a mistura por aproximadamente $3 \mathrm{~min}$. Em seguida, aumentouse a rotação da argamassadeira para velocidade 03 por 3 min. Antes de gerar as placas definitivas a massa foi homogeneizada na própria extrusora, alimentado a e retirando a massa por três vezes. Placas de 15 × $200 \mathrm{~mm}$ de espessura e comprimento, de acordo com as Figuras 18a, 18b e 18c, foram extrudadas para atender os métodos de caracterização mecânica propostos neste trabalho. 


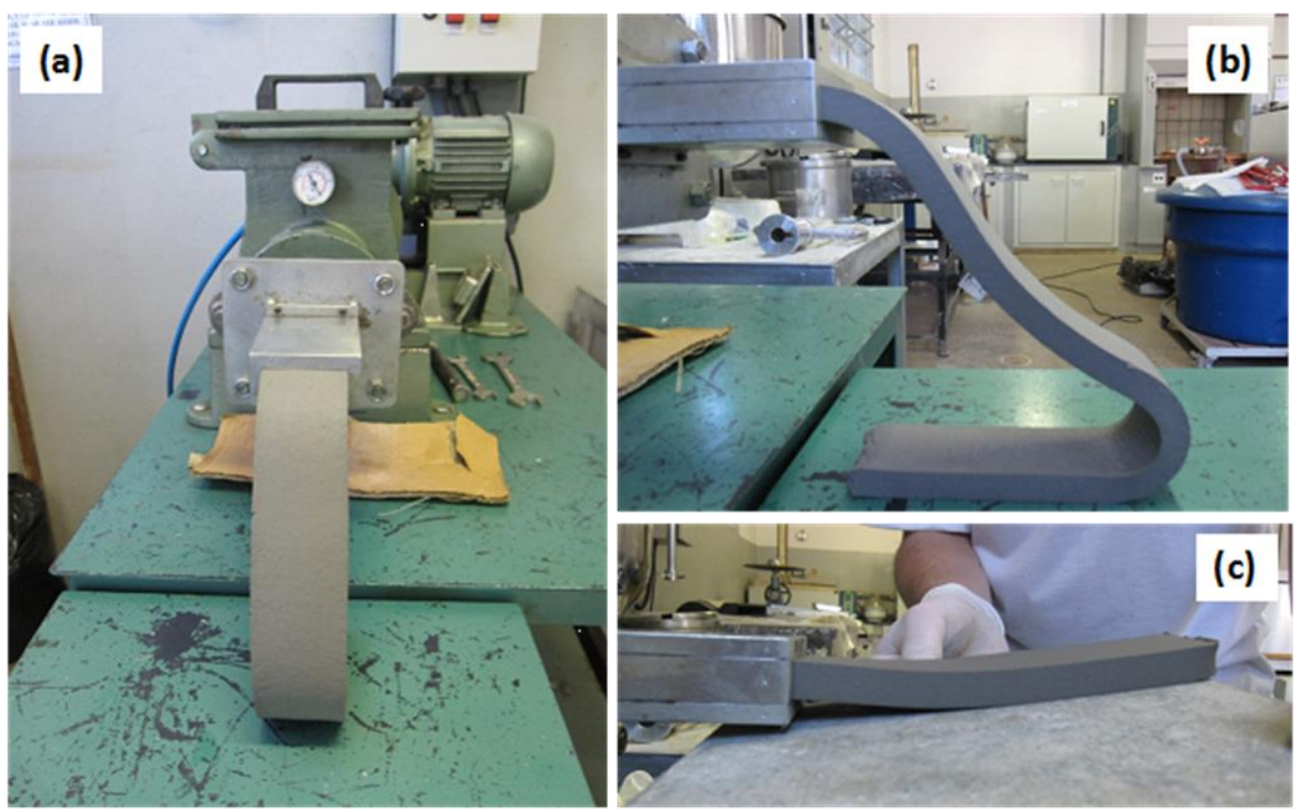

Figura 18 - (a) Vista frontal da máquina extrusora à vácuo. (b) Vista lateral ilustrando a saída de massa pela boquilha. (c) Colocação de um corpo extrudado sobre uma placa metálica.

Após a extrusão, no processo de cura, os corpos-de-prova foram colocados em ambientes saturados (sacos plásticos selados) em temperatura ambiente por dois dias. Depois desse período, as placas forma imersas em recipientes com água, em temperatura ambiente, por 26 dias. Para atender a todos os ensaios, a placa foi cortada em serra com disco de diamante refrigerada a água em corpos de prova com dimensões de $15 \times 20$ × 90 mm (Figura. 19).

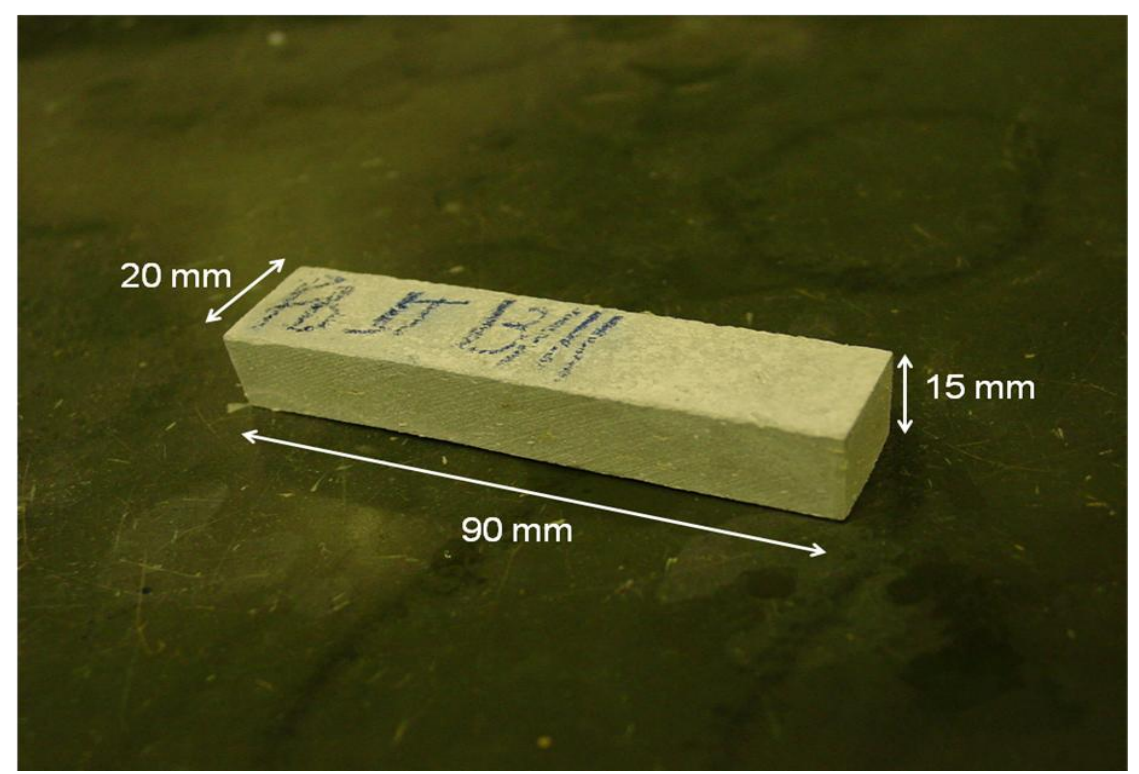

Figura 19 - Dimensões do corpo-de-prova usado nos experimentos 


\subsection{Caracterizações dos compósitos}

\subsubsection{Caracterização mecânica dos compósitos}

Os testes mecânicos foram executados em uma máquina de testes Instron modelo 5569 (Figura 20a), equipado com célula de carga de $1 \mathrm{kN}$. Uma configuração com quatro cutelos (diâmetro dos cutelos igual a $10 \mathrm{~mm}$ ), com vão inferior igual a $75 \mathrm{~mm}$ (Figura 20b) e taxa de deslocamento de $5,0 \mathrm{~mm} / \mathrm{min}$ foram empregados na determinação dos valores de tensão no limite de proporcionalidade (LOP), módulo de ruptura (MOR), módulo elástico (MOE) e tenacidade do material (TE). As fórmulas para o cálculo de LOP, MOR e MOE estão apresentadas nas Eqs.

3 a 5 :

$$
\begin{gathered}
L O P=\frac{P_{\text {lop }} \cdot L_{v}}{b \cdot h^{2}} \\
M O R=\frac{P_{\max } \cdot L_{v}}{b \cdot h^{2}} \\
M O E=\frac{276 \cdot L_{v}{ }^{3}}{1296 \cdot b \cdot h^{3}} \cdot(m)
\end{gathered}
$$

Nas citadas equações, $P_{\text {lop }}$ é a força no maior ponto da parte linear da curva força vs deflexão, $P_{\max }$ é a força máxima, $L_{v}$ é a medida do vão inferior de ensaio, $b$ e h são a largura e espessura dos compósitos respectivamente, $m$ é a tangente do ângulo de inclinação da curva força vs deflexão durante a deformação elástica. 


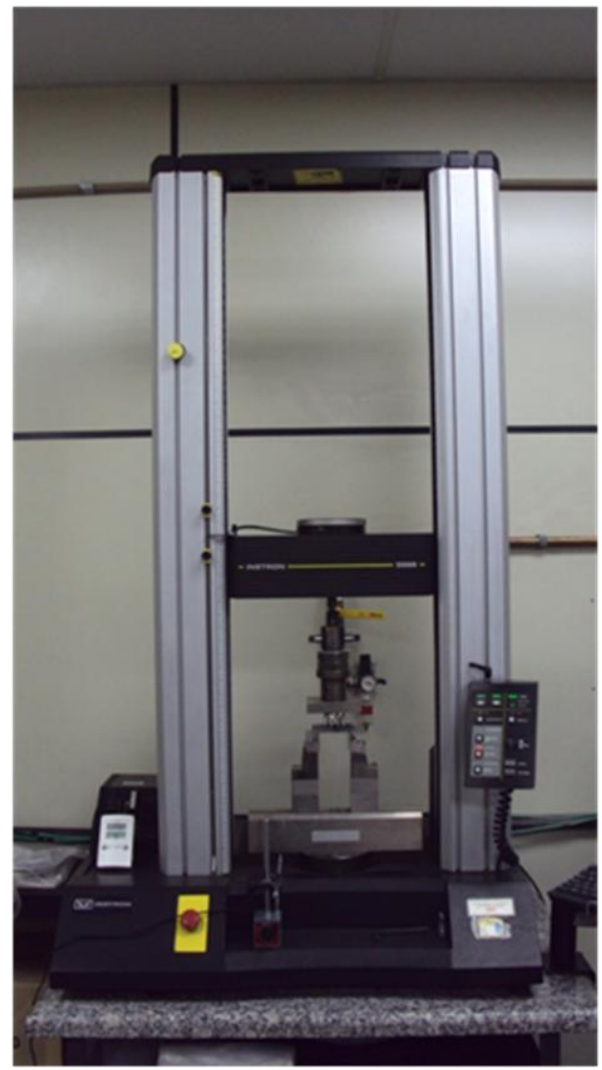

(a)

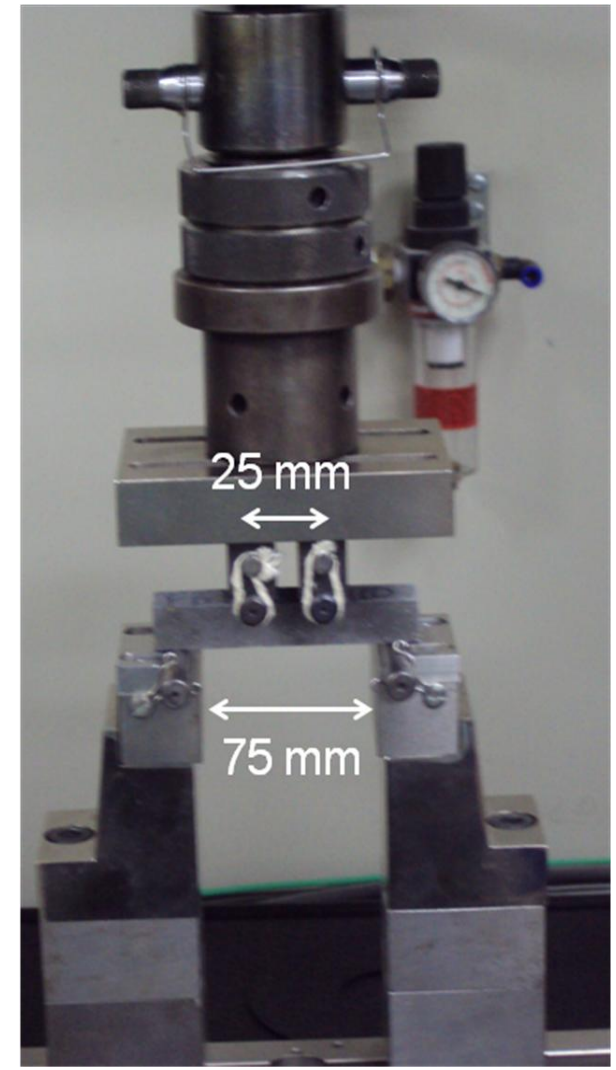

(b)

Figura 20 - (a) Vista geral da máquina de ensaios mecânicos da marca Instron, modelo 5569; (b) Dispositivo de flexão com quatro cutelos.

A tenacidade (TE) foi definida como a energia absorvida durante o teste de flexão, dividido pela área da seção transversal da amostra sob investigação (Eq. 6), como descrito previamente (20) e adaptado de RILEM (99). A energia absorvida foi obtida pela integral da área sob a curva força vs deflexão até o ponto correspondente a redução da capacidade de força para $90 \%$ da força máxima atingida. A deflexão durante o teste de flexão foi coletada por um deflectômetro posicionado no meio do vão, na face inferior do compósito. Os valores de tensão $(\sigma)$ foram calculados usando a Eq. 3 para cada valor de força, P. Os valores de deflexão foram divididos pela medida do vão $(75 \mathrm{~mm})$ e chamados no presente trabalho de deflexão específica (ס). A Figura 21 apresenta uma curva típica de tensão vs deflexão específica que define LOP, MOR, tenacidade (TE) usados no presente trabalho. MOE não está definida na Figura 21 porque foi determinado pela Eq. 5 usando as curvas força vs deflexão. 
Tenacidade $=\frac{\text { energia absorvida }}{b \cdot h}$

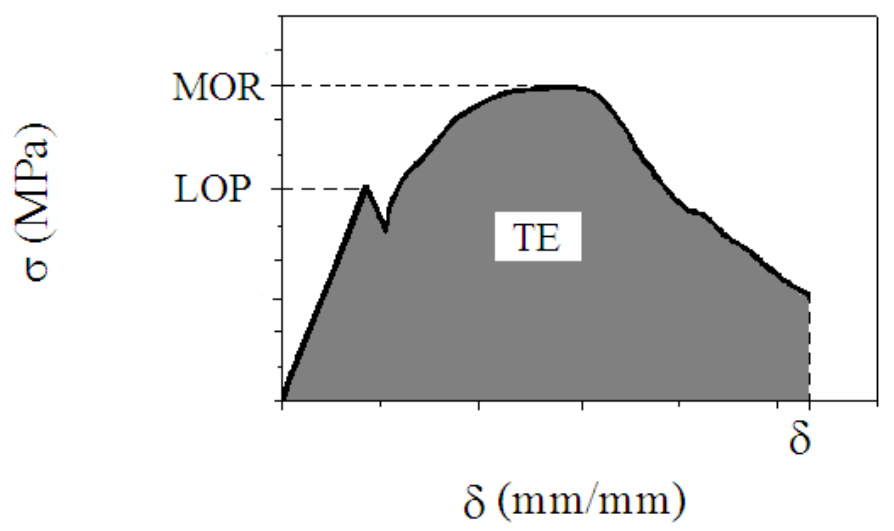

Figura 21 - Definição dos parâmetros mecânicos em uma curva típica de tensão vs deflexão específica (100).

\subsubsection{Caracterização física dos compósitos}

Os valores de absorção de água (AA), de porosidade aparente (PA) e de densidade aparente (DA) foram determinados pela média de seis corpos-de-prova para cada formulação, seguindo os procedimentos especificados pela norma ASTM C 948-81 (101).

A caracterização física dos compósitos foi realizada aos 28 dias e após os envelhecimentos acelerados. A equação 7 foi utilizada para o cálculo da absorção de água, $A A$, em \%, dos compósitos:

$$
A A=\left(\frac{M_{s s s}-M_{\text {seca }}}{M_{\text {seca }}}\right) \cdot 100
$$

Onde $\mathrm{M}_{\mathrm{sss}}$ é a massa do compósito saturado em água e com superfície seca e $\mathrm{M}_{\text {seca }}$ é a massa do compósito seco em estufa ventilada a $105^{\circ} \mathrm{C}$ por $48 \mathrm{~h}$.

\footnotetext{
* Densidade aparente no presente trabalho também é definida por outros autores como massa específica
} 
A porosidade aparente, $\mathrm{PA}, \mathrm{em} \%$ e a densidade aparente, DA, em $\mathrm{g} / \mathrm{cm}^{3}$, foram determinadas com as Eq. 8 e Eq. 9:

$$
\begin{gathered}
P A=\left(\frac{M_{\text {sss }}-M_{\text {seca }}}{M_{\text {sss }}-M_{i}}\right) \cdot 100 \\
D A=\left(\frac{M_{\text {seca }}}{M_{\text {sss }}-M_{i}}\right) \cdot \rho
\end{gathered}
$$

Onde $M_{i}$ é a massa do compósito saturado imerso em água e $\rho$ é a densidade da água $\left(\mathrm{g} / \mathrm{cm}^{3}\right)$.

\subsubsection{Microscopia eletrônica de varredura dos compósitos (MEV)}

O efeito das diferentes condições das fibras na microestrutura do compósito e na interface entre fibra e matriz foi avaliado por microscopia eletrônica de varredura (MEV) com detector de elétrons retroespalhados (BSE) em superfícies cortadas e polidas de secções transversais dos compósitos (Figura 22). As imagens BSE permitem a fácil identificação de fases cimentícias, pelo contraste entre números atômicos. Áreas escuras e claras estão relacionados a elementos leves e pesados, respectivamente. A localização dos átomos de cálcio (Ca), carbono (C) e silício (Si) na secção transversal dos compósitos foi realizada usando micro-análises de fluorescência de raios- $X$ com detector de energia dispersa (EDS) nas mesmas amostras com superfície polida.

Os procedimentos para preparação das amostras foram baseados em Savastano Jr., Warden e Coutts (102). A preparação das amostras para BSE e EDS foi realizada com a impregnação/embutimento a vácuo $(25 \mathrm{kPa})$ usando resina epóxi (MC-DUR1264FF). As amostras foram então lixadas com lixas de carbeto de silício (SiC) na seqüência de granulometrias de 120, 320 e 500 durante 4 min cada, usando etanol (Struers DP-lubricant), como lubrificante. O polimento final foi realizado com pasta de diamante de diferentes granulometrias na seguinte 
seqüência: 8-4 $\mu \mathrm{m}, 4-2 \mu \mathrm{m}$ e 1-0 $\mu \mathrm{m}$ durante 6 min cada. As amostras foram cobertas com carbono (grafite) antes de serem analisadas em um microscópio eletrônico LEO Leika S440 com aceleração de voltagem de 20 kV e corrente em torno de $150 \mathrm{~mA}$, como descrito na literatura (102).

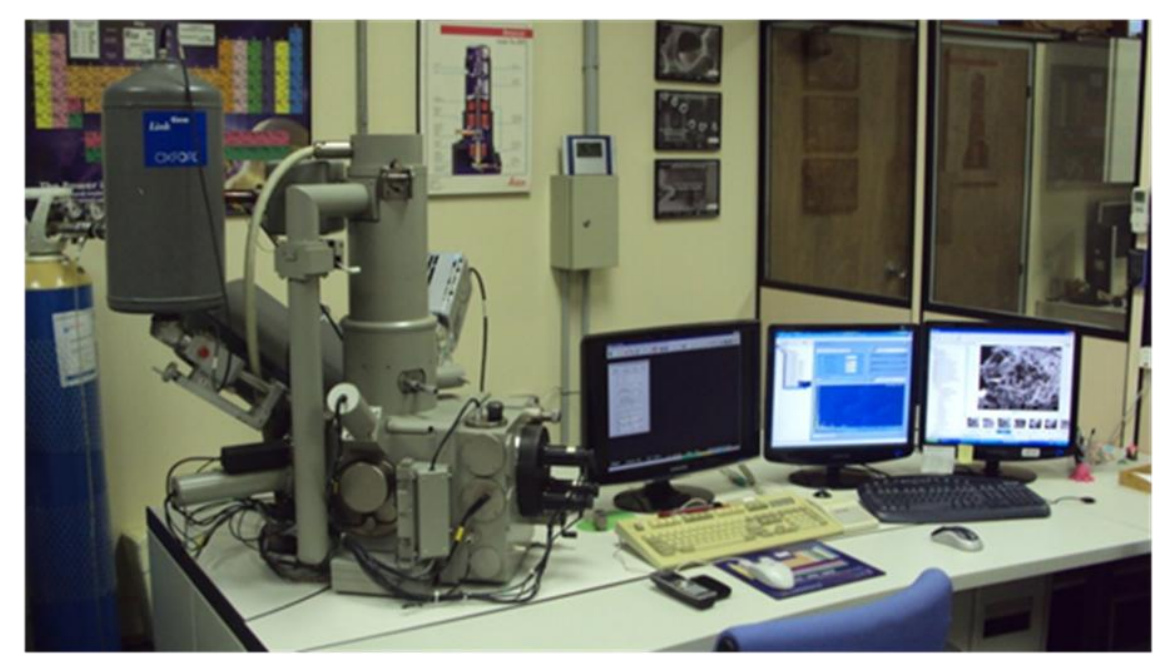

Figura 22 - Visão geral do microscópio eletrônico de varredura (MEV).

\subsubsection{Distribuição do tamanho de poros dos compósitos (PIM)}

A porosimetria por intrusão de mercúrio (PIM) foi utilizada para avaliação da distribuição do tamanho de poros em algumas amostras, com um equipamento Micromeritics Poresizer 9320, e pressão de até 200 MPa. Foi assumida uma tensão superficial de $0,495 \mathrm{~g} / \mathrm{cm}^{2}$ para o mercúrio e densidade de $13.534 \mathrm{~kg} / \mathrm{m}^{3}$. O tempo de equilíbrio entre a baixa e alta pressão foi de $10 \mathrm{~s}$. O ângulo de contato assumido para o avanço e o retrocesso foi de 130․ A quantidade de mercúrio intrudida em cada intervalo de pressão foi registrada. As amostras foram cortadas em dimensões nominais de $6 \mathrm{~mm}^{3}$, secas a temperatura de $70^{\circ} \mathrm{C}$ por $24 \mathrm{~h}$ e armazenadas em recipientes selados livres do contato com ar e umidade até o momento da análise.

Esta técnica foi adotada para a avaliação da distribuição do tamanho de poros, como normalmente é realizado na caracterização de materiais cimentícios (103-105). 


\subsubsection{Permeabilidade ao ar do compósito}

A permeabilidade pode ser associada com as propriedades da estrutura (por exemplo, empacotamento das partículas e poros permeáveis) e com a resistência à penetração de agentes de degradação. A avaliação experimental de permeabilidade ao ar, à temperatura ambiente em torno de $25^{\circ} \mathrm{C}$ foi realizado em um permeâmetro descrito por Innocentini et al. (106), (Figura. 23a).

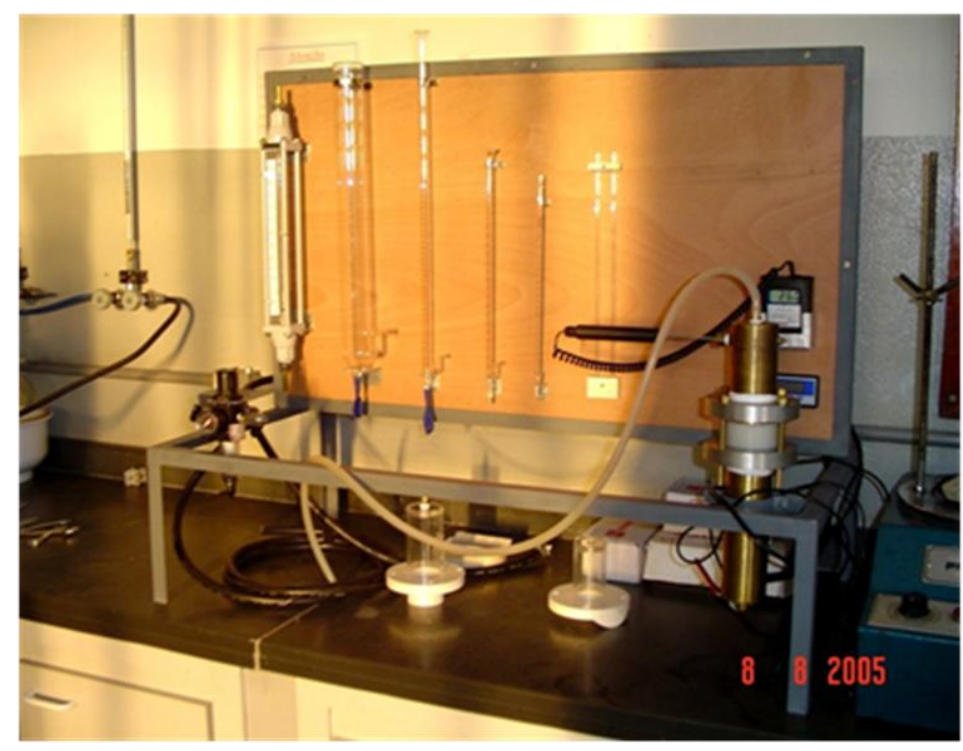

(a)

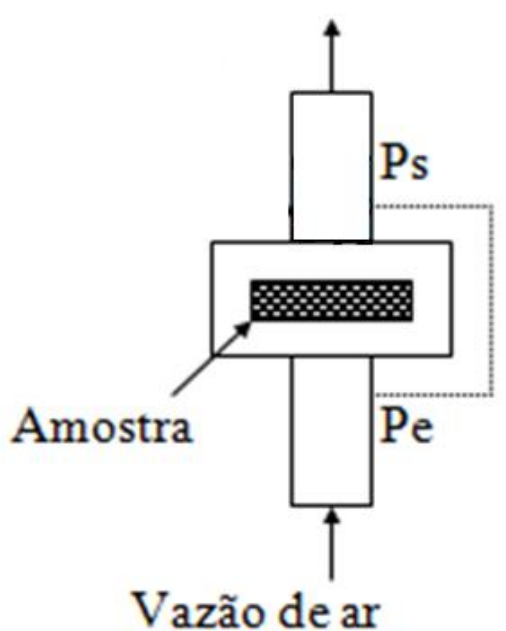

(b)

Figura 23 - (a) Vista geral do Permeâmetro; (b) Dispositivo de coleta de pressões de ar de entrada $(\mathrm{Pe})$ e pressão de saída (Ps).

A amostra foi fixada entre duas câmaras com uma área de testes de 4,91 x $10,4 \mathrm{~m}^{2}$. O experimento avaliou a facilidade do fluxo de ar que passa através da espessura da amostra (cerca de $15 \mathrm{~mm}$ ), medindo a velocidade do ar de saída em resposta às variações da pressão de entrada aplicada (Figura 23b). Testes de permeabilidade foram realizados em três amostras da formulação com 0\%, 5\% tratada e $5 \%+30 \%$ cinza. As amostras foram cortadas com diâmetro de $2,5 \mathrm{~cm}$ com auxílio de uma serra com disco diamantado refrigerado a água, em seguida a amostra foi preenchida com silicone nas laterais para evitar que o ar fuja. Após esse processo, as amostras foram postos a secar durante $2 \mathrm{~h}$ em estufa ventilada a 
$105^{\circ} \mathrm{C}$ marca Nova Ética, a umidade foi removida principalmente para evitar qualquer interferência da água livre sobre as medidas.

As constantes de permeabilidade $k_{1}$ e $k_{2}$ foram obtidos por meio do ajuste dos dados experimentais utilizando a equação de Forchheimer (Eq. 10), expressa para escoamento de fluidos compressíveis Innocentini et al. (107).

$$
\frac{P_{i}^{2}-P_{o}^{2}}{2 P_{o} L}=\left(\frac{\mu}{k_{1}}\right) v+\left(\frac{\rho}{k_{2}}\right) v^{2}
$$

onde:

Pi e Po: pressões de entrada e saída do ar, respectivamente;

v: é a velocidade do fluido;

$L$ : espessura da amostra;

$\mu$ : viscosidade do fluido;

$\rho$ : densidade do fluido;

$k 1$ e k2: constantes de permeabilidade.

A constante $k_{1}$, ou Darciana, representa os efeitos viscosos do escoamento (atrito e interações entre fluido e meio poroso) a constante $k_{2}$, ou não-Darciana, contabiliza os efeitos da tortuosidade do meio poroso quando a velocidade do escoamento é alta. Quanto maiores os valores de $k_{1}$ e $k_{2}$ mais permeável será o meio poroso (108).

\subsection{Envelhecimento acelerado (imersão-secagem)}

Um procedimento de imersão-secagem foi desenvolvido com o objetivo de estudar o comportamento do envelhecimento de fibras sob os efeitos do ambiente, estimulando o ataque da água alcalina dos poros nas fibras (por exemplo, condições envolvendo repetidas exposições à chuva e raios solares). $O$ envelhecimento 
acelerado de imersão-secagem para as placas foi baseado no procedimento da norma européia EN 494 (109).

Esse ensaio consiste em analisar comparativamente o desempenho físico e mecânico dos corpos-de-prova antes e após a realização de ciclos. Cada ciclo compreende uma imersão em água a temperatura ambiente durante $18 \mathrm{~h}$, e secagem em estufa ventilada a $60^{\circ} \mathrm{C} \pm 5^{\circ} \mathrm{C}$ com umidade relativa inferior a $20 \%$ durante $6 \mathrm{~h}$.

Esse procedimento foi repetido até se completarem 200 ciclos (200c). Segundo Soroushian e Marikunte (76), sob essas condições, as fibras entram em contato com a água alcalina dos poros do cimento durante a imersão, os produtos de decomposição são formados como um resultado da reação entre os componentes da fibra e a água do poro transportada para longe da fibra durante a fase de secagem.

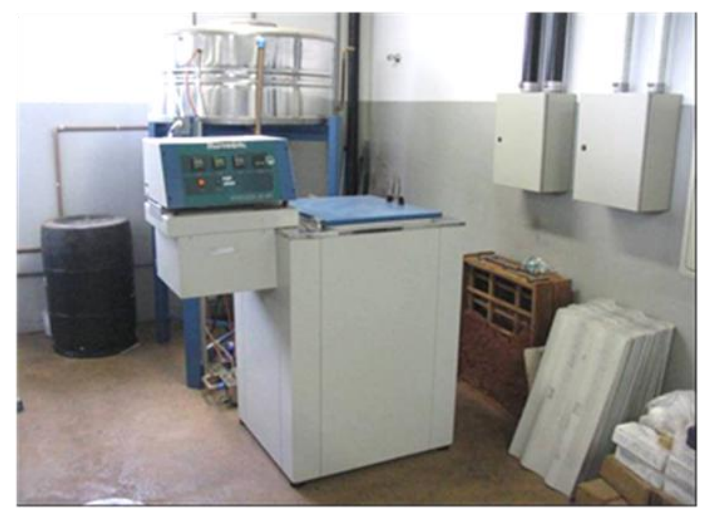

(a)

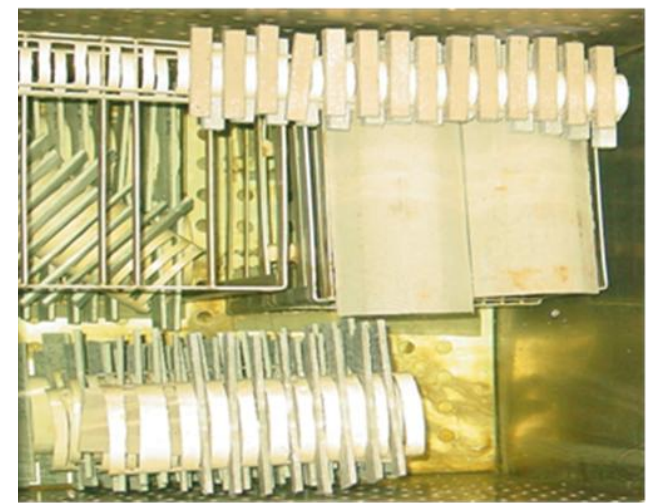

(b)

Figura 24 - (a) Estufa automática de operação dos ciclos de imersão-secagem; (b) Disposição das placas no interior do equipamento. 


\section{RESULTADOS E DISCUSSÃO}

Nesta seção são apresentados os resultados e discussões referentes às: estudo das fibras de bagaço de cana-de-açúcar (FBC) na seção 5.1 e 5.2; estudo das cinzas de bagaço de cana-de-açúcar (CBC) na seção 5.3.

Na seção 5.5 é apresentado o efeito dos diferentes níveis de reforço no desempenho dos compósitos. Em todas as avaliações mecânicas e caracterizações físicas foram utilizados no mínimo nove corpos-de-prova de cada formulação, para se ter uma média dos resultados e a dispersão dos valores.

\section{$\underline{5.1 \text { Caracterização das matérias-primas }}$}

Foram utilizados como matriz cimentícia o cimento Portland comum CPV-ARI (110) e a sílica cristalina \#500*. O fato do cimento não apresentar adições favorece um ambiente mais agressivo para o estudo da degradação/mineralização das fibras.

A sílica cristalina (foi utilizada como substituição parcial do cimento Portland, com o objetivo de reduzir custos de produção do compósito e melhorar o empacotamento da mistura. As composições químicas (\% em massa de óxidos) do cimento e da sílica cristalina foram determinadas pelo equipamento Axios Advanced da marca Panalytical.

A espectrometria de fluorescência de raios-X das matérias-primas está apresentada na Tabela 4.

\footnotetext{
* mesh \#500 (abertura 0,025 mm)
} 
Tabela 4 - Composição química (\% em massa de óxidos) dos cimentos Portland (CPV-ARI) e sílica cristalina.

\begin{tabular}{ccc}
\hline Óxidos & CPV-ARI $^{(\mathrm{a})}$ & Silica cristalina \#500 $^{(f)}$ \\
\hline $\mathrm{SiO}_{2}(\%)$ & 14,70 & $>99,0$ \\
$\mathrm{CaO}(\%)$ & 67,20 & $<0,10$ \\
$\mathrm{Al}_{2} \mathrm{O}_{3}(\%)$ & 2,85 & 0,28 \\
$\mathrm{Fe}_{2} \mathrm{O}_{3}(\%)$ & 3,50 & 0,05 \\
$\mathrm{MgO}(\%)$ & 1,03 & $<0,10$ \\
$\mathrm{P}_{2} \mathrm{O}_{5}(\%)$ & 0,24 & $<0,10$ \\
$\mathrm{SO}_{3}(\%)$ & 5,23 & $<0,10$ \\
$\mathrm{~K}_{2} \mathrm{O}(\%)$ & 0,75 & $<0,10$ \\
$\mathrm{SrO}(\%)$ & 0,24 & $<0,10$ \\
$\mathrm{MnO}(\%)$ & 0,06 & $<0,10$ \\
$\mathrm{TiO}_{2}(\%)$ & 0,19 & 0,04 \\
$\mathrm{P.F.}\left(1000^{\circ} \mathrm{C}\right)$ & 3,29 & 0,11 \\
Perda ao fogo (\%) & 2,65 & 0,01 \\
\hline
\end{tabular}

(a) NBR 5733 (1983) (b) peneira 200 mesh (\# 0,074 mm); (c) peneira 325 mesh (\# 0,045 $\mathrm{mm}$ ); (d) peneira 400 mesh (\# 0,038 mm); (e) $\mathrm{Nd}=$ não disponível até o momento e (f) peneira mesh 500 (\# 0,025 mm).

As distribuições do diâmetro de partículas das matérias-primas observam-se que 50 \% das partículas são menores que 11,0 $\mu \mathrm{m}$ e 5,0 $\mu \mathrm{m}$ para o cimento e para a sílica cristalina respectivamente. As distribuições do diâmetro do cimento e sílica cristalina estão apresentadas na Figura 25a e 25b respectivamente.

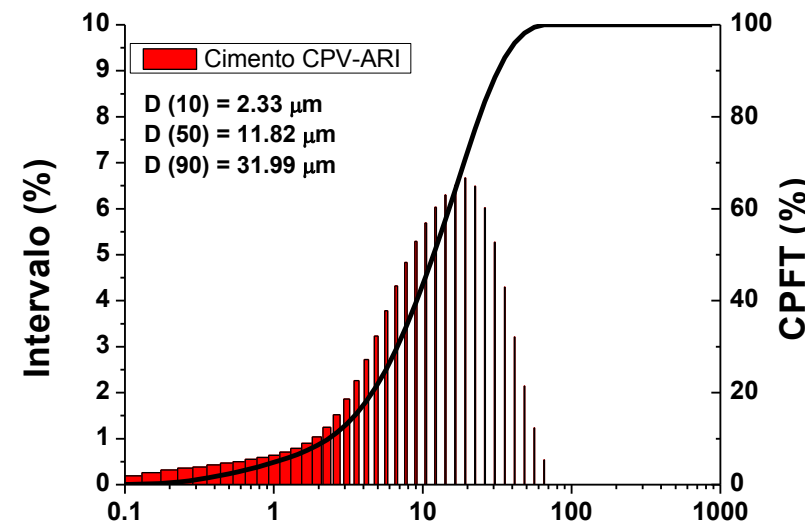

Diâmetro equivalente de particulas $(\mu \mathrm{m})$

(a)

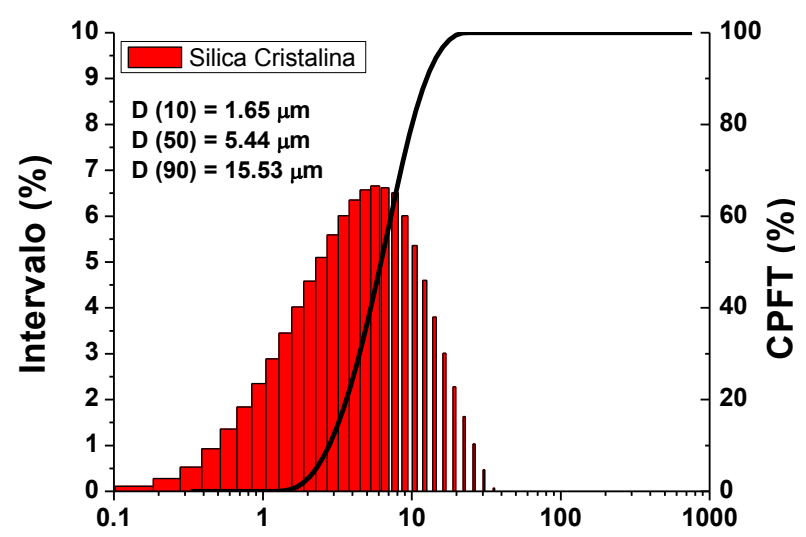

Diâmetro equivalente de particulas $(\mu \mathrm{m})$

(b)

Figura 25 - Distribuição do diâmetro de partículas: (a) cimento Portland (CPV-ARI); (b) sílica cristalina \#500. 
Embora as distribuições de tamanho de partículas do cimento Portland CPVARI e da sílica cristalina estejam indicando que $90 \%$ das partículas estão abaixo de $31 \mu \mathrm{m}$, estes contêm diferença na área superficial, como listada na Tabela 5, isto implica que pode auxiliar no comportamento reológico da mistura, com a diferença entre os tamanhos de partículas pode contribuir com a movimentação entre as mesmas, por conta de terem distribuições granulométricas diferentes.

Tabela 5 - Área superficial específica determinada pelo método BET a densidade real pelo método de deslocamento de hélio do cimento Portland CPV-ARI e da sílica cristalina utilizadas.

\begin{tabular}{ccc}
\hline Matéria-prima & BET (Single-point) $\left(\mathrm{m}^{2} / \mathrm{g}\right)$ & Densidade real $\left(\mathrm{g} / \mathrm{cm}^{3}\right)$ \\
\hline Cimento CPV-ARI & 0,98 & 3,10 \\
Sílica cristalina & 2,34 & 2,66 \\
\hline
\end{tabular}

\subsection{Resultados do estudo da FBC}

\subsubsection{Resultado do teor de extrativos de acú́cares residuais da FBC}

$\mathrm{Na}$ Tabela 6 apresenta o resultado do banho das FBC em água fervente após o recebimento para redução de teor de extrativos de açúcares residuais.

Sarmiento (84), através de análises por espectrofotômetro, pelo método antrona, conclui que o banho em água fervente por 30 min diminui o açúcar residual em torno de $60 \%$. Este resultado ainda será discutido posteriormente nesse trabalho.

Tabela 6 - Resultado da determinação de teor de açúcar residual.

\begin{tabular}{cc}
\hline Amostra & Redução do teor de açúcar residual (\%) \\
\hline FBC não tratada & 10,54 \\
\hline
\end{tabular}


5.2.2 Resultado das dimensões nominais das FBC

No Figura 26 estão apresentadas as principais características físicas das FBC, determinadas com a medição de comprimento e espessura. $30 \%$ das FBC utilizadas apresentam entre 10 e $15 \mathrm{~mm}$ de comprimento e quase $50 \%$ entre 0,25 e $0,50 \mathrm{~mm}$ de espessura. Como podem ser observadas as características das FBC, tem tamanhos variados em função da peneira escolhida.

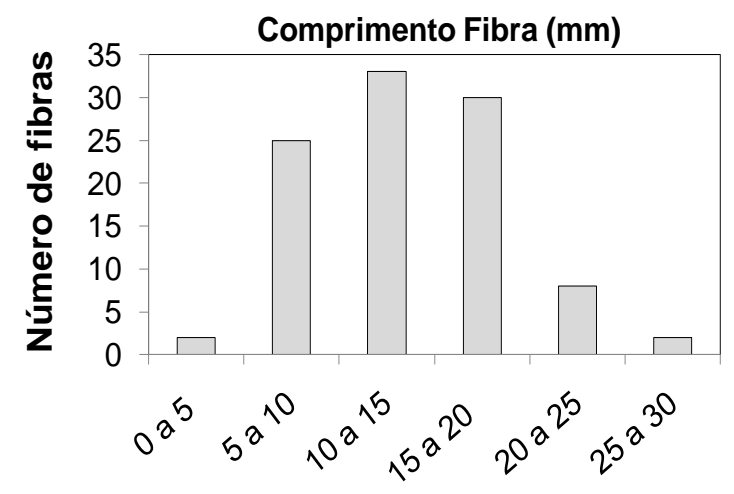

(a)

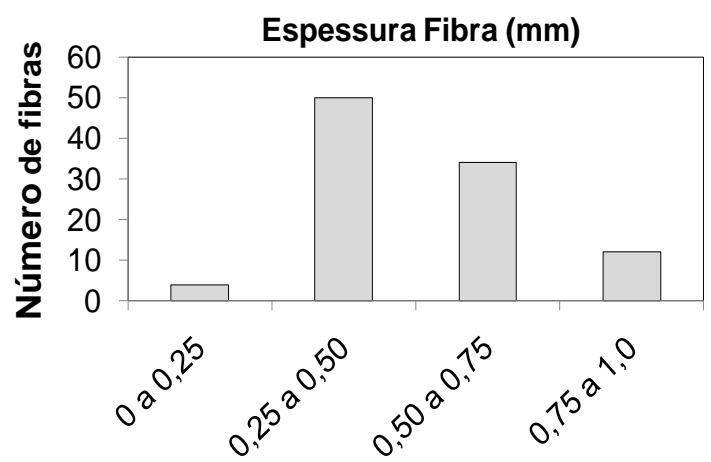

(b)

Figura 26 - Dimensões nominais das fibras de bagaço de cana-de-açúcar: (a) comprimento $(\mathrm{mm})$; (b) espessura $(\mathrm{mm})$.

\subsubsection{Resultado de absorção de água nas FBC}

A Figura 27 mostra a absorção de água obtida das FBC naturais, não tratadas e tratadas, realizada em uma câmara climática com controle de temperatura e umidade. 


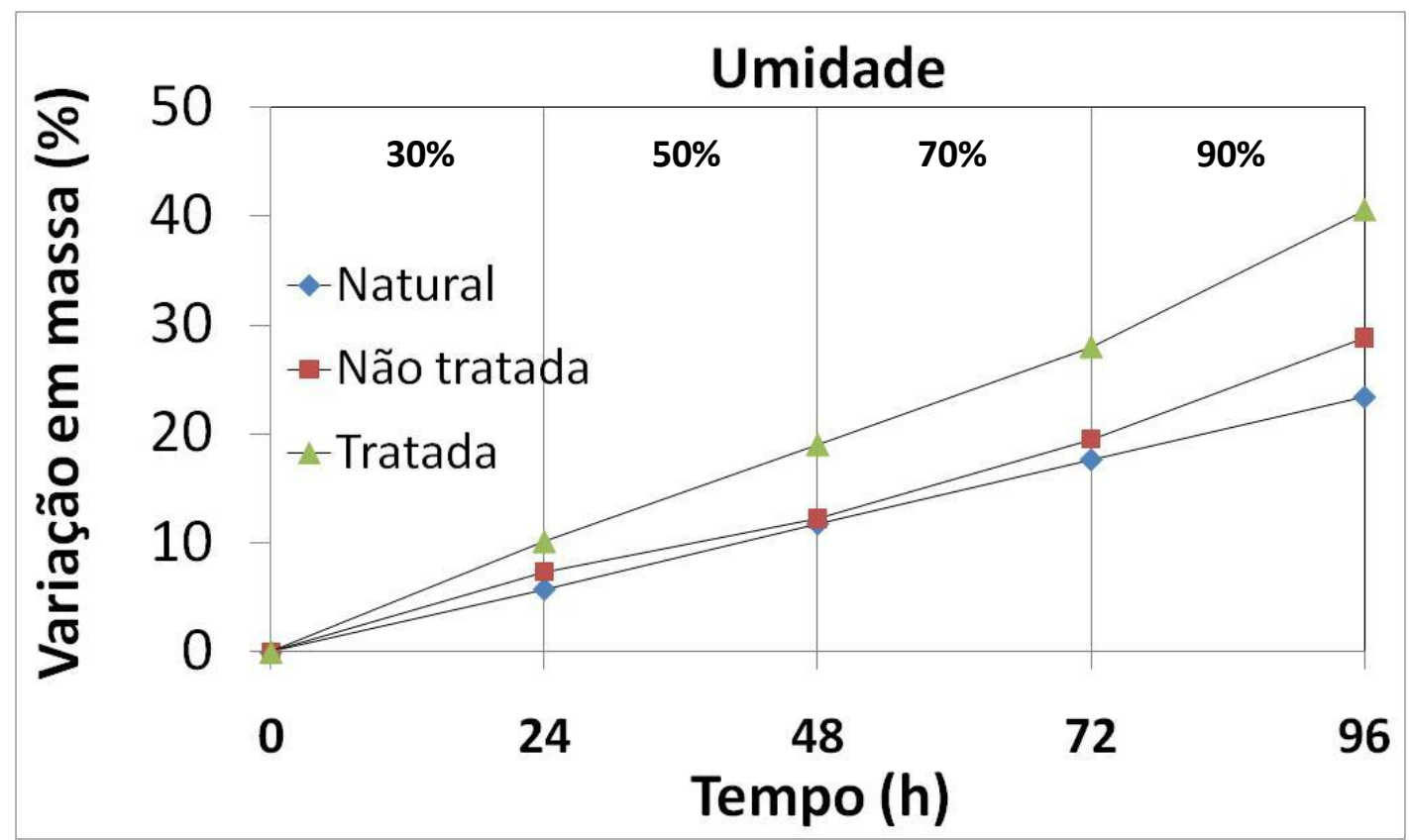

Figura 27 - Determinação de absorção de água por variação em massa (\%) das FBC natural, não-tratada e tratada em relação à porcentagem de umidade.

Através da Figura 27, podemos observar que a FBC tratada foi a que mais absorveu água na variação em massa em função do tempo com mudança de umidade.

Com 96 horas exposto a 90\% de umidade a FBC tratada variou sua massa em torno de $10 \%$ em relação à massa da FBC não tratada. Esse grande aumento de massa pode ser devido ao tratamento químico que degradou a celulose e hemicelulose e mineralizou as FBC. Esse resultado não confere ao encontrado por Sarmiento (84) que determinou a absorção de água pela diferença de peso entre as fibras utilizando cadinhos e estufa para a secagem. A redução chegou em torno de $50 \%$.

Esses resultados ainda serão abordados neste trabalho para ser mais bem discutido.

\section{$\underline{\text { 5.2.4 Resultado da densidade das FBC }}$}

A densidade da FBC está apresentada na Tabela 7. Este resultado analisado foi importante para o desenvolvimento das formulações estudadas. 
Tabela 7 - Resultado da densidade da FBC.

\begin{tabular}{cc}
\hline Amostra & Densidade real $\left(\mathrm{g} / \mathrm{cm}^{3}\right)$ \\
\hline FBC & 1,33 \\
\hline
\end{tabular}

\section{$\underline{5.2 .5 \text { Resultado da bromatológica das FBC }}$}

O resultado da análise bromatológica realizadas nas amostras de FBC natural e não tratada (fervida) está expressa na Tabela 8. Para fazer esta análise foi utilizada $100 \mathrm{~g}$ de cada amostra.

Tabela 8 - Resultado da análise bromatológica em porcentagem em massa utilizando como base a massa seca em $100 \%$ da FBC natural e não tratada (fervida)

\begin{tabular}{lcc}
\hline Análise & Fibra de bagaço natural & $\begin{array}{c}\text { Fibra de bagaço não } \\
\text { tratada (fervida) }\end{array}$ \\
\hline Matéria seca (MS) & 94,32 & 91,32 \\
Matéria mineral (MM) & 5,89 & 2,96 \\
Fibra em detergente ácido (FDA) & 63,88 & 68,58 \\
Lignina ácida (LDA) & 11,37 & 13,11 \\
\hline
\end{tabular}

MS esta relacionada com a parte fibrosa da FBC, onde a fervura diminuiu seu valor devido às impurezas encontradas na superfície da FBC natural. MM está relacionada à perda de nutrientes através da fervura como, por exemplo: cálcio, fósforo etc. FDA e LDA, onde apresentam valores de conteúdo celular e de lignina, onde o processo da análise é feito através da reação com ácido sulfúrico, a FBC não tratada (fervida) apresentou maior valor, pois o calor sofrido da FCB não tratada danificou parte das proteínas e parede celular (111). 


\subsection{Resultado das Caracterizações microestruturais das FBC}

\subsubsection{Resultado da difração de raios-X (DRX) das FBC}

A Figura 28 apresenta o difratograma obtidos da FBC. O índice de cristalinidade foi determinado pela equação 1 (item 4.4.1) e o resultado obtido é apresentado na Tabela 9.

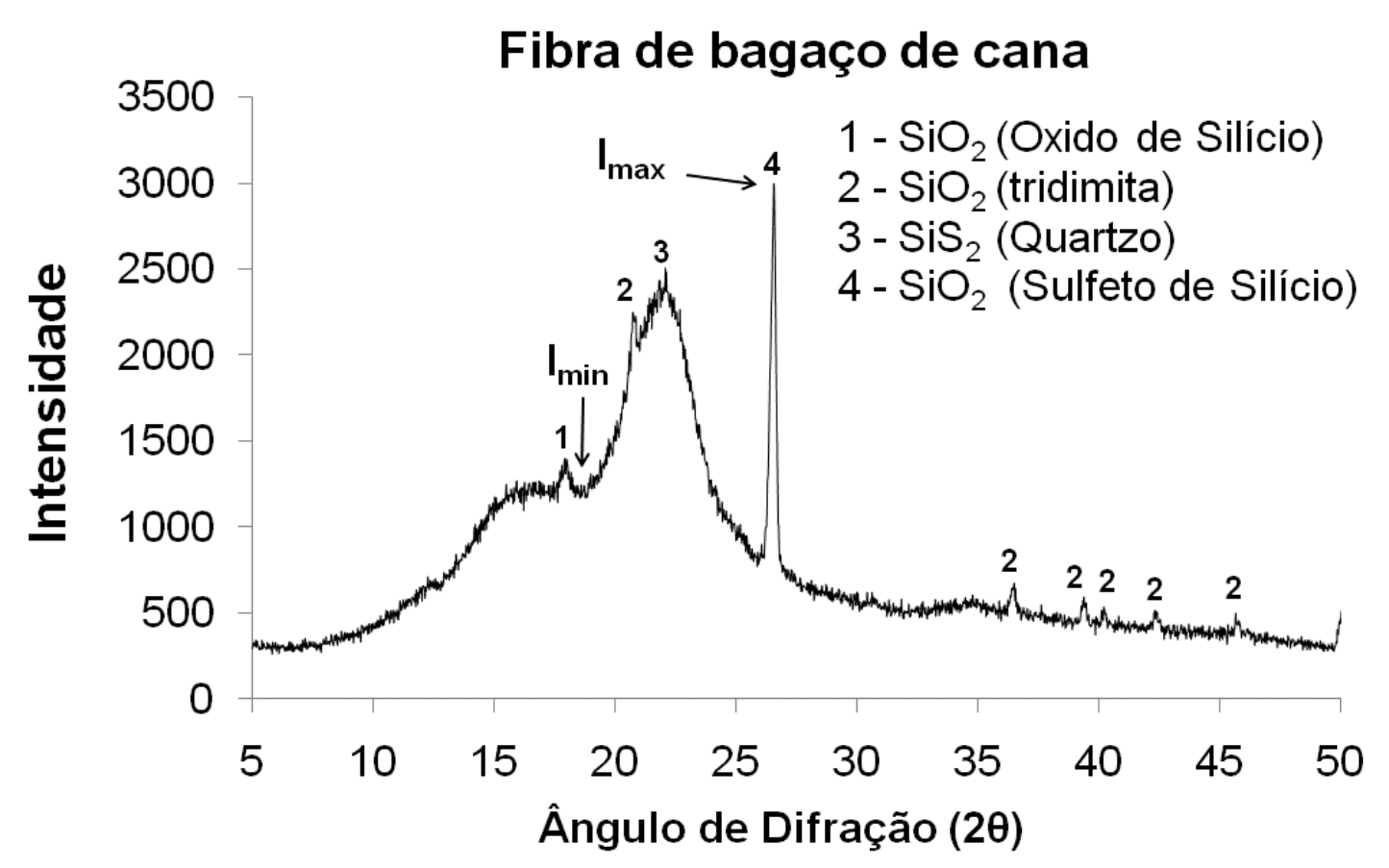

Figura 28 - Difratômetro de raios-X da FBC natural com sua intensidade em relação ao ângulo de difração $(2 \theta)$

Através do espectro podemos observar a região cristalina mínima encontra-se entre os ângulos $\left(18^{\circ}<2 \theta<19^{\circ}\right)$ e a região cristalina máxima entre os ângulos $\left(25^{\circ}<2 \theta<27^{\circ}\right)$. Este dado é importante, pois na região cristalina o acesso dos reagentes é dificultado pela região não cristalina (amorfas).

Tabela 9 - Resultado do índice de cristalinidade da FBC

\begin{tabular}{cc}
\hline Amostra & Índice de cristalinidade (\%) \\
\hline FBC & 40 \\
\hline
\end{tabular}


Este resultado encontrado é similar de alguns autores Guimarães (88), Anselmo (112), Satyanarayana e Wypych (113), índice de 37, 38 e 47\% respectivamente.

\subsubsection{Resultado da espectroscopia na região do Infravermelho (FTIR) das FBC}

A Figura 29 é apresentada o espectro na região do infravermelho da FBC natural, não tratada e tratada. As principais mudanças apresentadas foram destacadas na figura abaixo.

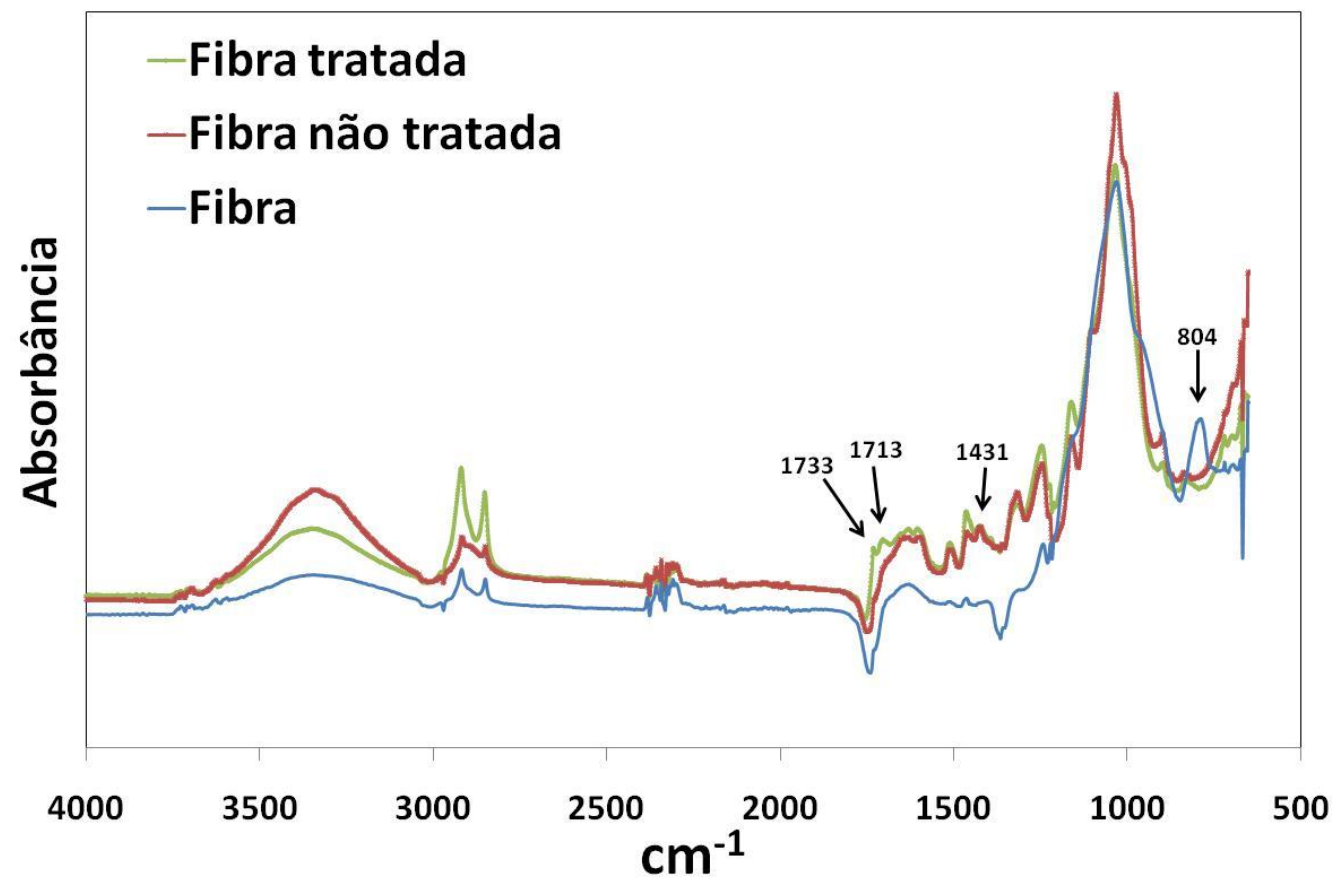

Figura 29 - Espectro na região de infravermelho da FBC natural, não tratada e tratada.

Para fibra tratada ocorreu o surgimento de bandas de 1733 e $1713 \mathrm{~cm}^{-1}$ destacadas na Figura 29. De acordo com Huang (114) que utilizou FTIR em fibras FBC, apresentaram nessas bandas variações de celulose e lignina. Estes resultados indicam vínculos de ligações glicosídicas $\beta$ em polissacarídeos e $\beta$ em ligações de éter do grupo carbonil na fibra tratada e ligações de ácido carboxílico $(\mathrm{COOH})$ entre 1733 e $1708 \mathrm{~cm}^{-1}$, respectivamente (115). Porém Vieira et al. (116) relatou que duas bandas importantes na FBC são $1512 \mathrm{~cm}^{-1}$ e $1250 \mathrm{~cm}^{-1}$ que estão ausentes no espectro, indica que uma parte da lignina não foi removida, ou seja, sugere que a 
FBC não tratada (fervida) e a tratada não removeram a lignina da fibra. Banda com picos de $1431 \mathrm{~cm}^{-1}$ representam estiramento simétricas e assimétricas no trecho de (COO), associado ao ácido carboxílico, sugerindo que tratamento químico reagiu, pois o pico é destacado na FBC não tratada (117).

A presença de grupos carboxilato verifica a ocorrência de copolimerização da FBC e os ácidos acrílicos estão parcialmente neutralizados (114). Já na fibra natural a banda $804 \mathrm{~cm}^{-1}$ apresenta ligações $\beta$ de glicosídicos entre as unidades de açúcar que indica que o processo de fervura (não tratada) da fibra tenha reduzido o açúcar residual em relação a não tratada e tratada. Este resultado corrobora com a análise realizada na determinação de açúcar residual (item 5.2.1) que apresentou uma redução de açúcar em torno de $10 \%$.

\subsubsection{Resultado da microscopia eletrônica de varredura (MEV) das FBC}

$\mathrm{Na}$ Figura 30 apresenta característica morfológica da FBC no sentido transversal. FBC tem formas quase esféricas, alguns deformados pelo amassamento que a moagem industrial proporciona, compactamente arranjadas e com paredes finas.

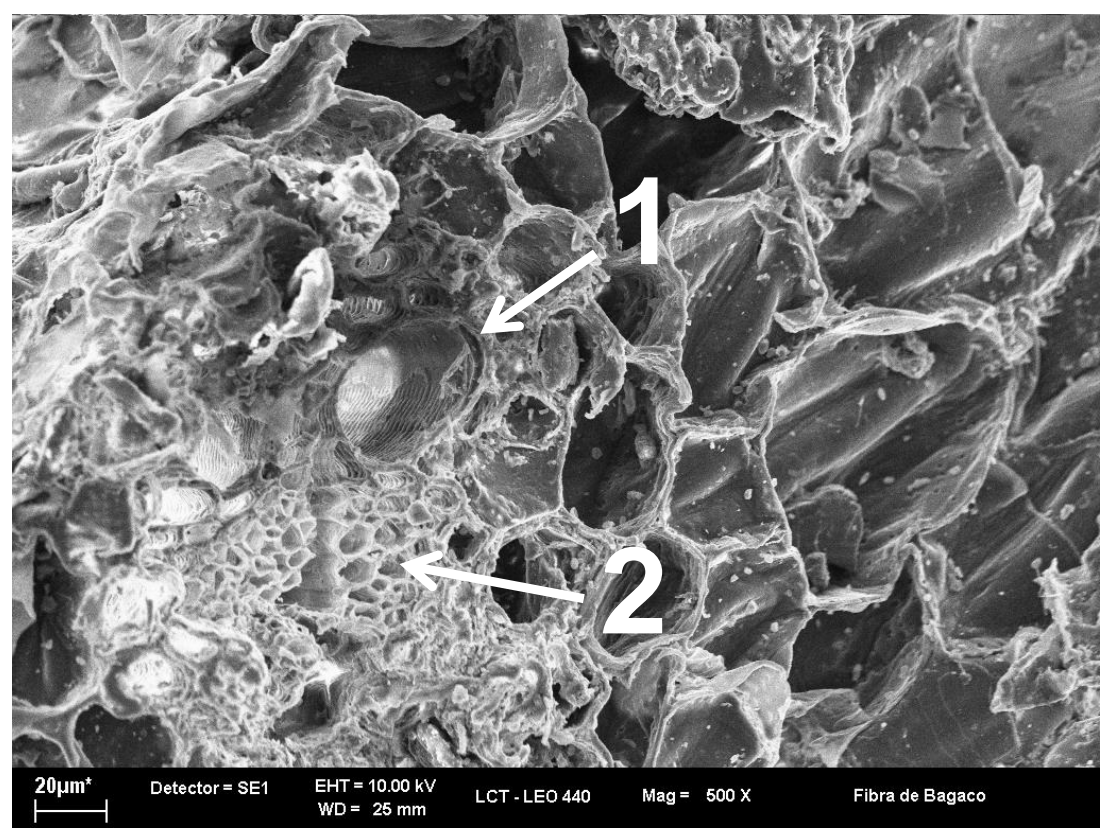

Figura 30 - Características morfológicas da FBC observadas por microscopia eletrônica de varredura (MEV). 
O lúmen central é elíptico (ou quase esférico) e de grande diâmetro (Figura 30 - seta 1). De acordo com Huang et al. (114), as fibras de bagaço de cana mostram enrolamento helicoidal de microfibrilas (Figura 30 - seta 2), que junta em todos os outros por um material de ligação (lignina). O interior destas microfibrilas mostra disposição longitudinal em alguns casos.
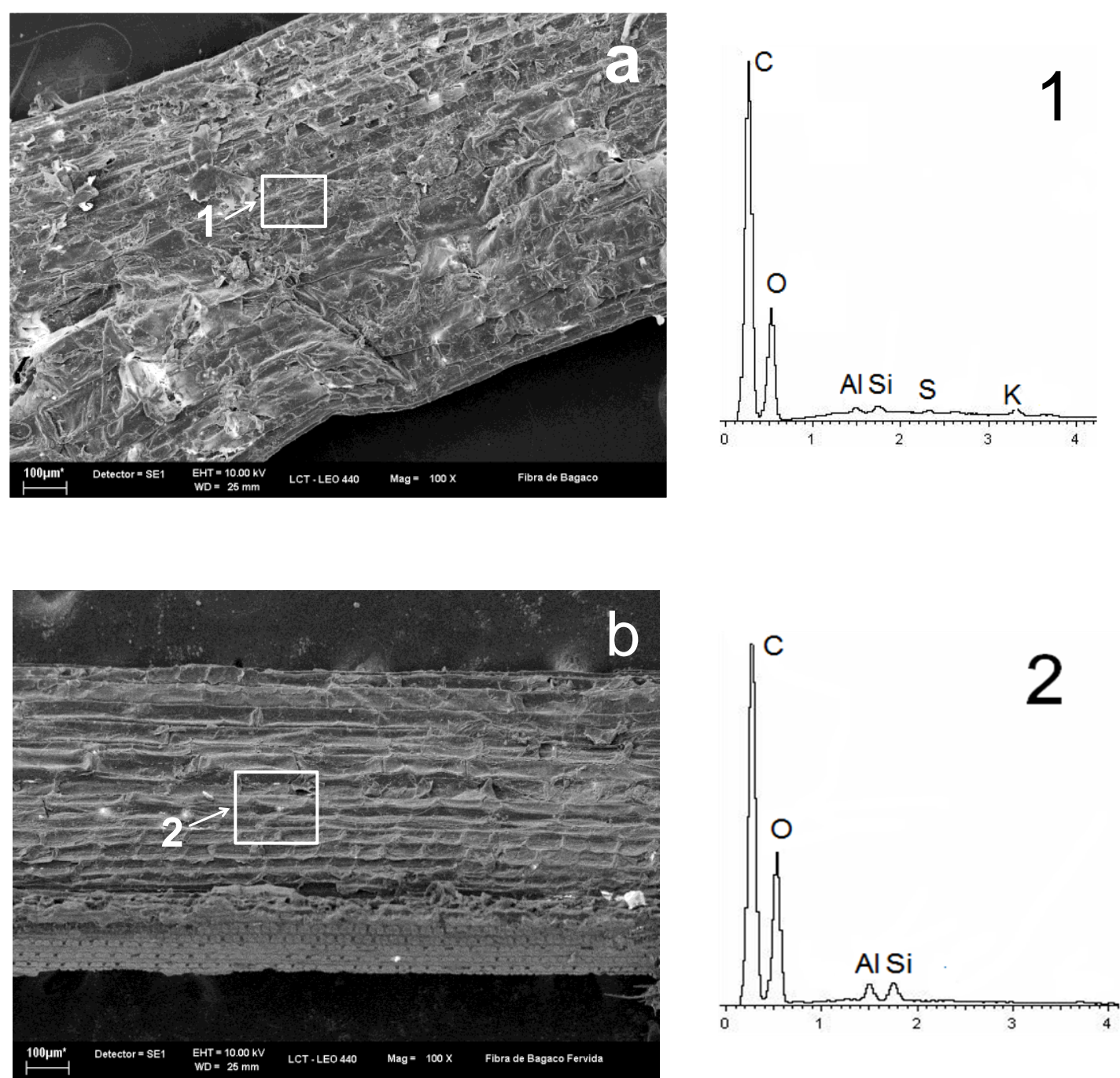
continuação
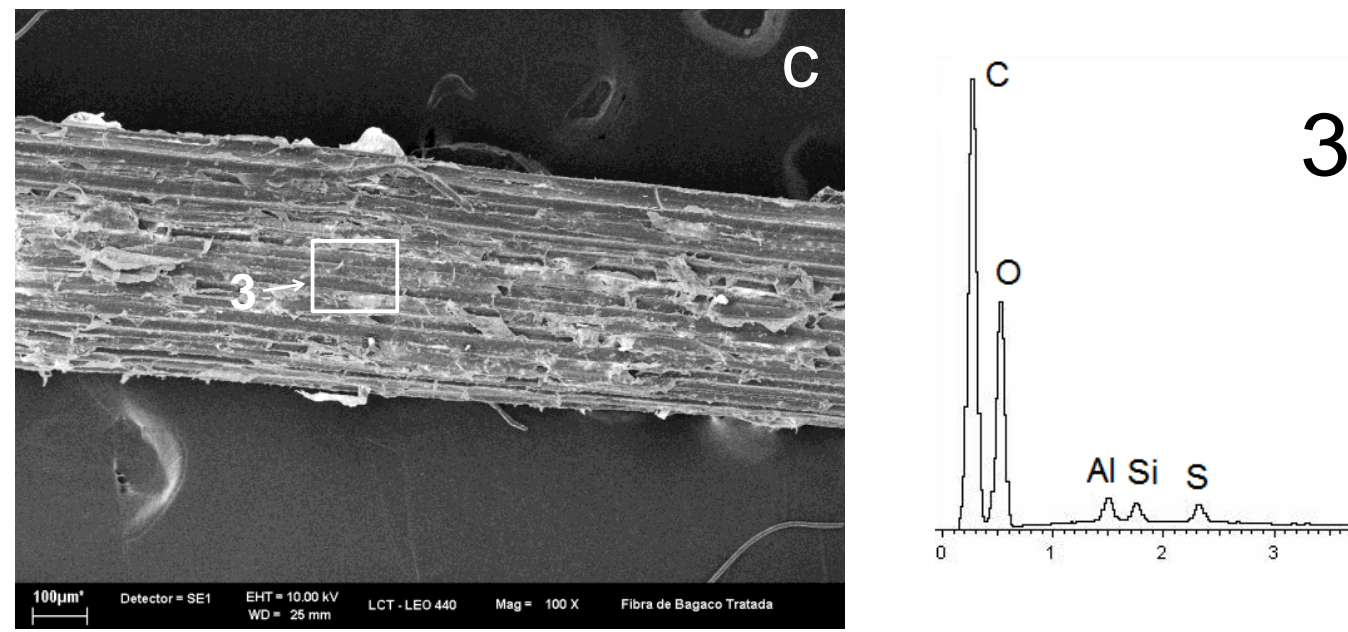

3

Al Si S

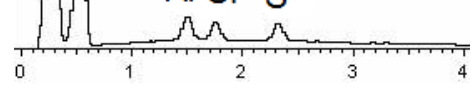

Figura 31 - Micrografia eletrônica de varredura (MEV): (a) fibra natural; (b) fibra não tratada (fervida); (c) fibra tratada com seus respectivos pontos de análise em EDS.

Nas Figuras 31a, 31b, e 31c não são perceptíveis diferenças superficiais. A superfície da fibra não mostra qualquer modificação decorrente da sua fervura (não tratada) (Figura 31b). Quanto ao tratamento químico (Figura 31c), apresenta somente imperfeições. A diferença da intensidade relativa do sinal de carbono em relação ao oxigênio apresentada no EDS é maior para a fibra não natural, em relação à fibra não tratada e tratada, provavelmente devido à lignina (principalmente hidrocarbonetos), que é parcialmente removido pelo tratamento (118). Esse resultado esta de acordo com o infravermelho onde as bandas destacaram a remoção parcial de lignina da FBC. Huang et al. (114) que trabalhou com FBC com tratamento com hidróxido de sódio observou através de micrografia a eliminação de aglutinante da lignina no FBC que forneceu a superfície das fibras uma maior rugosidade. Esta rugosidade na superfície da FBC também foi observada por Bilba et al. (119) que estudou compósitos cimentícios reforçados com FBC com tratamento químico a base de silanos. Como o tratamento químico não apresentou nenhuma diferença superficial da fibra, como rugosidade e não apresentou elementos químicos utilizados pelo tratamento químico realizado na FBC que tenha se destacado através do EDS pode ser um indicativo que o tratamento químico não aderiu fisicamente à fibra. 


\subsubsection{Considerações parciais dos resultados da FBC}

Do estudo feito nas FBC podemos concluir que:

- A lavagem do bagaço de cana-de-açúcar com água quente diminui consideravelmente o teor de açúcar residual;

- O tratamento químico utilizando o sulfato de sódio $30 \%$ e o silicato de alumínio 5\% nas fibras de bagaço de cana-de-açúcar não diminuiu a absorção de água da FBC, pelo contrario, aumentou a absorção de água não apresentando resultado satisfatório;

- Na análise de infravermelho não destacou diferença entre as FBC não tratada e tratada;

- Na análise de MEV, as FBC não tratada e tratada não apresentou diferenças superficiais e entre os elementos químicos utilizados pelo tratamento químico que tenha se destacado através do EDS.

\subsection{Resultado do estudo da caracterização das cinzas de bagaço de cana-de- açúcar (CBC)}

\subsubsection{Resultado da espectroscopia de fluorescência de Raios-X das CBC}

Na Tabela 10 apresenta-se a composição química da CBC. Neste caso, a cinza apresenta baixo teor de carbono, em torno de 4\%. Segundo COOK (120), em materiais à base de cimento com incorporação de cinza, a presença de até cerca de $20 \%$ de carbono na cinza não afeta significativamente os resultados mecânicos. 
Tabela 10 - Composição química (em \% em massa de óxidos) da cinza de bagaço utilizada.

\begin{tabular}{ccccccccccccc}
\hline Óxidos & $\mathrm{Na}_{2} \mathrm{O}$ & $\mathrm{MgO}$ & $\mathrm{Al}_{2} \mathrm{O}_{3}$ & $\mathrm{SiO}_{2}$ & $\begin{array}{c}\mathrm{P}_{2} \mathrm{O}_{5} \\
(\% \text { em massa })\end{array}$ & $\mathrm{SO}_{3}$ & $\mathrm{~K}_{2} \mathrm{O}$ & $\mathrm{CaO}$ & $\mathrm{TiO}_{2}$ & $\mathrm{MnO}$ & $\mathrm{Fe}_{2} \mathrm{O}_{3}$ & $\begin{array}{c}\mathrm{P} . \mathrm{F} . \\
\left(1000^{\circ} \mathrm{C}\right)\end{array}$ \\
\hline $\begin{array}{c}\text { Cinza } \\
\text { de } \\
\text { bagaço }\end{array}$ & 0,05 & 0,80 & 1,29 & 81,3 & 0,55 & 1,57 & 1,71 & 5,73 & 0,17 & 0,26 & 2,29 & 4,02 \\
\hline
\end{tabular}

De acordo com a Tabela 10, observa-se que a composição química da CBC assemelha-se àquelas relatadas por Freitas (48) e Cordeiro (40), com teor de sílica de cerca de $80 \%$. Segundo Amorim et al. (121) este teor de sílica é considerado elevado fato desejável, pois ao longo do tempo tem-se reações que formam silicatos de cálcio hidratados importantes para a resistência mecânica de pastas, argamassas e concretos.

\subsubsection{Resultado da distribuição granulométrica das CBC}

A distribuição do diâmetro do CBC está apresentada na Figura 32. Cerca de $90 \%$ dos grãos da CBC é de $313 \mu \mathrm{m}$. O perfil de distribuição granulométrica da cinza em substituição ao cimento apresenta uma maior quantidade de partículas finas em relação a outros perfis, como o cimento e a sílica cristalina.

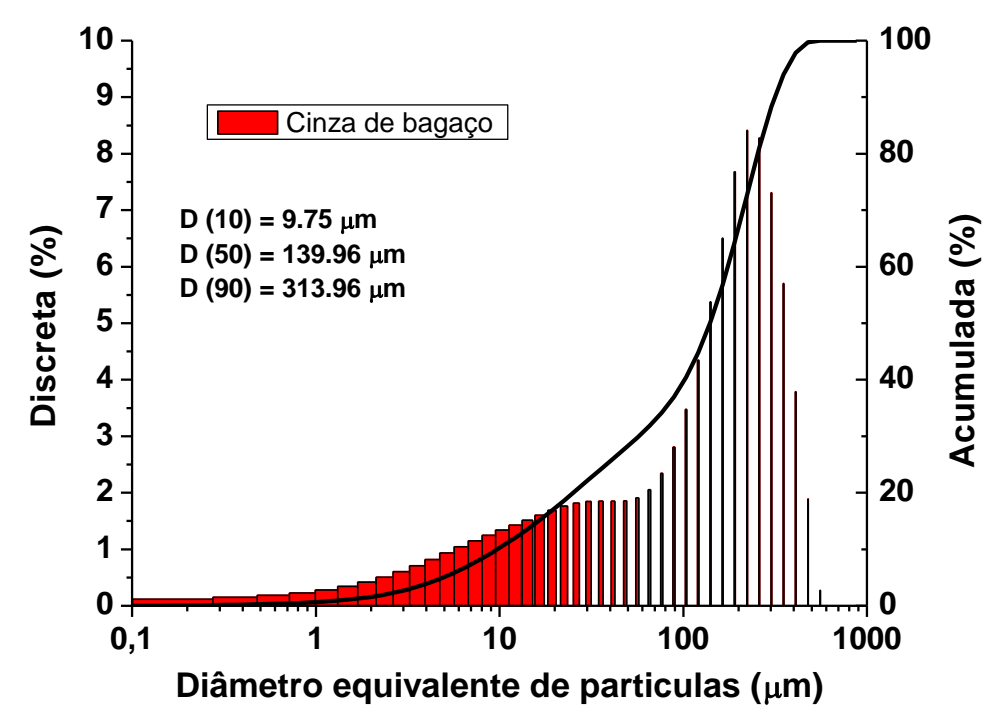

Figura 32 - Distribuição do diâmetro de partículas da cinza de bagaço de cana-de-açúcar. 


\subsubsection{Resultado da área de superfície específica das CBC}

A área de superfície específica expressa, para uma dada quantidade de material, a área total superficial de suas partículas. Quanto maior a área de superfície específica, maior o contato entre as partículas da cinza de bagaço com o cimento. Portanto maior a reatividade.

A Tabela 11 apresenta a área de superfície das cinzas de bagaço de cana.

Tabela 11 - Área de superfície específica das cinzas de bagaço de cana.

\begin{tabular}{cc}
\hline Amostra & Área de superfície específica BET $\left(\mathrm{m}^{2} / \mathrm{g}\right)$ \\
\hline CBC & 5,74 \\
\hline
\end{tabular}

5.4.4 Resultado da determinação da densidade das CBC

A Tabela 12 apresenta o resultado da densidade real das CBC. Quanto maior a densidade, maior será o empacotamente auxiliando o fluxo da mistura extrudada.

Tabela 12 - Resultado da densidade real da CBC

\begin{tabular}{cc}
\hline Amostra & Densidade real da $\mathrm{CBC}\left(\mathrm{g} / \mathrm{cm}^{3}\right)$ \\
\hline $\mathrm{CBC}$ & 2,69 \\
\hline
\end{tabular}

Houve uma pequena diferença encontrada por Dias e Pessanha (122), Freitas (123) com o valor de 2,58 e $2,57 \mathrm{~g} / \mathrm{cm}^{3}$ respectivamente. Essa pequena diferença da densidade pode ser destacada pela alteração da configuração da queima. 


\subsubsection{Resultado da difração de raios-X das CBC}

A Figura 33 mostra os difratogramas de raios- $X$ da $C B C$. A CBC é uma pozolana é constituído basicamente de sílica em estado amorfo. A amorficidade indica a capacidade de reatividade do material em determinados sistemas, no caso das adições CBC, a característica indica a sua capacidade de reagir com o cimento Portland. Analisando a Figura 33, indicam que a estrutura da CBC apresenta as fases cristalinas da sílica, quartzo (1), hematita (2) e anidrita (3). Freitas (123) conclui que a presença da fase cristalina de quartzo torna a CBC menos reativo, e consequentemente com baixa atividade pozolânica.

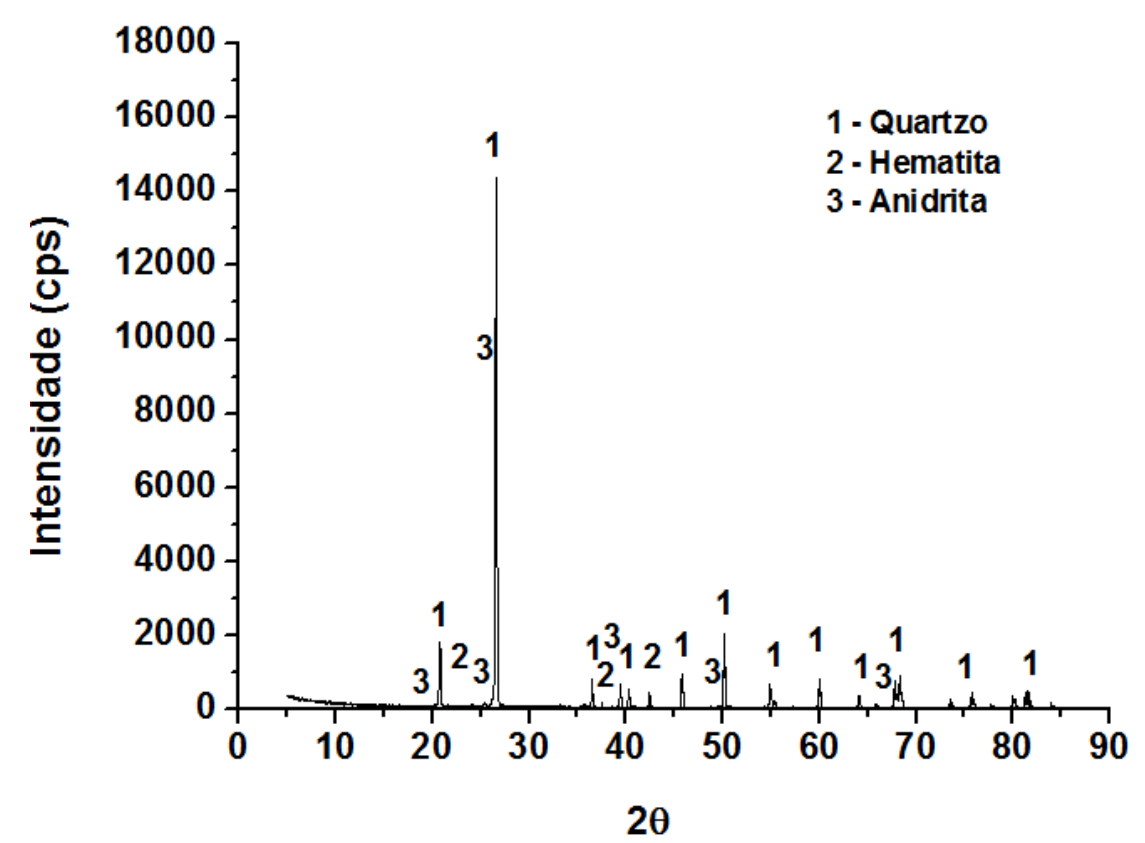

Figura 33 - Difratograma de raios $X$ das cinzas de bagaço.

A presença de quartzo pode ter ocorrido devida aos seguintes fatores: a) ocorrência de contaminação do bagaço por areia, uma vez que este é despejado no pátio da indústria. Neste caso, a presença de quartzo pode ser evitada com a lavagem do bagaço; b) decorrência do processo de queima, os parâmetros podem ser adequados (de forma empírica) de modo a obter uma cinza predominantemente amorfa (124). 


\subsubsection{Resultado da microscopia eletrônica de varredura (MEV) das CBC}

Um fator que pode alterar a condição de empacotamento das partículas é a morfologia. A caracterização microestrutural das cinzas mostra a presença de grandes e pequenas partículas, prevalecendo as menores. Quanto mais afastada do formato esférico for à partícula, menor será a densidade de empacotamento de uma distribuição que a contenha, como é o caso do CBC (Figura 34a) (125). Na Figura 34b mostra o formado alongado com a visualização de epidermes.

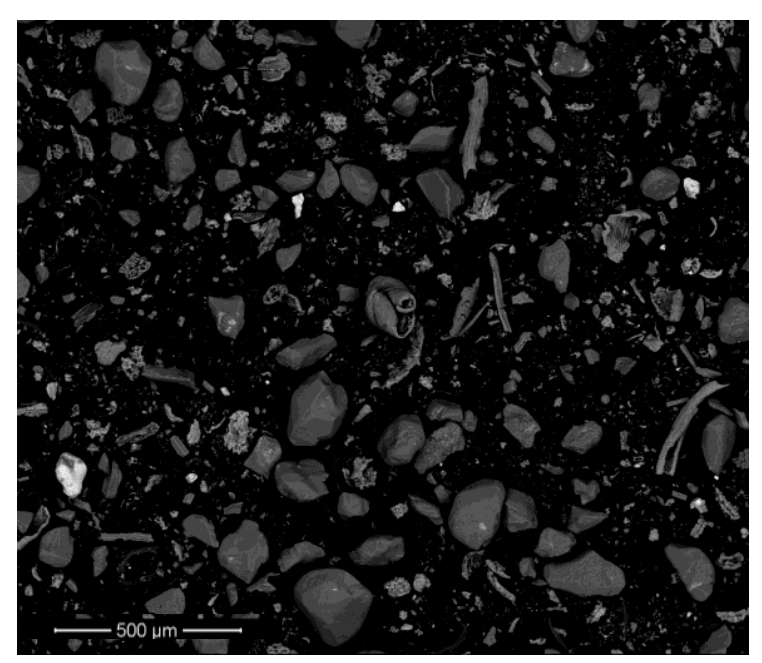

(a)

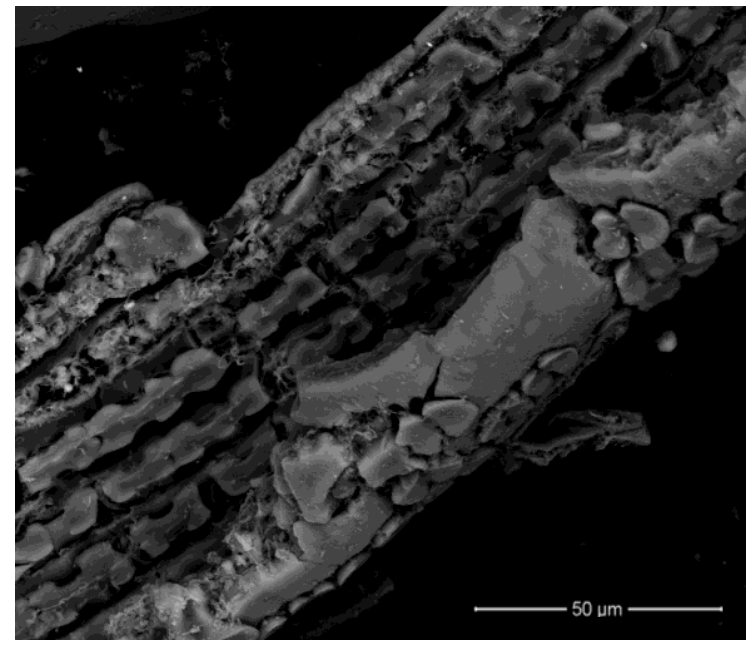

(b)

Figura 34 - Características morfológicas das partículas observadas por microscopias eletrônicas de varredura: (a) e (b) cinza de bagaço.

A porosidade interna das partículas é outro fator complicador na obtenção de empacotamentos de alta densidade relativa. As partículas podem ser densas, com porosidade interna fechada ou com porosidade aberta.

Além desse efeito morfológico, partículas desse tipo também afetam o processamento, pois possuem uma maior capacidade de absorção de fases liquidas através dos poros (Figura 34b). 
5.4.7 Resultado da avaliação das reações pozolânicas das cinzas através de condutividade elétrica

A Figura 35 apresenta os resultados das CBC e da sílica cristalina e destaca o material mais reativo com $\mathrm{Ca}(\mathrm{OH})_{2}$.

A CBC contém mais constituintes ativos do que a sílica cristalina de acordo com os resultados obtidos dos ensaios de condutividade elétrica, realizados a $60^{\circ} \mathrm{C}$ em função do tempo, os quais indicaram uma maior taxa de consumo de $\mathrm{Ca}^{2+}$ no sistema $\mathrm{CBC}$ e hidróxido de cálcio $\mathrm{Ca}(\mathrm{OH})_{2}$. No entanto, observa-se que a sílica cristalina começa a reagir intensamente a partir das $17 \mathrm{~h}$ e alcança o mesmo valor da condutividade do sistema $\mathrm{Ca}(\mathrm{OH})_{2}$ com cinza de bagaço que reage significativamente com o $\mathrm{Ca}(\mathrm{OH})_{2}$. Esta atividade $\mathrm{CBC}$ com $\mathrm{Ca}(\mathrm{OH})_{2}$ pode estar relacionada com a morfologia e o tamanho das partículas.

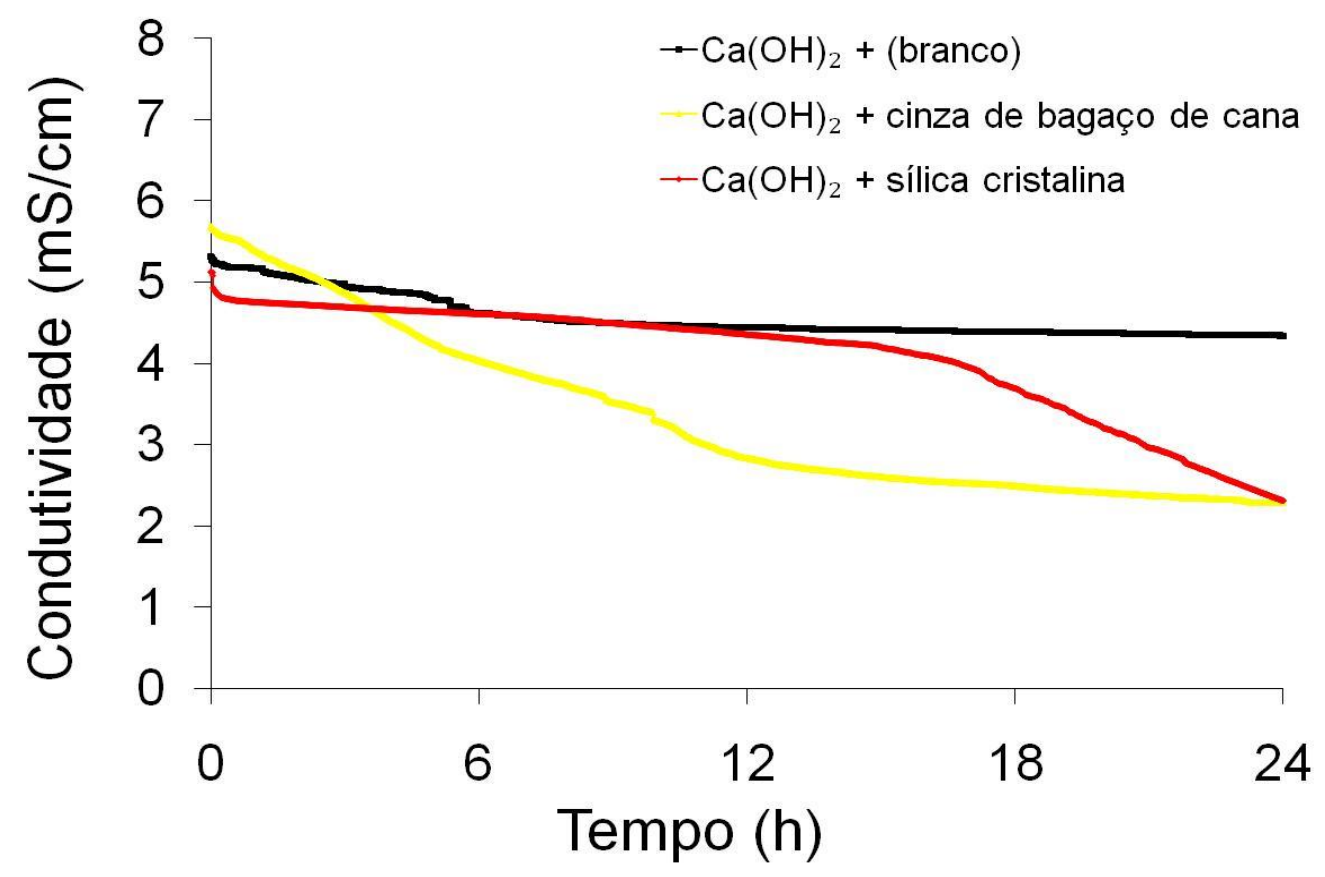

Figura 35 - Condutividade elétrica de CBC e sílica cristalina do sistema de hidróxido de cálcio, em temperatura constante de $60^{\circ} \mathrm{C}$.

Este comportamento concorda com os resultados apresentados pela difração de raios-X e distribuição granulométrica, pois mostraram que as CBC são amorfas e bem reativas. Estas características físicas podem favorecer a reatividade 
pozolânica, o que reforça os resultados obtidos no ensaio de distribuição granulométrica. (126)

\subsubsection{Considerações parciais dos resultados das CBC}

Do estudo feito nas CBC podemos concluir que:

- Espectroscopia de raios-X determinou que mais de $80 \%$ das $\mathrm{CBC}$ é $\mathrm{SIO}_{2}$;

- O método da condutividade elétrica se mostrou uma técnica rápida e útil para comparar o grau de reatividade entre a CBC e a sílica cristalina em sistema com hidróxido de cálcio;

- A CBC apresentou mais componentes ativos que reagem com o cimento Portland determinado pela condutividade elétrica.

\subsection{Resultados da caracterização microestruturais dos compósitos cimentícios extrudados}

$\underline{\text { 5.5.1 Resultados físicos e mecânicos dos compósitos cimentícios extrudados }}$

Os valores médios de todos os resultados e desvio-padrão de todas as propriedades mecânicas e físicas com 28 dias e 200 ciclos de envelhecimento dos compósitos cimentícios reforçados com fibra e cinza de bagaço de cana-de-açúcar estados apresentados no apêndice A e B.

A Figura 36 compara o efeito dos diferentes níveis de reforço de FBC tratado e não tratado nos resultados físicos e mecânicos em compósitos cimentícios extrudados com 28 dias. 
28 Dias

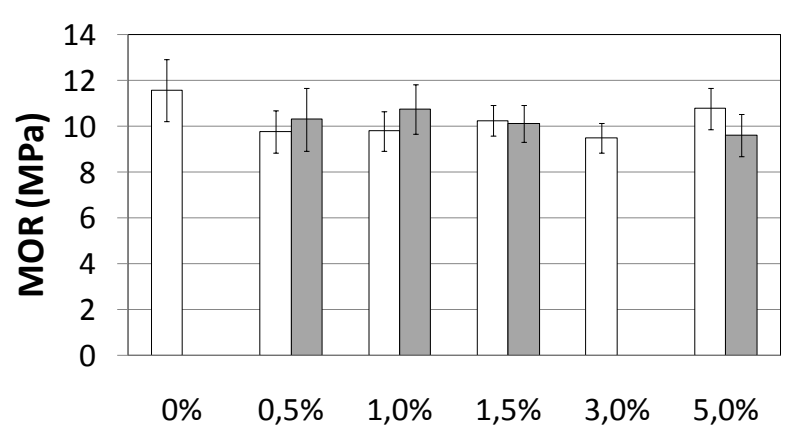

(a)

28 dias

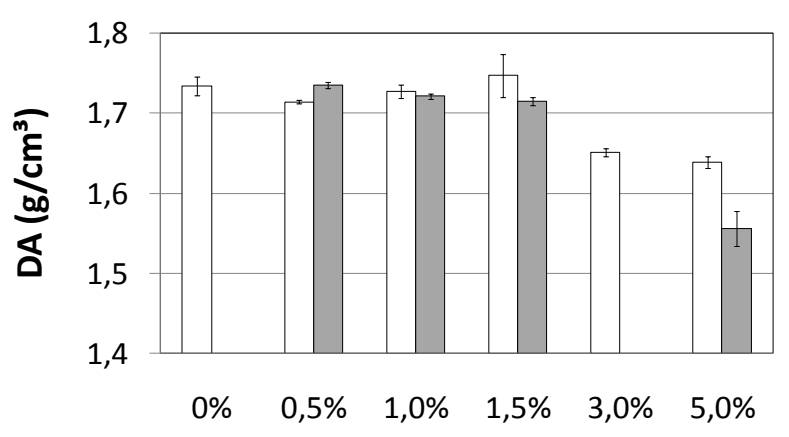

(c)
28 Dias

$\square$ Não Tratada $\square$ Tratada

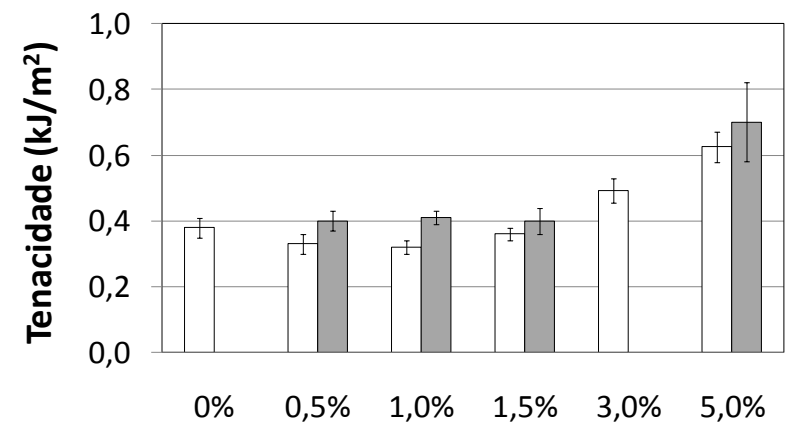

(b)

28 dias

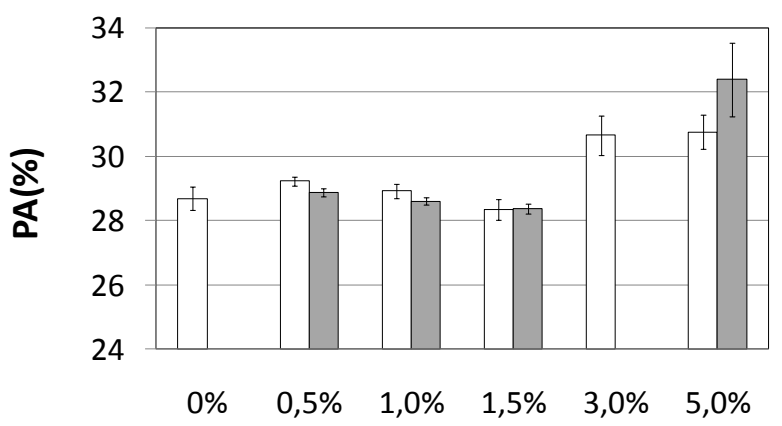

(d)

Figura 36 - Efeito dos níveis de reforço nos resultados físicos e mecânicos de fibras de bagaço de cana-de-açúcar tratadas e não tratadas: (a) módulo de ruptura (MOR); (b) tenacidade (TE); (c) densidade aparente (DA) e (d) porosidade aparente (PA) em compósitos cimentícios extrudados com 28 dias de idade.

O módulo de ruptura (MOR) não apresentou diferença significativa entre os diferentes níveis de reforço e tratamento químico indicado na Figura 36a, mas esse resultado de 10,77 MPa com 5\% de FBC foi superior de 9,60 MPa, encontrado por Aggarwal (42). Com 5\% de reforço de FBC, o compósito extrudado apresentou maior tenacidade (TE), observado na Figura 36b, em relação aos outros compósitos com menos níveis de reforço, mas não apresentou diferença entre o tratamento químico. Tenacidade (TE) esta relacionada à energia absorvida ao impacto. $\mathrm{O}$ resultado variou entre 0,3 para o compósito não tratado com $1 \%$ de reforço e 0,7 $\left(\mathrm{kJ} / \mathrm{m}^{2}\right)$ para compósito tratado com $5 \%$ de reforço, este resultado esta relacionado à incorporação do maior teor de FBC no compósito, provocando maior energia de fratura. Através desse resultado de tenacidade (TE) apresentado com compósitos com reforço de $5 \%$ com FBC tratada com 28 dias foi escolhida a formulação que foi adicionada $30 \%$ de cinza. 
Os resultados físicos apresentados na Figura 36c e 36d de densidade aparente (DA) e porosidade aparente (PA) respectivamente, onde a incorporação de $5 \%$ de FBC diminui sua densidade e proporcionou ao compósito maior porosidade.

Essa diminuição da densidade está diretamente relacionada com 0 tratamento químico (84), e pela substituição da fração da sílica cristalina (densidade em torno de 2,6 $\mathrm{g} / \mathrm{cm}^{3}$ ) por FBC (densidade em torno de $1,3 \mathrm{~g} / \mathrm{cm}^{3}$ ).

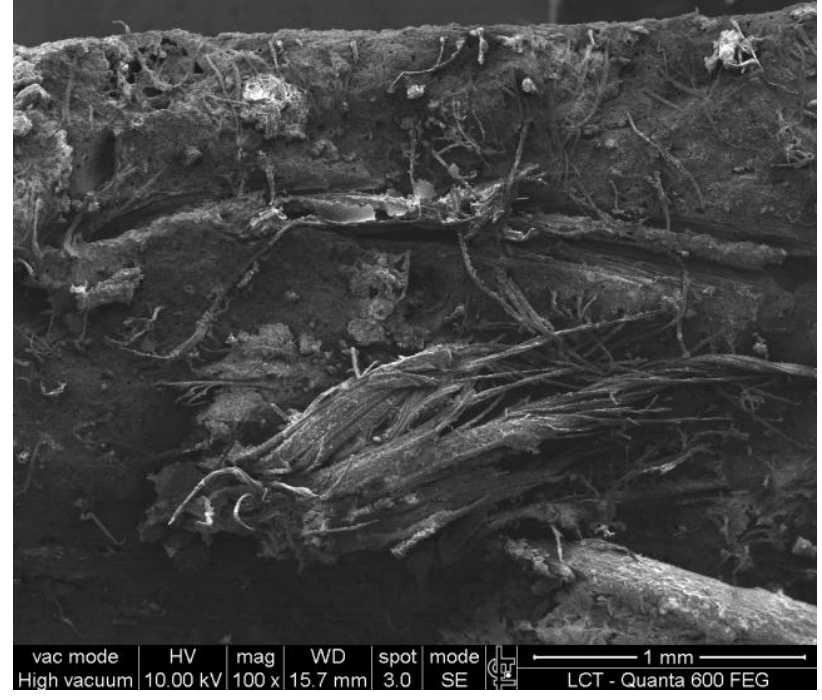

(a)

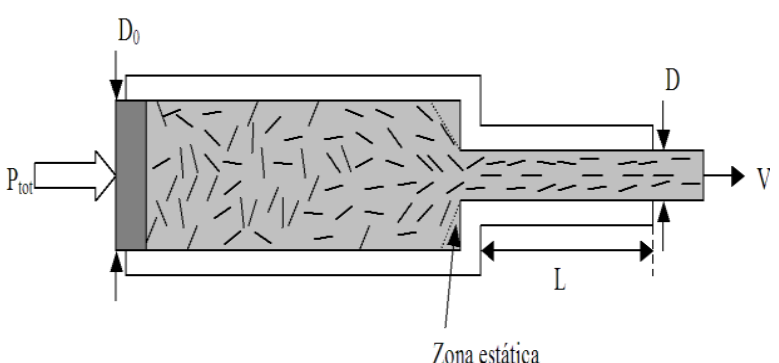

(b)

Figura 37 - (a) Micrografia de superfície de fratura de elétrons secundários de compósito cimentício extrudado com $5 \%$ de fibra de bagaço de cana-de-açúcar tratada com 28 dias; (b) alinhamento das fibras na direção do fluxo do compósito (127).

O aumento de porosidade esta relacionada à incorporação de grandes teores FBC que provoca defeitos na sua microestrutura e prejudica o empacotamento.

Esse defeito é provavelmente uma conseqüência associada à dificuldade de dispersão das matérias-primas e pelo processo do empacotamento pela adição FBC proporcionado pela extrusora. Essa dispersão deficiente pode ser a responsável pelo baixo desempenho que pode ser observada na Figura 37a, onde apresentou um aglomerado de FBC na mesma região, perto da superfície, e revela que as fibras estão em vários sentidos (não alinhadas) no interior do compósito cimentício, o que não acontece na Figura 37b, onde o processo de extrusão flui de forma que as fibras apresentam um alinhamento (127).

A Figura 38 apresenta o efeito dos diferentes níveis de reforço de FBC tratado e não tratado nos resultados físicos e mecânicos em compósitos cimentícios extrudados com 200 ciclos de envelhecimento. 


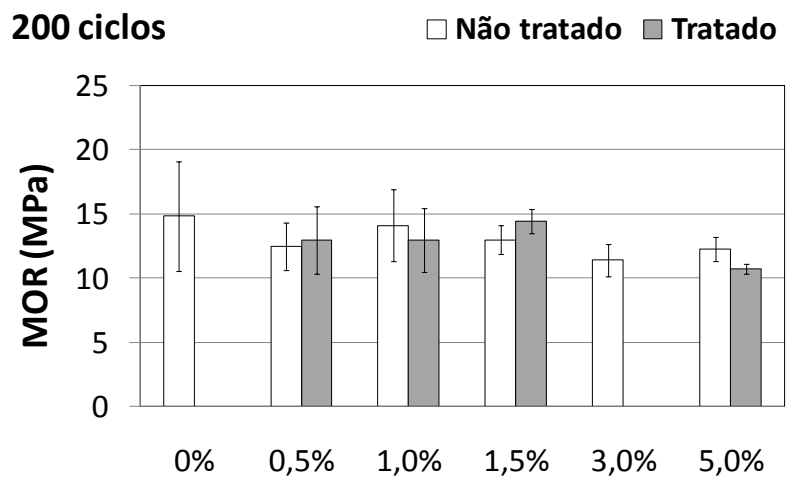

(a)

200 ciclos

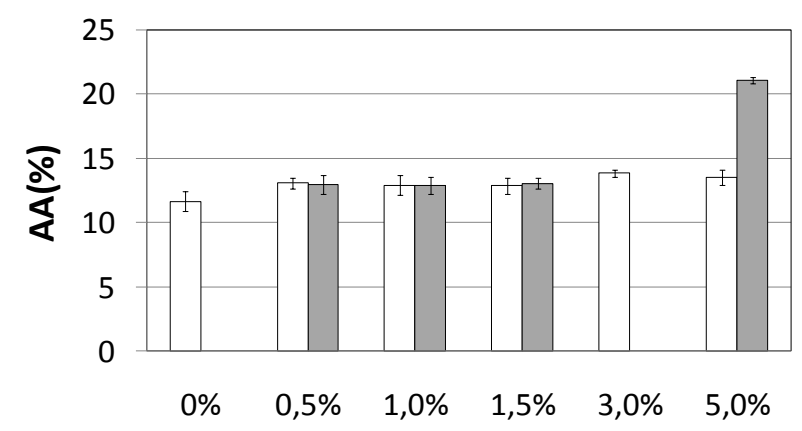

(c)

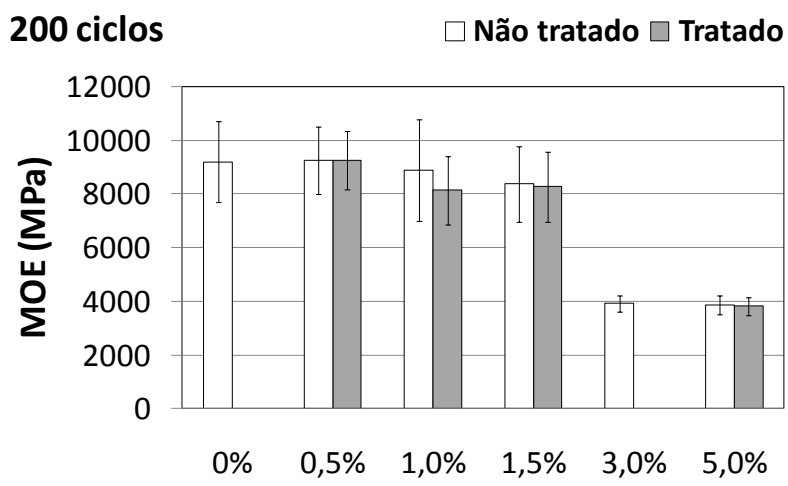

(b)

200 ciclos

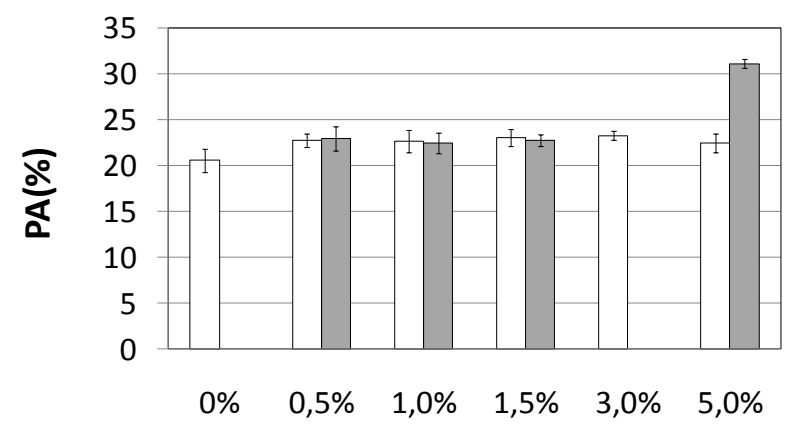

(d)

Figura 38 - Efeito dos níveis de reforço os resultados físicos e mecânicos de fibras de bagaço de cana-de-açúcar tratadas e não tratadas: (a) módulo de ruptura (MOR); (b) módulo elástico (MOE); (c) absorção de água (AA) e (d) porosidade aparente (PA) em compósitos cimentícios extrudados com 200 ciclos de envelhecimento.

No resultado de MOR (Figura 38a) com 200 ciclos de envelhecimento também não apresentou diferença significativa entre os níveis de teores de FBC e entre o tratamento.

Módulo de elasticidade (MOE) mede a rigidez do material, que apresentou resultados inferiores com 3 e 5\% de reforço de FBC analisado na Figura 38b. $O$ envelhecimento diminuiu significamente o valor do módulo de elasticidade (MOE) e aumentou significativamente AA e PA (Figura 38c e 38d) nas FBC tratadas. Esse comportamento pode ser atribuído ao descolamento da fibra (Figura 39 - seta 1).

Este comportamento também pode ser atribuído ao tratamento químico realizado na FBC que pode ter mineralizado as fibras de forma drásticas, degradando-as e perdendo sua eficiência (Figura 39a - seta 2). A variação dimensional da FBC em função do seu teor de umidade e estado de tensão provocou a descolagem na zona de transição fibra/matriz gerando maior absorção e porosidade aparente que pode ter contribuído para o baixo resultado de $\mathrm{MOE}$. 
Essa descolagem corrobora com resultados encontrados por Savastano Jr. (102) e Tonoli (92) que estudaram compósitos cimentícios com fibras vegetais e celulósicas respectivamente com ciclos de envelhecimento.

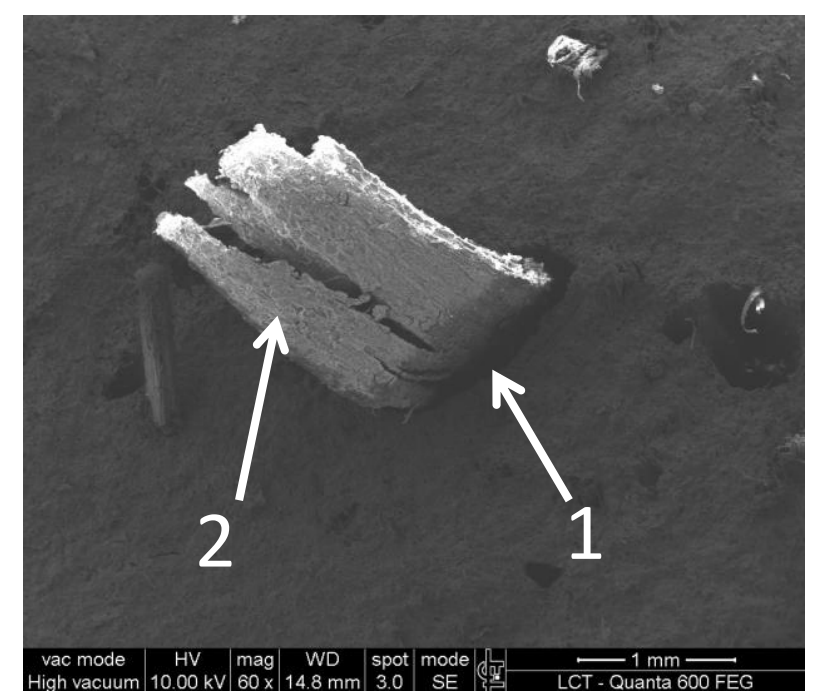

Figura 39 - Micrografias de superfície de fratura de compósitos cimentícios extrudados com $5 \%$ de fibra de bagaço de cana tratada com 200 ciclos de envelhecimento.

A Figura 40 compara o efeito dos diferentes níveis de reforço de $\mathrm{FBC}$ com 28 dias de cura vs 200 ciclos de envelhecimento nos resultados físicos e mecânicos em compósitos cimentícios extrudados. O envelhecimento mostrou causar aumento significativo de MOE para os compósitos com níveis de reforço entre $0,5 \%$ a $1,5 \%$ em relação aos 28 dias observado na Figura 40a, que pode estar relacionado com a densificação do compósito e com a melhora na aderência da fibra o que não apresentou com reforço de 3 e $5 \%$ de FBC onde a aderência foi prejudicada pela variação dimensional e mineralização da FBC. Tenacidade (Figura 40b) houve um melhor resultado aos 28 dias a partir de $3 \%$ de reforço com FBC, esse comportamento pode ser atribuído à fragilização das fibras pelos ciclos de envelhecimento devido à sua mineralização. Sarmiento (84) que utilizou FBC em argamassas conclui que o tratamento químico promoveu aumento nos resultados mecânicos e redução nos resultados físicos, mas nesse trabalho, o uso do tratamento químico em compósitos cimentícios extrudados não apresentou 0 mesmo resultado. A re-hidratação dos produtos do cimento ao redor das FBC ocorrida através dos ciclos de envelhecimento explica a maior densidade (Figura 40c) e a menor porosidade (Figura 40d). 
$\square 28$ dias $\square 200$ ciclos

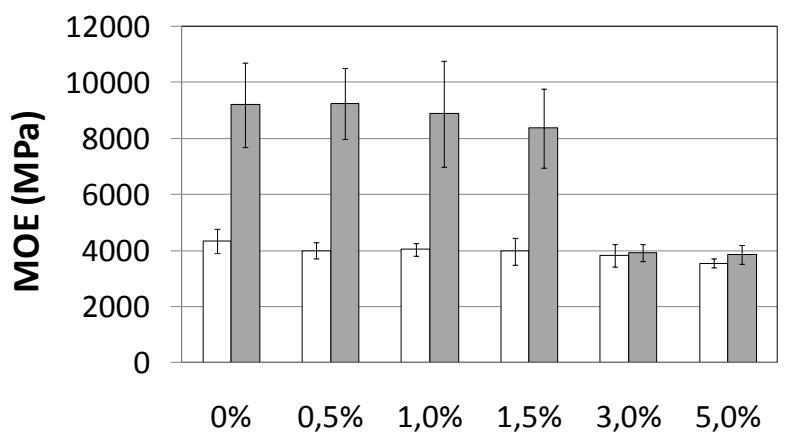

(a)

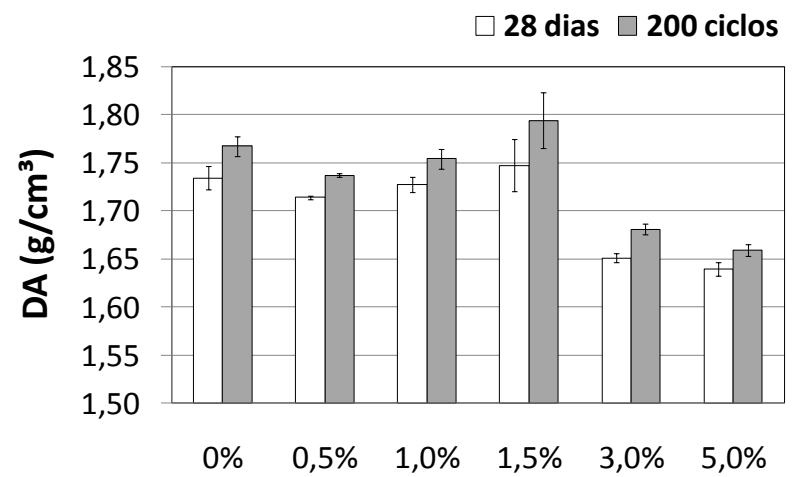

(c)

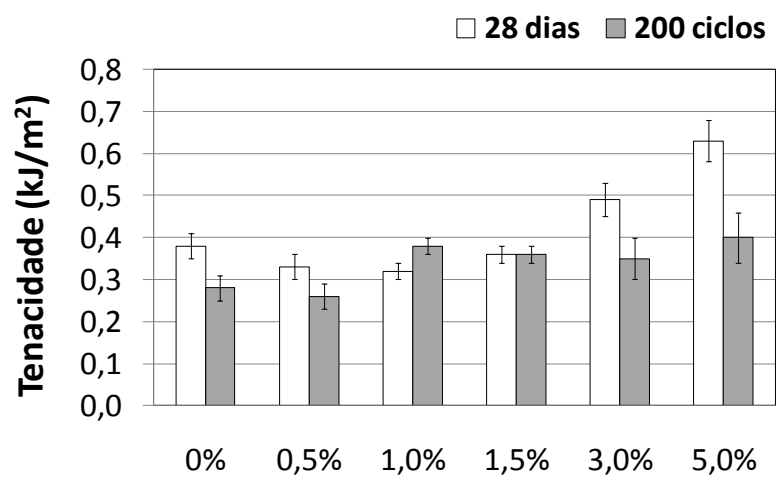

(b)

$\square 28$ dias $\square 200$ ciclos

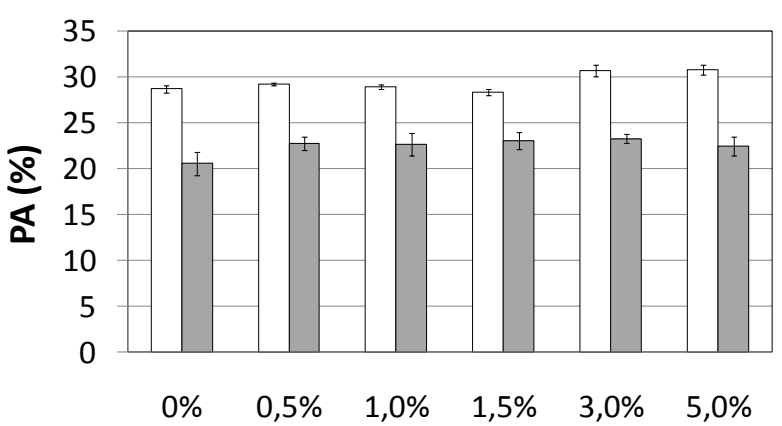

(d)

Figura 40 - Efeito dos níveis de reforço nos resultados físicos e mecânicos de fibras de bagaço de cana-de-açúcar não tratadas: (a) módulo elástico (MOE); (b) tenacidade; (c) densidade aparente (DA) e (d) porosidade aparente (PA) em compósitos cimentícios extrudados de 28 dias VS. 200 ciclos de envelhecimento.

As curvas tensão deformação dos compósitos contento FBC tratada e ano trada com diferentes níveis de reforço e condição são apresentados na Figura 41.

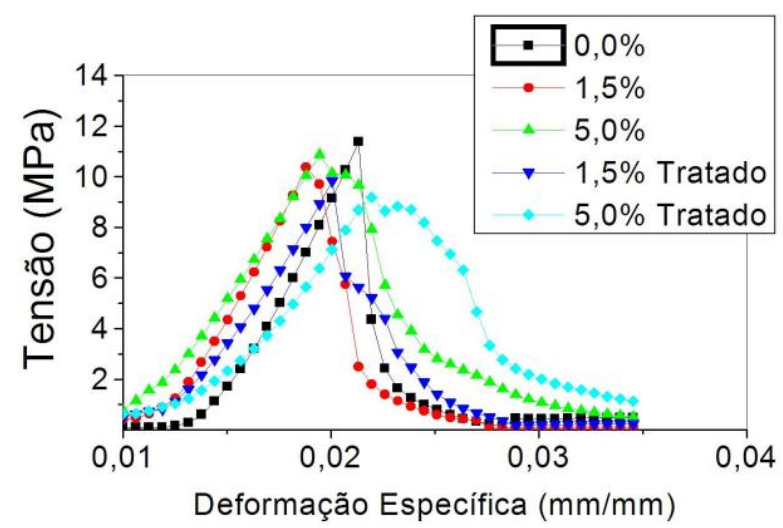

(a)

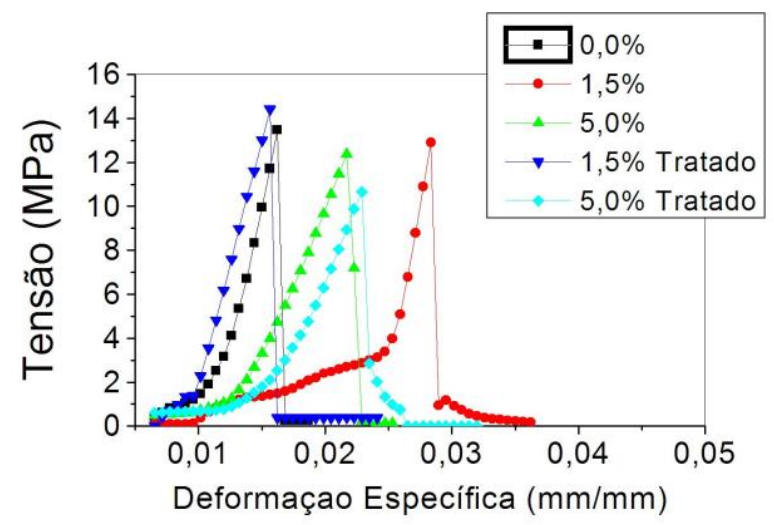

(b)

Figura 41 - Curvas tensão-deformação para compósitos cimentícios extrudados com fibras de bagaço de cana-de-açúcar não tratada e tratada com diferentes níveis de reforço: (a) 28 dias; (b) 200 ciclos de envelhecimento. 
O limite de proporcionalidade (LOP) representa a região elástica da curva tensão-deformação e também está relacionado com a resistência máxima do compósito antes da curva perder a linearidade.

28 dias de idade e 200 ciclos de envelhecimento os compósitos tratados e não tratados apresentaram comportamentos semelhantes (Figura 41a e 41b). 0 envelhecimento mostrou causar aumento do LOP, que pode estar relacionado com a re-precipitação dos produtos de hidratação do cimento na interface fibra e matriz, mas causa danos pelos produtos dentro da fibra (Figura 42) que por sua vez diminui sua flexibilidade e acelera sua mineralização. Entre os tratamentos não houve diferença significativa. As curvas apresentadas mostraram um comportamento frágil do compósito, destacando os resultados já discutidos onde o compósito cimentício não apresentou uma grande tenacidade.

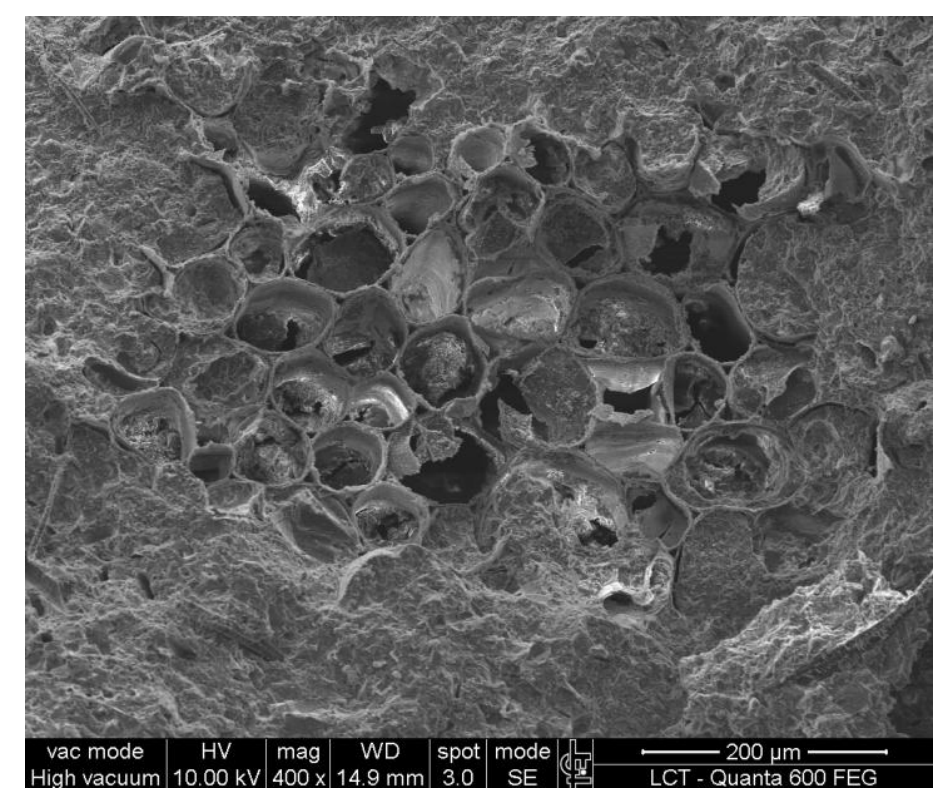

Figura 42 - Micrografias de superfície de fratura de compósitos cimentícios extrudados com $5 \%$ de fibra de bagaço de cana tratada com 200 ciclos de envelhecimento.

O compósito depende da formação de fibra-matriz, matriz-matriz e fibra-fibra, ou seja, sua capacidade de ligação. A ligação pode ser afetada por dimensões, condições da superfície e do número de fibras presentes em um determinado volume de material (42).

Na Figura 43 apresenta os resultados físicos e mecânicos dos compósitos extrudados com FBC e CBC com diferentes níveis de reforço e condições. 

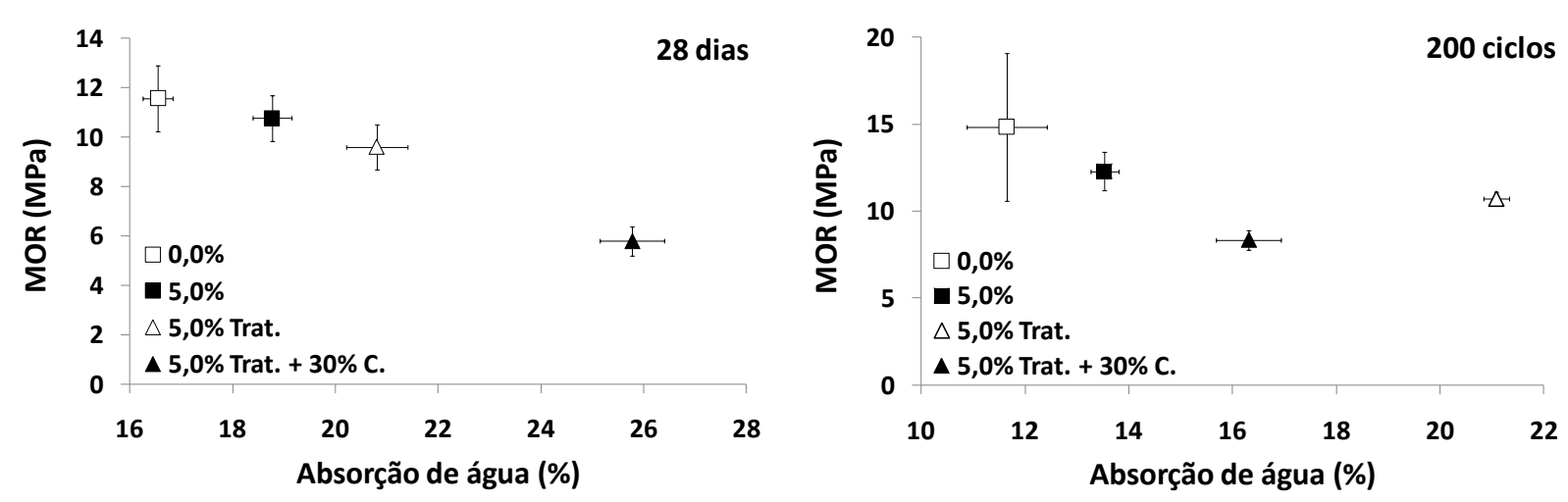

Figura 43 - Efeito dos níveis de reforço nos resultados físicos e mecânicos de fibras de bagaço de cana-de-açúcar não tratadas e tratadas com substituição de cimento por $30 \%$ de cinza de bagaço de cana-de-açúcar com 28 dias e 200 ciclos de envelhecimento: (a, b) módulo de ruptura (MOR) VS absorção de água (AA).

$\mathrm{Na}$ Figura 43a apresenta um resultado menor de MOR em compósito extrudados com $5 \%$ de FBC tratada com substituição de 30 de cimento por $\mathrm{CBC}$ com 28 dias. O compósito extrudados com 30\% de CBC valor de MOR $6 \mathrm{MPa}$ enquanto o compósito com $5 \%$ de FBC tratada apresentou um valor de MOR 9,56 MPa. Esse decréscimo no valor de MOR corrobora com Paula (98) e Freitas (123) que substituiu $20 \%$ do cimento Portland por CBC, sem prejuízo da resistência à compressão, mas com a substituição de $30 \%$ de CBC provoca um decréscimo significativo na resistência à compressão.

Houve também uma maior absorção de água nos compósitos extrudados com cinza. De acordo com Barbosa (128) este fato relacionado com o teor/água e cimento e com sua área específica.

$\mathrm{Na}$ condição com 200 ciclos de envelhecimento (Figura 43b) houve um pequeno aumento do valor de MOR devido a hidratação e um menor valor de absorção de água. Em comparação com 5\% de FBC tratada, De acordo com Paula (98) argamassas com maiores teores de cinza tendem a ser mais poroso, o que justifica os maiores valores de absorção encontrados. Em relação à massa específica, a substituição parcial do cimento Portland por até $30 \%$ de cinzas na mistura não provocou qualquer modificação significativa. 
5.5.2 Resultado da microscopia eletrônica de varredura (MEV) em compósitos cimentícios extrudados

A Figura 44 mostra as micrografias dos compósitos reforçados com fibras não tratada, tratada e com substituição parcial de $30 \%$ de cimento por CBC. As áreas escuras na imagem (devido ao baixo número atômico) são as secções longitudinais das fibras.
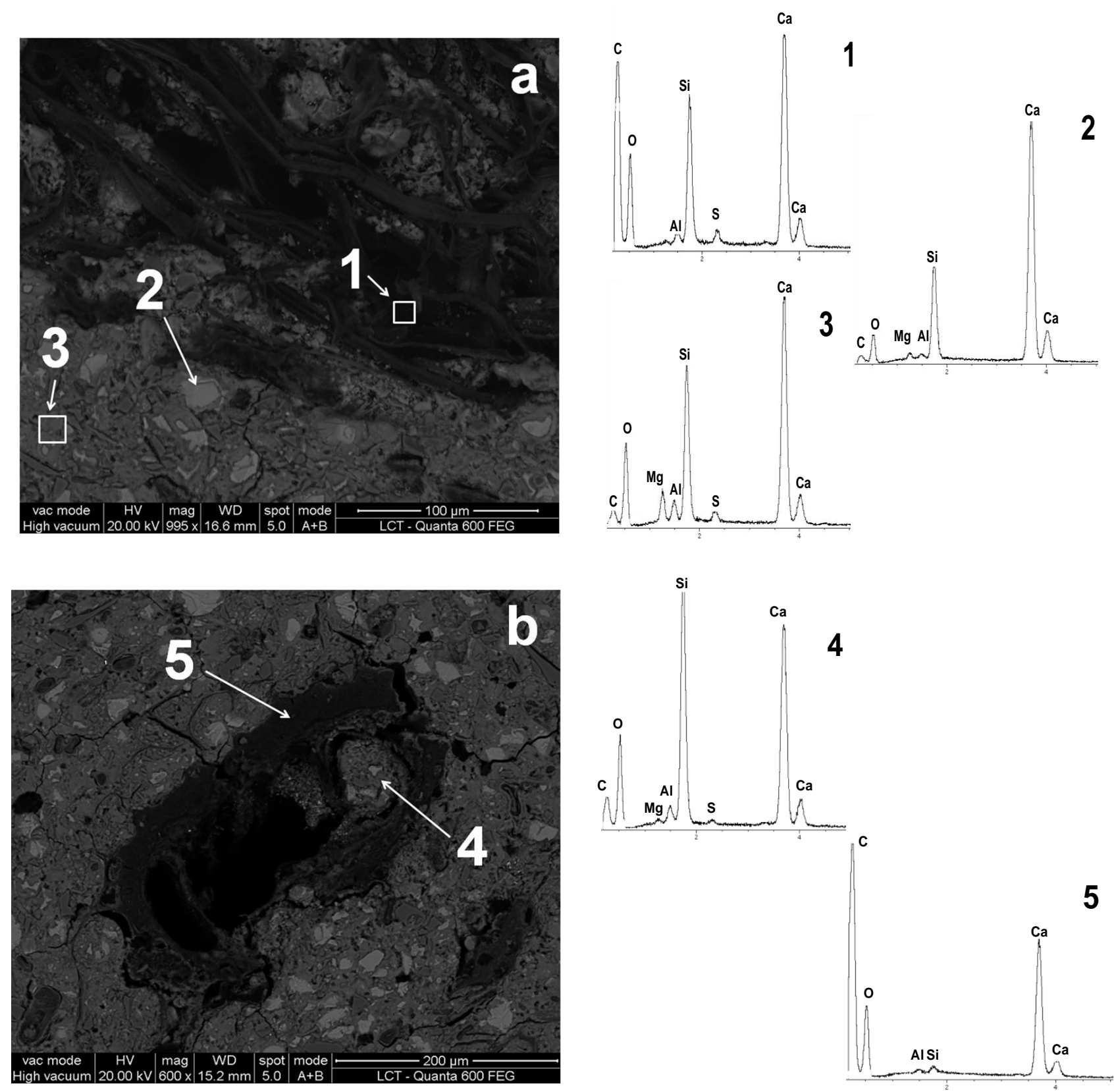

continua 
continuação
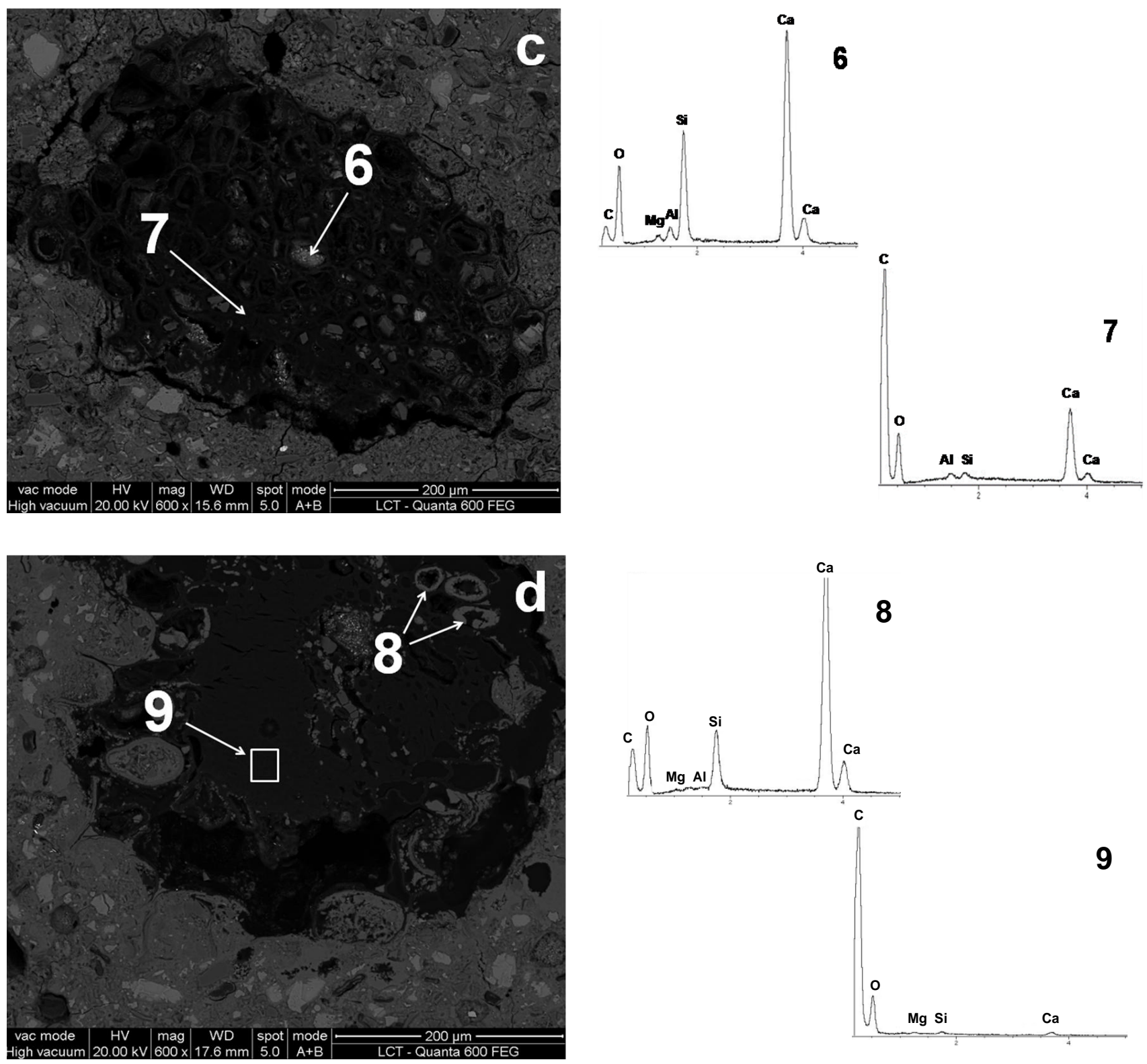

continua 
continuação
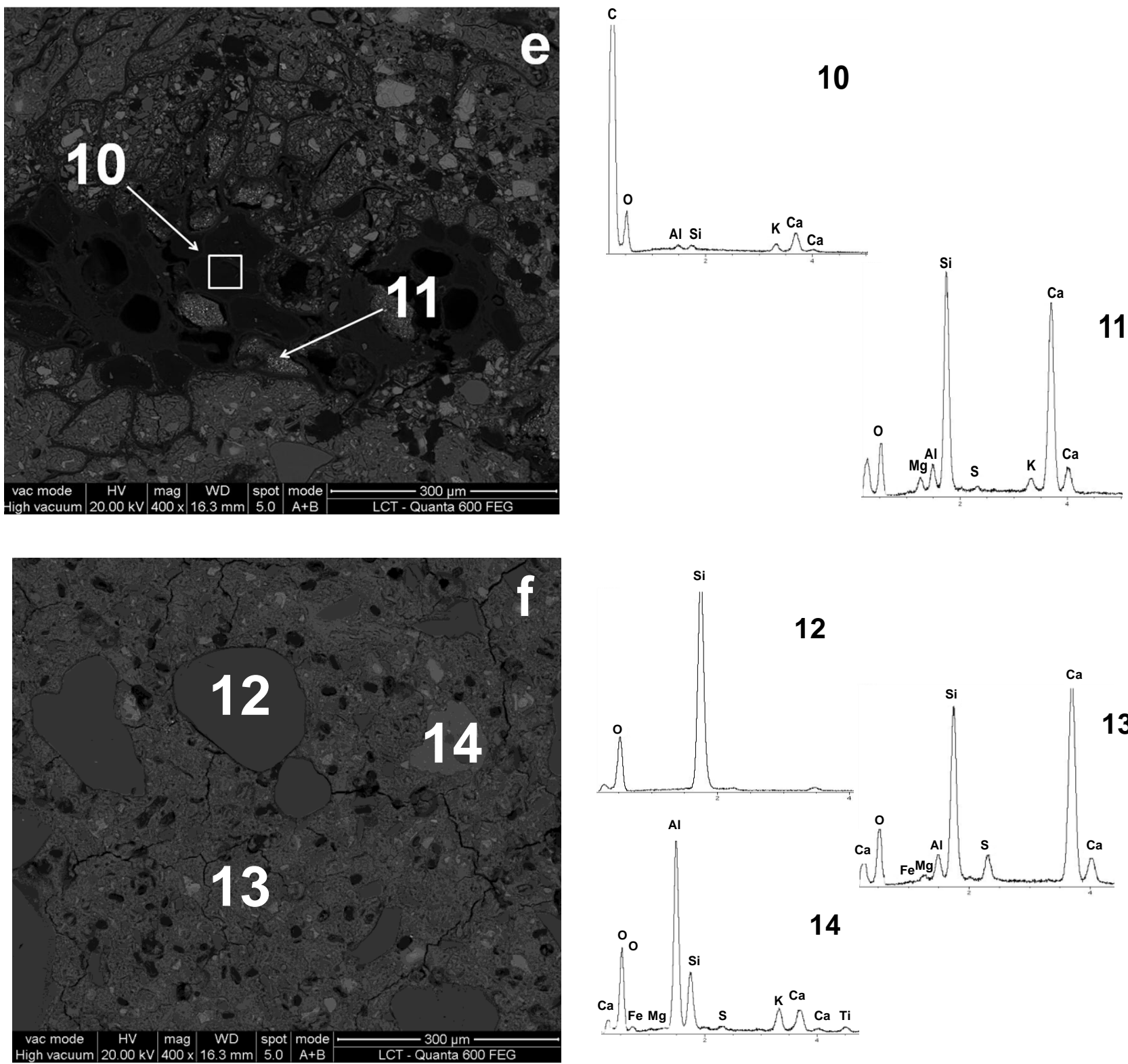

Figura 44 - Imagens em microscopia eletrônica de varredura (MEV-BSE) de superfícies polidas de compósitos reforçados com: (a) 0\% de reforço com 28 dias; (b) $5 \%$ de reforço com 28 dias; (c) $5 \%$ de reforço tratada com 28 dias; (d) $5 \%$ de reforço com 200 ciclos de envelhecimento e $(e, f) 5 \%$ de reforço tratado com $30 \%$ de substituição de cinzas com 28 dias. Pontos de análises de EDS estão sinalizados nas imagens (pontos 1 a 14).

Foi observado que nas FBC com $0 \%$ de reforço na (Figura 44a) apresentam as polpas de eucalipto não branqueada com alto índice de cálcio e silício (ponto 1), que evidência que a polpa absorveu água de hidratação do cimento. Resultado similar apresentado por Tonoli (92) que estudo fibra celulósica não branqueada de eucalipto. No ponto 2 e 3 da Figura 44a mostra claramente um grão formado de 
constituintes do cimento. Nas Figuras 44b e 44c, destacado com setas, ao redor da FBC tanto não tratada quanto tratada, descolamento da fibra/matriz, é devido à variação do volume da fibra em função do seu teor de umidade e estado de tensão, ocasionando buracos (poros), levando-a maior absorção de água, maior porosidade e baixa resistência.

Savastano Jr. (20) explica que melhor desempenho é conseguido por melhor aderência de fibra/matriz. A melhor adesão se consegue pela redução da porosidade e pela menor concentração de portlandita (cristais de hidróxido de cálcio) nas proximidades da fibra.

Na Figura 44b é apresentada FBC não tratada, na qual os grãos do cimento foram absorvidos pela água com cimento, as FBC destacado no ponto 4 onde prevalece os principais elementos químicos do cimento o silício e o cálcio. Entre as Figuras $44 \mathrm{~b}$ e $44 \mathrm{e}$ a cavidade do lúmen foi preenchida por produtos de hidratação do cimento.

Estas fibras mostram evidência da formação hidróxido de cálcio $\mathrm{Ca}(\mathrm{OH})_{2}$ dentro do lúmen das fibras. Isto é particularmente evidente nos pontos de EDS (1 a 11 na Figura (44e), onde o cálcio é o elemento predominante observado no lúmen das fibras (22). Também pode ser observado pelo EDS precipitado dos elementos químicos, como, $\mathrm{Al}, \mathrm{S}, \mathrm{K}$ e Mg. Este fenômeno pode ser associado à mineralização de fibras como inferido pelo Bentur e Akers (129).

$\mathrm{Na}$ Figura 44d com 5\% de reforço de FBC tratadas com 200 ciclos de envelhecimento por imersão em água, os íons livres formados pela dissolução das fases cimentícias do cimento Portland penetraram dentro do lúmen das fibras, provocando a formação da etringita/monosulfatos e de hidróxido de cálcio $\mathrm{Ca}(\mathrm{OH})_{2}$ (22). Batic et al. (130) mostrou que a re-precipitação de etringita em microtrincas e em poros da pasta cimentícia pode ocorrer sob condições normais (temperatura ambiente) de cura. Essa formação tem sido previamente sugerida como um dos mecanismos de degradação das fibras dentro da matriz de cimento $(19,131)$. Como observado na Figura 44d, um dos estágios de mineralização das fibras parece ser a formação de camadas de etringita/monosulfatos na borda interna da cavidade do lúmen. A mesma observação foi reportada por Mohr (19) onde foi utilizada fibras celulósicas, após 2 ciclos de envelhecimento, observou a formação de camadas de etringita com forma de agulha, formada perpendicularmente à superfície da borda interna do lúmen. A re-precipitação de hidróxido de cálcio $\mathrm{Ca}(\mathrm{OH})_{2}$ foi observada no 
centro da cavidade do lúmen, circundada pela camada de etringita (ainda dentro do lúmen) nas fibras tratadas.

Desse modo podemos afirmar que o tratamento químico não apresentou efeito nas FBC, pois ficam evidentes que as FBC absorveram os grãos de cimento.

Para tanto foi comprovado pelo testes de absorção de água, MEV das fibras e também no resultado de ensaio mecânicos, onde a FBC tratada não apresentou diferença em relação a FBC não tratada. Na Figura $44 f$ destaca-se no ponto 12 , um grão com um alto índice de silício proveniente da substituição de $30 \%$ de cimento por CBC. No ponto 14 o grão (cor mais clara) onde predomina o cálcio que evidencia um grão de cimento. Pelo EDS no ponto 14 explica a substituição do cimento por $30 \%$ CBC, onde apresenta vários elementos químicos oriundos da CBC apresentado.

\subsubsection{Resultado da porosimetria por intrusão de mercúrio nos compósitos (PIM)}

A Figura 45 mostra o comportamento da distribuição de poros dos compósitos cimentícios extrudados com 0\%, 1,5\% e 5\% de reforço de FBC.

Picos entre 6 e $100 \mathrm{~nm}$ apresentaram grande variação entre os diferentes níveis de reforços de FBC. FBC com $5 \%$ de reforço apresentaram maiores picos em relação aos demais níveis. Essa afirmação pode ser explicada pelo maior número de fibras no interior do compósito que gera maiores poros e, portanto maiores defeitos.

Mehta e Monteiro (35) mostraram intrusão de mercúrio similar às do presente experimento, em torno de $0,05 \mathrm{~mL} / \mathrm{g}$, para poros ao redor de $60 \mathrm{~nm}$ em argamassas sem fibras. De acordo com essa afirmação, os picos entre 6 e $100 \mathrm{~nm}$ nos gráficos abaixo são relacionados com os poros típicos da matriz cimentícia formados durante a hidratação.

Esses resultados também foram encontrados por Tonoli (97) que estudou fibrocimento com diferentes níveis de refino de fibras celulósicas. 


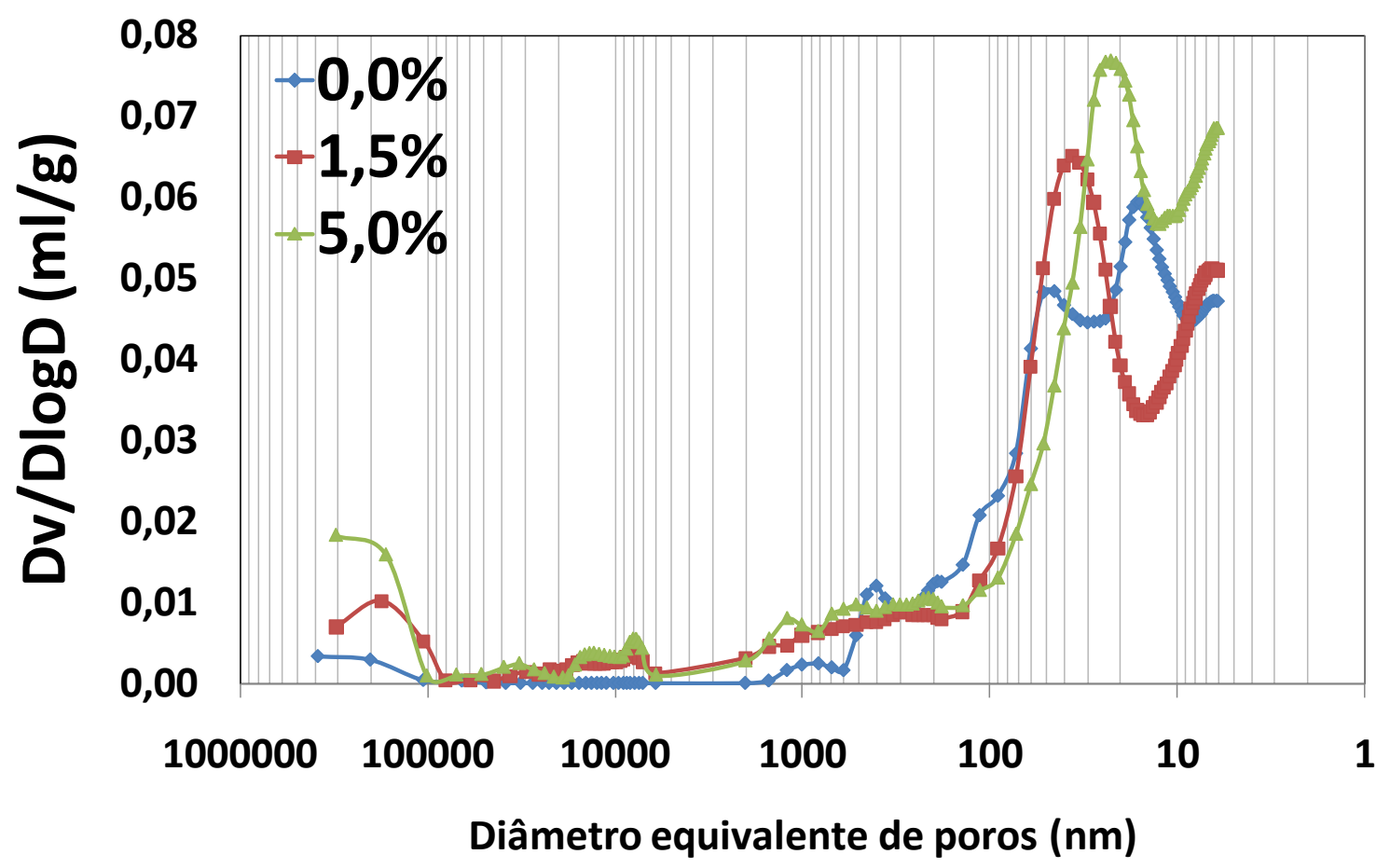

Figura 45 - Porosimetria por intrusão de mercúrio (PIM) acumulativa em compósitos extrudados com $0,0 \%, 1,5 \%$ e $5,0 \%$ de reforço em fibra de bagaço de canade-açúcar.

Entre 700 e 3000 nm houve uma diminuição no tamanho dos diâmetros dos poros.

Essa diminuição pode ser ocasionada pela falta de rugosidade da FBC, apresentado no item 5.3.3, que pode ter ocasionado o descolamento das fibras na interface da matriz durante sua variação dimensional o que pode ter gerado espaços vazios na zona de transição. Essa falta de rugosidade pode ter ocasionado também a falta de ancoragem da fibra com a matriz produzindo maiores diâmetros de poros e consequentemente maior absorção de água, maior porosidade e comportamento frágil do compósito cimentício.

A faixa entre 100.000 e $1.000 .000 \mathrm{~nm}$ (grandes poros) pode ser atribuída aos níveis de reforço das FBC. Outra informação importante a faixa entre 100 e 10.000 nm apresentou baixo diâmetro de poros, o que não foi apresentado por Tonoli (97) que estudou placas de fibrocimento com diferentes níveis de refino de fibras celulósicas. Essa diferença pode ser explicada pelo processo de fabricação.

O processo de extrusão transfere a mistura de uma grande câmara para um pequeno orifício promovendo a compactação da mistura, diminuindo seus poros. 
5.5.4 Resultado da permeabilidade ao ar dos compósitos

A Figura 46 apresenta o resultado da permeabilidade dos compósitos cimentícios com $0 \%, 5 \%$ tratada e $5 \%$ tratado com $30 \%$ de CBC.

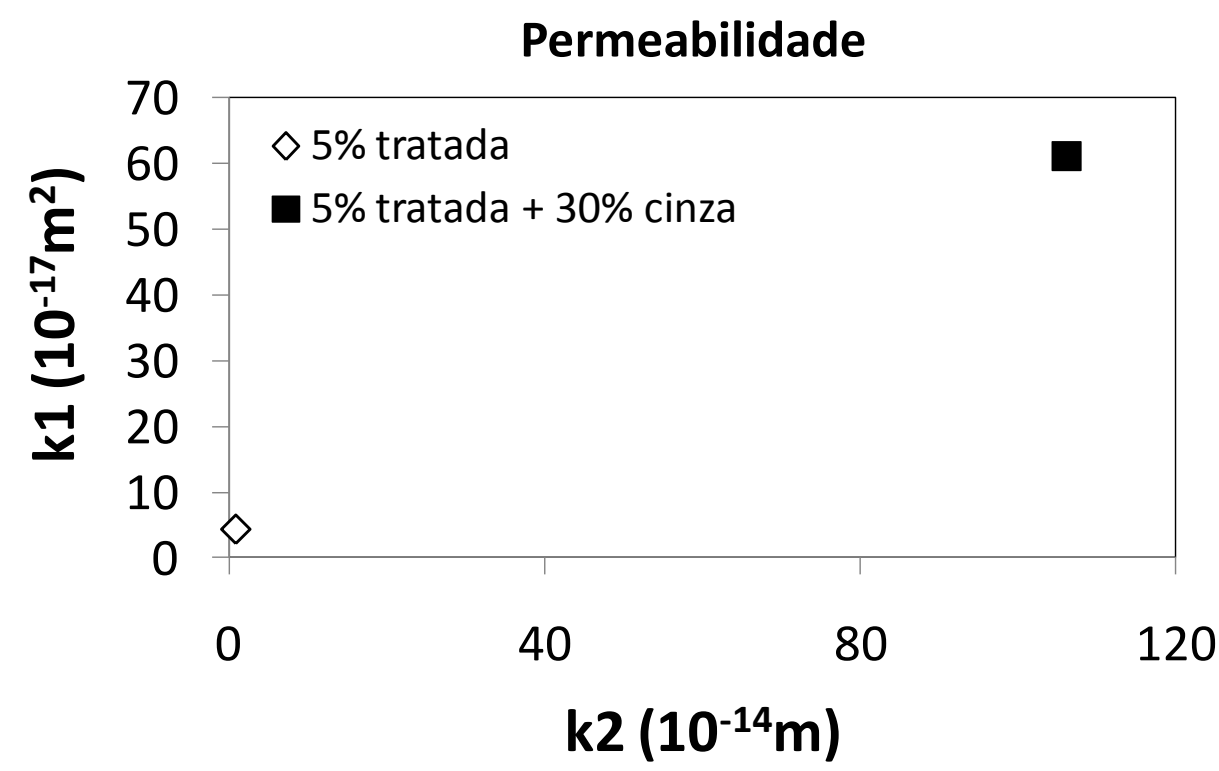

Figura 46 - Influência da permeabilidade ao ar nos compósitos cimentícios extrudados com 28 dias.

A permeabilidade é uma propriedade física de extrema importância para o desenvolvimento de elementos duráveis para a construção civil. A permeabilidade pode ser associada com a resistência à penetração dos agentes de degradação e as propriedades da estrutura (por exemplo, empacotamento das partículas permeáveis e os poros). A inter-relação entre as constantes de permeabilidade Darciana, $k_{1}$, e não Darciana, $k_{2}$, pode ser visto na Figura 46 . O resultado do compósito com $0 \%$ de reforço de FBC não está apresentado na Figura 46, pois não foi possível fazer sua permeabilidade ao ar com este procedimento, indicando que sua permeabilidade seja quase nula. Essa redução de poros permeáveis pode ser esclarecida pelo processo de extrusão onde a mistura é fortemente compactada.

Com $5 \%$ de reforço com FBC tratada apresentou uma diminuição na constante $\mathrm{k}_{1}$ e $\mathrm{k}_{2}$ em relação ao compósito com 5\% de FBC tratada com $30 \%$ de cinza. A constante $k_{1}$ indica que $o$ atrito e interações entre fluido e porosidade são menores no compósito com $5 \%$ de FBC tratada. Na constante $\mathrm{k}_{2}$ significa a 
tortuosidade do meio poroso devido a redução dos poros capilares causados por produtos de hidratação e grandes poros permeável permaneceram como principais rotas para o fluxo de fluido que apresentou o compósito com 5\% de FBC tratada.

Este resultado corrobora com a absorção de água (AA) e porosidade aparente nos resultados físicos dos compósitos com 5\% de FBC com 30\% de cinza onde apresentou um maior resultado em relação ao compósito com $5 \%$ de FBC tratado. Esta relação pode ser explicada pela utilização de maior volume de água/cimento na mistura pela sua área especifica.

\subsubsection{Resultado do custo de produção por matéria prima}

Na Tabela 13 apresenta o custo de produção do compósito cimentício pelo processo de extrusão em comparação ao processo sucção e prensagem (simulação do processo hatschek), que é normalmente usada pelas indústrias de fibrocimento para a fabricação de placas e telhas.

Os preços das matérias primas estão relacionados a uma quantidade feita por cada formulação realizada nesse trabalho com um total em massa de $4 \mathrm{~kg}$. É importante ressaltar que a quantidade de água utilizada pelo processo de extrusão é bem menor do que usado pelo processo de sucção e prensagem de $850 \mathrm{~g}$ para $19000 \mathrm{~g}$ respectivamente.

Tabela 13 - Comparação de custo de matérias-primas por produção de compósito cimentício.

\begin{tabular}{lccc}
\hline $\begin{array}{l}\text { Custo das } \\
\text { matérias-primas }\end{array}$ & $\begin{array}{c}\text { Preço em reais (venda } \\
\text { comercial) por quantidade }(\mathrm{kg})\end{array}$ & Placa extrudada (R\$) & $\begin{array}{c}\text { Placa sucção e } \\
\text { prensagem (R\$) }\end{array}$ \\
\hline $\begin{array}{l}\text { Cimento CPV-ARI } \\
\text { Sílica cristalina \# }\end{array}$ & 18 reais $/ 40 \mathrm{Kg}$ & 1,36 & 1,36 \\
500 & 700 reais $/ 1000 \mathrm{Kg}$ & 0,07 & 0,07 \\
ADVA 170 & 15 reais $/ \mathrm{Kg}$ & 0,60 & - \\
HPMC k-60 & 16 reais $/ \mathrm{Kg}$ & 0,64 & - \\
$\begin{array}{l}\text { Polpa não } \\
\text { branqueada }\end{array}$ & 500 reais $/ 1000 \mathrm{~kg}$ & 0,13 & 0,13 \\
\hline
\end{tabular}

Preço estimado em (R\$) das matérias-primas em agosto de 2010. 


\section{CONCLUSÕES}

A partir dos resultados apresentados nesse trabalho, conclui-se que:

- A lavagem do bagaço de cana-de-açúcar com água quente diminui consideravelmente o teor de açúcar residual;

- O tratamento químico utilizando o sulfato de sódio $30 \%$ e o silicato de alumínio 5\% nas fibras de bagaço de cana-de-açúcar não diminuiu a absorção de água da FBC, pelo contrario, aumentou a absorção de água não apresentando resultado satisfatório;

- A análise de infravermelho não destacou diferença entre as FBC não tratada e tratada;

- Na análise de MEV, as FBC não tratada e tratada não apresentaram diferenças superficiais e entre os elementos químicos utilizados pelo tratamento químico que tenha se destacado através do EDS;

- Espectroscopia de raios-X determinou que mais de 80\% das $\mathrm{CBC}$ é $\mathrm{SIO}_{2}$;

- O método da condutividade elétrica se mostrou uma técnica rápida e útil para comparar o grau de reatividade entre a CBC e a sílica cristalina em sistema com hidróxido de cálcio;

- A CBC apresentou mais componentes ativos que reagem com o cimento Portland determinado pela condutividade elétrica;

- O processo de extrusão para fibrocimento foi viabilizado, altamente produtivo e com capacidade de reproduzir matrizes com boas resistências mecânicas; 
- Compósitos cimentícios extrudados com 5\% de reforço de FBC apresentou maior tenacidade (TE) devido à maior introdução de fibras com 28 dias, mas não apresentou diferença significativa em relação ao tratamento químico;

- Compósitos cimentícios extrudados com 5\% de reforço de FBC não tratada e tratada com 28 dias e 200 ciclos apresentou descolamento das fibras na zona de transição da interface fibra/matriz, devido à variação do volume da fibra em função do seu teor de umidade e estado de tensão aumentando sua absorção de água (AA) e porosidade aparente (PA);

- Foi possível a utilização de FBC utilizado como reforço em compósito cimentício apresentou resultados mecânicos satisfatório com reforço de 5\%. No entanto, as fibras foram drasticamente degradadas pela ação alcalina proporcionada pelo cimento, tanto com 28 dias de idade, como 200 ciclos de envelhecimento;

- Os resultados obtidos quanto ao desempenho mecânico das matrizes com reforço de $5 \%$ de $\mathrm{FBC}$ e $30 \%$ de CBC em substituição ao cimento, sugerem que esses resíduos agroindustriais nas condições de beneficiamento propostas neste trabalho, pode ser utilizados com elementos construtivos, apesar de diminuírem o desempenho mecânico e aumentarem a absorção de água e porosidade;

- Compósitos cimentícios extrudados com 5\% apresentou maior porosidade determinada por porosimetria por intrusão de mercúrio em relação a menores teores de fibra apresentado maiores imperfeições no compósito;

- Compósito extrudado com $0 \%$ de reforço de fibra de bagaço de cana-deaçúcar não foi possível realizar sua permeabilidade ao ar, indicando que sua permeabilidade seja quase nula. Essa redução de poros permeáveis pode ser esclarecida pelo processo de extrusão onde a mistura é fortemente compactada. 


\subsection{Sugestões para trabalhos futuros}

Torna-se necessária a investigação mais detalhada do processo da mistura e do processo de fabricação.

Avaliar outras formas de desfibrilação das polpas, com a diminuição de quantidade de água, a dispersão da polpa é prejudicada, o que pode ocasionar aglomeração de polpas no interior do compósito cimentício

Estudo para a substituição de aditivos sintéticos por adições minerais para realizar a mesma função reológica, acarretando barateamento do produto final.

Utilizar outros tratamentos químicos na fibra vegetal, a fim de se evitar a variação dimensional da fibra melhorando a zona de transição interface fibra/matriz.

Estudo aprofundado da área geométrica da boquilha para evitar seu entupimento ou produzir placas com larguras e espessuras maiores.

Estudo dos parâmetros da queima do bagaço a fim de melhorar a homogeneidade das cinzas tornando materiais mais reativos.

Estudo do compósito cimentício extrudados para melhorar seu desempenho, sua reologia, para futuramente ser utilizado em produção industrial.

E hoje, sem dúvida, é de fundamental importância um estudo do desempenho, uma vez que resistência mecânica e durabilidade são indissociáveis. 


\section{REFERÊNCIAS}

1 FERREIRA, A. A.; SILVEIRA, A. A.; DAL MOLIN, D. C. C. A cinza da casca de arroz : possibilidades de utilização como insumo na produção de materiais de construção.In: ENCONTRO NACIONAL SOBRE EDIFICAÇÕES E COMUNIDADES SUSTENTÁVEIS, 1,1997,Canela, RS. Anais... Canela: ANTAC,1997.p.293-298.

2 COMPANHIA NACIONAL DE ABASTECIMENTO - CONAB. Produção de canade-açúcar, safra 2008/2009. Disponível em:< http://www.conab.gov.br.>. Acesso em: janeiro de 2010 .

3 FREIRE, W. J. Materiais alternativos de construção In: BERALDO, A. L. et al. Construções rurais: materiais. Rio de Janeiro: Livros Técnicos e Científicos Editora, 1991.p.105-161.

4 DAFICO, D. A. Método de produção de cinza de casca de arroz para utilização em concretos de alto desempenho. Disponível em: <www.ucg.br/Institutos/nucleos>. Acesso em: 04 de janeiro de 2004, 2003.

5 AFONSO, W. M. Caracterização de resíduo de corte de rochas na produção de argamassas. 2005. 122p.Tese (Mestrado em Engenharia Civil) - Universidade Estadual do Norte Fluminense Darcy Ribeiro - UENF, Rio de Janeiro,2005.

6 DELLA, V. P.; KUHN, I.; HOTZA, D. Caracterização de cinza de casca de arroz para uso como matéria-prima na fabricação de refratários de sílica. Química Nova, São Paulo, v.4, n. 6, p778-782, 2001.

7 SHAO, Y.; MARIKUNTE, S.; SHAH, S. Extruded fibre-reinforced composites. Concrete International, v.17, n.4, p.48-52, 1995.

8 SHAO, Y.; MORAS, S.; ULKEM, N.; KUBES, G. Wood fibre-cement composites by extrusion. Canadian Journal of Civil Engineering, v. 27, n.3, p.543-552, 2000.

9 SRINIVASAN, R.; DEFORD, D.; SHAH, P. S. The use of extrusion rheometry in the development of extrudate fibre-reinforced cement composites. Concrete Science and Engineering, v. 1, n. 11, p. 26-36, 1999. 
10 SHAO, Y.; SHAH, S. Mechanical properties of PVA fibre reinforced cement composites fabricated by extrusion processing. American concrete institute Material Journal, v. 994, n.6, p.555-564. 1997.

11 QIAN, X.; ZHOU, X.; MU, B.; LI, Z. Fibre alingment and property direction dependency of FRC extrudate. Cement and Concrete Research, v.33, n.10, p.1575-1581, 2003.

12 TAKASHIMA, H.; MIYAGAY, K.; HASHIDA, T.; LI, V. C. A design approach for the mechanical properties of polypropylene discontinuous fibre reinforced cementitious composites by extrusion molding. Engineering Fracture Mechanics, v. 70, n.7-8, p. 853-870, 2003.

13 HORST, G. G. Extrusion of FRC products: technology and practical aspects. In: INTERNATIONAL CONFERENCE INORGANIC-BONDED WOOD AND FIBER COMPOSITE MATERIALS, v 8., Sun Valley, 2002. Proceedings... Sun Valley, Idaho, USA, 2002.

14 BERALDO, L. A. Tecnologia e materiais alternativos de construção Campinas, SP: Editora da UNICAMP, 2003.

15 BATTLE, E.; RODRÍGUES, N. Tecnologia de la producción de tabletos de fibras, in Los devirados de la caña de azúcar. Cuba: ICIDCA - Instituto Cubano de Investigaciones de los Derivados de la Caña de azúcar,1980. p.178-201.

16 HESCH, R. Início da indústria integrada de placas aglomeradas de bagaço no Paquistão. Brasil Açucareiro, v. 75, n.2, p.33-50,1970.

17 BOURLIN, G. P. Manufacture of lightweight concrete produts, SIA, v. 29. n.11, pp. 236-37. 1967.

18 PATURAU, J.M. By- products of the cane sugar industry. 2nd ed. Amsterdan: Elsevier, 1982. (Sugar Series, no 3).

19 MOHR, B. J.; BIERNACKI, J. J.; KURTIS, K. E. Microstructural and chemical effects of wet/dry cycling on pulp fibre-cement composites. Cement and Concrete Research, v. 36, n. 7, p. 1240-1251, 2006.

20 TONOLI, G. H. D.; JOAQUIM, A. P.; ARSÈNE, M. A.; BILBA, K.; SAVASTANO JUNIOR, H. Performance and durability of cement based composites reinforced with 
refined sisal pulp. Materials and Manufacturing Processes, v. 22, n. 2, p. 149-156, 2007.

21 EL-ASHKAR, N. H.; NANKO, H.; KURTIS, K. E. Effect of moisture state on mechanical behavior and microstructure of pulp fibre-cement mortars. Journal of Materials in Civil Engineering, v. 19, n. 8, p. 691-699. 2007.

22 ROMA JUNIOR, L. C.; MARTELLO, L. S.; SAVASTANO JUNIOR, H. Evaluation of mechanical, physical and thermal performance of cement-based tiles reinforced with vegetable fibres. Construction and Building Materials, v. 22, n. 4, p. 668-674, 2008.

23 MACVICAR, R.; MATUANA, L. M.; BALATINECZ, J. J. Aging mechanism in cellulose fibre reinforced cement composites. Cement and Concrete Composites, v. 21, n. 3, p. 189-96, 1999.

24 CAMPBELL, M. D.; COUTTS, R. S. P. Wood fibre-reinforced cement composites. Journal of Materials Science, v. 15, n. 8, p. 1962-1970, 1980.

25 COUTTS, R. S. P.; WARDEN, P. G. Effect of compaction on the properties of aircured wood fibre reinforced cement. Cement and Concrete Composites, v. 12, n. 3, p. 151-156, 1990.

26 COUTTS, R. S. P.; NI, Y. Autoclaved bamboo pulp fibre reinforced cement. Cement and Concrete Composites, v. 17, n. 2, 99-106, 1995.

27 SAVASTANO JUNIOR, H.; WARDEN, P. G.; COUTTS, R. S. P. Brazilian waste fibres as reinforcement for cement-based composites. Cement and Concrete Composites, v. 22, n. 5, p. 379-384. 2000.

28 SAVASTANO JUNIOR, H.; WARDEN, P. G.; COUTTS, R. S. P. Potential of alternative fibre cements as building materials for developing areas. Cement and Concrete Composites, v. 25, n. 6, p. 585-592, 2003.

29 TONOLI, G. H. D.; SANTOS, S. F.; JOAQUIM, A. P.; SAVASTANO JUNIOR, H. Effect of accelerated carbonation on cementitious roofing tiles reinforced with lignocellulosic fibre. Construction and Building Materials, v. 24, n. 2, p. 193-201, 2010.

30 SOROUSHIAN, P.; SHAH, Z.; WON, J.; HSU, J. Durability and moisture sensitivity of recycled wastepaper-fibre-cement composites. Cement \&Concrete Composites v. 16, n. 2, p. 115-128. 1994. 
31 RAMOS, L. P. Fundamentals involved in pretreating and hydrolysing of lignocellulosic materials. In: INTERNATIONAL SEMINAR ON BIOMASS FOR ENERGY PRODUCTION (INTERBIO), 2001, Rio de Janeiro. Proceedings... Rio de Janeiro, RJ: Centro de Nacional de Referência em Biomassa, 2001. 14 p.

32 KRAUS, J; LOURO R. R. P.; ARDIUN M.; ESTELITA M. E. A célula vegetal. In. APPEZZATO-DA-GLÓRIA, B. CARMELLO-GUERREIRO, S. M. Anatomia Vegetal. 2.ed.. Viçosa: Editora da Universidade Federal de Viçosa, 2006. p. 32-67.

33 STIKLEN, M. B. Plant genetic engineering for biofuel production: towards affordable cellulosic ethanol. Nature Reviews Genetic, Londres, v. 9 n. 1, p. 433443, 2008.

34 AGOPYAN, V.; SAVASTANO JUNIOR, H. Uso de materiais alternativos à base de fibras vegetais na construção civil: experiência brasileira. In: SEMINÁRIO IBEROAMERICANO DE MATERIALES FIBRORREFORZADOS, 1.,1997, Cali.; REUNIÓN PROYECTO PIP VIII.5 CYTED, 3.,1997, Cali. Proceedings... Cali: Universidad del Valle, 1997. p. 23-40.

35 MEHTA, P. K.; MONTEIRO, P. J. M. Concreto estrutura, propriedades e materiais. São Paulo: Editora PINI, 1994.

36 MANGAT, P. S.; AZARI, M. M. Shrinkage of steel fibre reinforced cement composites. Materiaux at construsions, v. 21, n. 3, p.163-71, 1988.

37 BALAGURU, P. N.; SHAH, S. P. Fibre reinforced cement composites New York: McGraw-Hill, 1992.

38 MACVICAR, R.; MATUANA, L. M.; BALATINECZ, J. J. Aging mechanisms in cellulose fibre reinforced cement composites. Cement \& Concrete Composites, v. 21, n. 3, p. 189-196, 1999.

39 PROGRAMA DAS NAÇÕES UNIDAS PARA O DESENVOLVIMENTO (PNUD) La diversificación de la agroindustria de la caña de azucare en América Latina y el Caribe. [S.I.]: ICIDCA- GEPLACEA, 1986. 137 p.

40 CORDEIRO, G. C.; TOLEDO FILHO, R. D.; FAIRBAIRN, E. M. R.; TAVARES, L. M. M. Estudo do processo de moagem da cinza do bagaço da cana-de-açúcar visando seu emprego como aditivo mineral para concreto. In: CONFERÊNCIA BRASILEIRA DE MATERIAIS E TECNOLOGIAS NÃO-CONVENCIONAIS: 
HABITAÇÕES E INFRA-ESTRUTURA DE INTERESSE SOCIAL- NOCMAT, 2004, Pirassununga. Anais do Brasil NOCMAT. Pirassununga-SP: 2004.

41 CEPED - Centro de Pesquisa e Desenvolvimento. Utilização de fibras vegetais no fibro-cimento e no concreto-fibra. Rio de Janeiro: BNH-DEPEA, 1982.

42 AGGARWAL, L. K. Bagasse-reinforced cement composites. Cement \& Concrete Composites, v.17, n.2, p. 107-112, 1995.

43 BILBA, K.; ARSENE, M. A.; OUENSANGA, A. Sugar cane bagasse fibre reinforced cement composites. Part 1. Influence of botanical components of bagasse on the setting of bagasse/cement composite. Cement \& Concrete Composite v. 25, n. 1, p. 91-96, 2003.

44 AZIZ, M. A.; PARAMASIVAM, P.; LEE, S. L. Concrete reinforced with natural fibres. In: SWAMY, R. N. (Ed.) New reinforced concretes - concrete technology and design. London-UK: Blackie \& Son, 1984. v. 2, p.106-140.

45 GUIMARÃES, S. S. Experimental mixing and moulding with vegetable fibre reinforced cement composites, In: GHAVAMI K.; FANG H. Y. (Eds.). INTERNATIONAL CONFERENCE ON DEVELOPMENT OS LOW-COST AND ENERGY SAVING CONSTRUCTIONS MATERIALS., 1984, Rio de Janeiro. Proceedings... Rio de Janeiro: [s.n.], 1984. p 37-52.

46 SARMIENTO, C. R. ; FREIRE, W. J. Tratamento aplicado ao bagaço de cana-deaçúcar visando sua utilização para fins de material de construção. In: WORKSHOP RECICLAGEM E REUTILIZAÇÃO DE RESÍDUOS COMO MATERIAIS DE CONSTRUÇÃO CIVIL. 1996, São Paulo. Anais... São Paulo: Associação Nacional de Tecnologia do Ambiente Construído, 1996. pp. 132-37.

47 FURUNO, T.; UEHARA, T.; JODAI, S. Combinations of wood and silicate. I. impregnation by water glass and applications of aluminum sulfate and calcium chloride as reactants. Mokuzai Gakkaishi, v. 37, n. 5,p. 462-72, 1991.

48 FREITAS, E. G. A.; RODRIGUES, E. H. V.; ARAUJO, R. C. L.; FAY, I. Efeito da adição de cinzas de bagaço de cana na resistência à compressão de argamassa normal. In: CONGRESSO BRASILEIRO DE ENGENHARIA AGRÍCOLA, 27. 1998, Poços de Caldas. Anais... Lavras: Sociedade Brasileira de Engenharia Agrícola,1998. v.4, p.219-21. 
49 CINCOTTO, M. A. Utilização de subprodutos e resíduos na indústria da construção civil. A Construção, São Paulo, v.1855, p.27-30, 1983. (IPT - Encarte TE, 9).

50 JOHN, V. M.; CINCOTTO, M. A.; SILVA, M. G. Cinza e aglomerantes alternativos. In: FREIRE, W. J.; BERALDO, A. L. Tecnologia e materiais alternativos de construção. Campinas: Editora da UNICAMP, 2003. cap.6, p.145-190.

51 GRAY, R. J. Analysis of the effect of embedded fibre length on fibredebonding and pull-out from an elastic matrix - part 2: application to a steel fibre-cementitious matrix composite system. Journal of Materials Science, v.19, n.5, p.1680-91, 1984.

52 SHAH, S. P. Fibre reinforced concrete. In: KONG, F. K.; COHEN, E.; ROLL, E. F. (Eds.). Handbook of structural concrete. New York: McGraw-Hill Book Company, 1984.

53 COUTTS, R. S. P. Wood fibre reinforced cement composites. In: SWAMY, R.N., (Ed.) Natural fibre reinforced cement and concrete. Glasgow:Blackie,1988. p.20842. (Concrete Technology and Design, 5)

54 BARTOS, P. Review paper: bond in fibre reinforced cements and concretes. International Journal of Cement Composites, v.3, n.3, p.159-77, Aug. 1981.

55 BENTUR, A. Fibre-reinforced cementitious materials. In: SKALNY, J.P. (Ed.). Material science of concrete I. Westerville: American Ceramic Society, 1989. p.223-84.

56 GRAY, R. J.; JOHNSTON, C. D. The influence of fibre-matrix interfacial bond strength on the mechanical properties of steel fibre reinforced mortars. The International Journal of Cement Composites and Lightweight Concrete, v.9, n.1, p.43-55, 1987.

57 AGOPYAN, V.; SAVASTANO JUNIOR, H.; JOHN, V.M.; CINCOTTO, M.A. Developments on vegetable fibre-cement based materials in São Paulo, Brazil: an overview. Cement \& Concrete Composites; v. 27, n. 5, p. 527-536. 2005.

58 TAYLOR, H. F. W. Cement chemistry. London: Academic Press, 1990. 475p.

59 RAMACHANDRAN, V. S. Concrete science. In: RAMACHANDRAN, V. S.; BEAUDOIN, J. J. (Eds.). Handbook of analytical techniques in concrete science and technology - principles, techniques and applications. New Jersey: Noyes Publication; New York: Willian Andrew Publishing,1999. cap.1. 934p. 
60 ROSSETTO, H. L. Contribuições para a ciência e engenharia dos materiais cimentícios: processamento, durabilidade e resistência mecânica. 2007. $124 \mathrm{f}$. Tese (Doutorado). Escola de Engenharia de São Carlos, Instituto de Física de São Carlos, Instituto de Química de São Carlos, Universidade de São Paulo, São Carlos, 2007.

61 NÄGELE, E. W. The transient zeta potential of hydrating cement. Chemical Engineering Science, v. 44, n. 8, p. 1637-1645, 1989.

62 YANG, M.; NEUBAUER, C. M.; JENNINGS, H. M. Interparticle potential and sedimentation behavior of cement suspensions. Advanced Cement Based Materials, v. 5, n. 1, p. 1-7, 1997.

63 PETER, M. A.; MUNTEAN, A.; MEIER, S. A.; BÖHM, M. Competition of several carbonation reactions in concrete: a parametric study. Cement and Concrete Research, v. 38, n. 12, p. 1385-1393, 2008.

64 PADE, C.; GUIMARAES, M. The $\mathrm{CO}_{2}$ uptake of concrete in a 100 year perspective. Cement and Concrete Research, v. 37, n. 9, p. 1348-1356, 2007.

65 ROSSETTO, H. L.; DE SOUZA, M. F.; PANDOLFELLI, V. C. Adesão em materiais cimentícios: "in-built nanotechnology". Cerâmica, v. 55, n. 334, p. 199-205, 2009.

66 JEFFREY, G. A. An introduction to hydration bonding. New York: Oxford University Press. Inc., 1997.

67 SAVASTANO JUNIOR, H. Zona de transição entre fibras e pasta de cimento Portland: caracterização e inter-relação com as propriedades mecânicas do compósito. 1992. 249p. Tese (Doutorado) - Escola Politécnica da Universidade de São Paulo, São Paulo, 1992.

68 AGOPYAN, V. Materiais reforçados com fibras para a construção civil nos países em desenvolvimento: uso de fibras vegetais. 1991. 204p. Tese (LivreDocência) - Escola Politécnica, Universidade de São Paulo, São Paulo, 1991.

69 SAVASTANO JUNIOR, H.; DANTAS, F. A. Z.; AGOPYAN, V. Materiais reforçados com fibras: correlação entre a zona de transição fibra-matriz e as propriedades mecânicas. São Paulo: IPT/Pini, 1994. 56p. (Publicação IPT 2158 Boletim 67). 
70 MINDESS, S.; ODLER, I.; SKALNY, J. Significance to concrete performance of interfaces and bond: challenges of the future. In: INTERNATIONAL CONGRESS ON THE CHEMISTRY OF CEMENT, 1986, Rio de Janeiro. Proceedings... Rio de Janeiro: Abla, 1986. v.1, p.151-7.

71 GRAM, H. E. Durability of natural fibres in concrete. In: SWAMY, R.N.(Ed.) Natural fibre reinforced Cement and Concrete. Glasgow: Blackie, 1988. p.256-85. (Concrete Technology and Design, 5).

72 AKERS, S. A. S.; STUDINKA, J. B. Ageing behaviour of cellulose fibre cement composites in natural weathering and accelerated tests. International Journal of Cement Composites and Lightweight Concrete, v.11, n.2, p.93-7, 1989.

73 TOLÊDO FILHO, R. D.; SCRIVENER, K.; ENGLAND, G. L.; GHAVAMI, K. Durability of alkali sensitive sisal and coconut fibres in cement based composites. Cement \& Concrete Composites, v. 22, n. 2, p. 127-143. 2000.

74 GRAM, H. E. Durability of natural fibres in concrete. Swedish cement and concrete research institute. CBI Research, Stockholm, n. 1-83, p. 255, 1983.

75 DELVASTO, S.; BOTACHE, C. A.; ALBÁN, F.; GUTIÉRREZ, R. M.; PERDOMO, F.; SEGOVIA, F.; AMIGÓ, V. Effect of fique fibre surface chemical treatments on the physical and mechanical properties of the fibre subjected to aggressive mediums. In: Conferência Brasileira de Materiais e Tecnologia Não-convercinais: Habitações e Infra-estrutura de Interesse Social - 2004, Pirassununga. Anais do Brasil-NOCMAT. Pirassununga, SP: 2004.

76 SOROUSHIAN, P.; MARIKUNTE, S. Statistical evaluation of long-term durability characteristics of cellulose fiber reinforced cement composites. Americam Concrete Institute. v. 91, n. 9, p. 607-616. 1995.

77 IKAI, S.; REICHERT, J. R.; RODRIGUES, A. V.; ZAMPIERI, V. A. Asbestos-free technology with new high toughness polypropylene (PP) fibres in air-cured Hatschek process. Construction and Building Materials, v. 24, n. 2, p. 171-180, 2010.

78 BEZERRA, E. M.; JOAQUIM, A. P.; SAVASTANO JUNIOR, H.; JOHN, V. M.; AGOPYAN, $V$. The effect of different mineral additions and synthetic fibre contents on properties of cement based composites. Cement and Concrete Composites, v. 28, n. 6, p. 555-563, 2006. 
79 PORTER, M. Técnicas para el análisis de los sectores industriales y de la competencia. 23 ed. México: Compañía Editora Continental, 1998.

80 SOTO, Y. J. M.; TONOLI, G. H. D.; TEIXEIRA, R. S.; SANTOS, S. F.; SAVASTANO JUNIOR, $\mathrm{H}$. Prospective study on vegetable wastes as reinforcement in extruded fibre-cement. International Conference on Non-Conventional Materials and Technologies: Ecological Materials and technologies for Sustainable Constructions, 1997, Maceió. Anais do Brasil-NOCMAT. (Abmtenc) Maceió, 1997

81 BRAUN, D. B.; ROSEN, M. R. Rheology modifiers handbook practical use and application. Norwich: New York, 2000.

82 SHEN, B. Experimental approaches for determining rheological properties of cement-based extrudates. 2003. 124 p. Dissertação (Mestrado) Programa de Pós-Graduação da Universidade de Ciências e Tecnologia de Hong Kong, Hong Kong, 2003 (em inglês).

83 BOBBIO, P. A; BOBBIO, F. O. Química do processamento de alimentos. São Paulo: Varela,1992.p.11-24

84 SARMIENTO, C. R. Argamassa de cimento reforçada com fibras de bagaço de cana-de-açúcar e sua utilização como material de construção. 1996. Dissertação (Mestrado). Universidade Estadual de Campinas - UNICAMP, Campinas, 1996.

85 MOTTA, L. A. C. Melhoria do desempenho de fibras de coco e sisal para reforço de matrizes cimentícias através de tratamento termomecânico e impregnação de resinas. 2005. 133f. Tese (Doutorado) - Escola Politécnica, Universidade de São Paulo, São Paulo, 2005.

86 FRAILE, V.; LESCANO, C. A. A.; ROCHA, S. C. S. Caracterização física do resíduo de leite de soja úmido e seco e do material inerte utilizado na secagem em leito de jorro. In: CONGRESSO INTERNO DE INICIAÇÃO CIENTíFICA DA UNICAMP, 13., 2005, Campinas. Anais... Campinas: Unicamp, 2005. Não paginado.

87 SILVA, J.; QUEIROZ, A. C. Análise de alimentos: métodos químicos e biológicos. 3ed. Viçosa: UFV, 2002. 235p.

88 GUIMARÃES, J. L.; FROLLINI, E.; SILVA, C. G.; WYPYCHC, F.; SATYANARAYANA, K. G. Characterization of banana, sugarcane bagasse and 
sponge gourd fibres of Brazil. Industrial Crops and Products. v. 30, n. 3, pp.407415, 2009.

89 BUSCHLEDILLER, G.; ZERONIAN, S.H. Enhancing the reactivity and strength of cotton fibres. Journal of Applied Polymer Science. v. 45, n. 6, p. 967-979, 1992.

90 GONCALVES, M. C. Microscopia eletrônica de varredura. In: CANEVALORO JUNIOR, S.V. (Ed). Técnicas de caracterização de polímeros. São Paulo: Artliber, 2004. p.165-175.

91 VILLAR-COCIÑA, E.; VALENCIA-MORALES, E.; GONZÁLEZ-RODRÍGUEZ, R.; HERNÁNDEZ-RUÍZ, J. Kinetics of the pozzolanic reaction between lime and sugarcane straw ash by electrical conductivity measurement: a kinetic-diffusive model, Cement and Concrete Research, v. 33, n. 4, p. 517-524, 2003.

92 MORALES E. V.; VILLAR-COCIÑA, E.; FRÍAS, M.; SANTOS, S. F.; SAVASTANO JUNIOR., $\mathrm{H}$. Effects of calcining conditions on the microstructure of sugar cane waste ashes (SCWA): influence in the pozzolanic activation. Cement and Concrete Composites, v. 31, n. 1, p. 22-28, 2009.

93 TONOLI, G. H. D. Fibras curtas de Eucalipto para novas tecnologias em fibrocimento.2010. 148p. Tese (Doutorado em Ciência e Engenharia de Materiais)Instituto de Física de São Carlos,Instituto de Química de São Carlos, Escola de Engenharia de São Carlos, Universidade de São Paulo,São Carlos, 2010.

94 TONOLI, G. H. D.; FUENTE, E.; MONTE, C.; SAVASTANO JUNIOR, H.; ROCCO LAHR, F.A.; BLANCO, A. Effect of fibre morphology on flocculation of fibre-cement suspensions. Cement and Concrete Research, v. 39, n. 11, p. 1017-1022, 2009.

95 PELED, A; SHAH, S. Processing effects in cementitious composites: extrusion and casting. Journal of Materials in Civil Engineering, v. 15, n. 2, p.192-199, 2003.

96 ALDEA, C.; MARIKUNTE, S.; SHAH, S. Extruded Fibre Reinforced Cement Pressure Pipe. Advanced Cement Based Material. v. 8, n. 2, p. 47-55, 1998.

97 TONOLI, G. H. D. Aspectos produtivos e análise do desempenho do fibrocimento sem amianto no desenvolvimento de tecnologia para telhas onduladas. 2006. 129p. Dissertação (Mestrado) - Faculdade de Zootecnia e Engenharia de Alimentos, Universidade de São Paulo, Pirassununga, 2006. 
98 PAULA, M. O. Potencial de cinza do bagaço da cana-de-açúcar como material de substituição parcial do cimento Portland. 2006. 77p. Dissertação (Mestrado)- Universidade Federal de Viçosa, Viçosa, 2006.

99 REUNION INTERNATIONALE DES LABORATOIRES D'ESSAIS ET DES RECHECHES SR LEX MATERIAUX ET LES CONSTRUCTIONS (RILEM). RILEM 49TFR: testing methods for fibre reinforced cement-based composites. Materiaux et Constructions, v. 17, n. 102, p. 441-456. 1984.

100 TONOLI, G. H. D.; RODRIGUES FILHO, U. P.; SAVASTANO JUNIOR, H.; BRAS, J.; BELGACEM, M. N.; ROCCO LAHR, F. A. Cellulose modified fibres in cement based composites. Composites Part A: Applied Science and Manufacturing, v. 40, n. 12, p. 2046-2053, 2009.

101 AMERICAN SOCIETY FOR TESTING AND MATERIALS. ASTM C 948-81: test method for dry and wet bulk density, water absorption, and apparent porosity of thin sections of glass-fibre reinforced concrete. West Conshohocken, PA, USA. 1981.

102 SAVASTANO JUNIOR, H.; WARDEN, P. G.; COUTTS, R. S. P. Microstructure and mechanical properties of waste fibre-cement composites. Cement and Concrete Composites, v. 27, n. 5, p. 583-592, 2005.

103 KUDER, K. G.; SHAH, S. P. Effects of pressure on resistence to freezing and thawing of fibre-reinforced cement board. ACI Materials Journal, v. 100, n. 6, p. 463-468, 2003.

104 NITA, C.; JOHN, V. M.; DIAS, C. M. R.; SAVASTANO JUNIOR, H; TAKEASHI, M. S. Effect of metakaolin on the performance of PVA and cellulose fibres reinforced cement. In: ASCE ENGINEERING MECHANICS CONFERENCE 17, 2004, Newark. Proceedings... Newark: University of Delaware, 2004.11p.

105 MEHTA, P. K.; MONTEIRO, P. J. M. Concrete: microstructure, properties, and materials. 3rd ed. New York: McGraw Hill, 2006. 659p.

106 INNOCENTINI, M. D. M.; PARDO, A. R. F.; PANDOLFELLI, V. C. Modified pressure-decay technique for evaluating highly dense refractories permeability. Journal American Ceramic Society. v. 83, n. 1, p. 220-222, 2000.

107 INNOCENTINI, M. D. M.; PARDO, A. R. F.; MENEGAZZO, B. A.; BITTENCOURT, L. R. M.; RETTORE, R. P.; PANDOLFELLI, V. C. Permeability of 
high-alumina refractory castables based on various hydraulic binders. Journal American Ceramic Society. v. 85, n. 6, p. 1517-21, 2002.

108 SALOMÃO, R.; CARDOSO, F. A.; INNOCENTINIL, M. D. M.; BITTENCOURT, L. R. M.; PANDOLFELLI, V. C. Polymeric fibres and the permeability of refractory castables. Cerâmica. v. 49, n. 309, p. 23-28, 2003.

109 EUROPEAN COMMITTEE FOR STANDARDIZATION. EN 494: fibre-cement profiled sheets and fittings for roofing - products specification and test methods. London, UK.: BSI - British Standards Institution, 1994.

110 ASSOCIAÇÃO BRASILEIRA DE NORMAS TÉCNICAS. NBR 5733: cimento Portland de alta resistência inicial, especificação. Rio de Janeiro, Brazil, 1983. 5p.

111 VAN SOEST, P. J. Development of a comprehensive system of feed analysis and its application to forage. Journal Animal Science, v. 26, n. 1, p. 119-128, 1967.

112 ANSELMO, P.; BADR, O. Biomass resources for energy in North-eastern Brazil. Applied Energy. v. 77, n. 1, p. 51-67, 2004.

113 SATYANARAYANA, K. G.; WYPYCH, F. Characterization of natural fibres. In: FAKIROV, S.; BHATTACHARYA, D. (Eds.). Engineering biopolymers: homopolymers, blends and composites. Munich: Hanser Publishers, 2007. p. 3-48. ISBN 978-1-56990-405-3

114 HUANG, Z.; LIANG, X.; HU, H.; GAO, L.; CHEN, Y.; TONG, Z. Influence of mechanical activation on the graft copolymerization of sugarcane bagasse and acrylic acid. Polymer Degradation and Stability. v. 94, n. 10, p. 1737-1745, 2009.

115 YIN, L. H.; FEI, L. K.; CUI, F.Y.; TANG, C.; YIN, C. H. Superporous hydrogels containing poly(acrylic acid-co-acrylamide)/O-carboxymethyl chitosan interpenetrating polymer networks. Biomaterials. v. 28, n. 6, p. 1258-66, 2007.

116 VIERA, R. G. P.; FILHO, G. R.; ASSUNÇÃO, R. M. N.; MEIRELES, C. S. Synthesis and characterization of methylcellulose from sugar cane bagasse cellulose. Carbohydrate Polymers. v. 67, n. 2, p. 182-189, 2007.

117 MARLSSON, J. O.; ANDERSSON, M.; BERNTSSON, P.; CHIHANI, T.; GALENHOLM, P. Swelling behavior of stimuli-responsive cellulose fibres. Polymer. v. 39, n. 16, p. 3589-95, 1998. 
118 LÓPEZ, R.; POBLANO, V. M.; LICEA-CLAVERÍE, A.; AVALOS, M.; ALVAREZCASTILLO, A.; CASTAÑO, V. M. Alkaline surface modification of sugar cane bagasse. Advanced Composite Material. v. 9, n. 2, p. 99-108, 2000.

119 BILBA, K.; ARSENE, M-A. Silane treatment of bagasse fibre for reinforcement of cementitious composites. Composites: Part A, Applied Science and Manufacturing, v. 39, n. 9, p. 1488-1495, 2008.

120 COOK, D. J. Rice husk ash. In: SWAMY, R. N. (Ed.) Concrete techonology and design. 1986 London-UK: Blackie \& Son Ltd., 1986. 170 p. v.3.

121 AMORIM, L. V.; PEREIRA, A. S. G.; NEVES, G. A; FERREIRA, H. C. Reciclagem de rejeitos da construção civil para uso em argamassas de baixo custo. Revista Brasileira de Engenharia Agrícola e Ambiental. v. 3, n. 2, p. 222-228. 1999.

122 DIAS, D. P.; PESSANHA, M. C. R. Ativação alcalina da cinza do bagaço de cana. In: CONGRESSO BRASILEIRO DE CIÊNCIA E TECNOLOGIA EM RESÍDUOS E DESENVOLVIMENTO SUSTENTÁVEL. "Cimento ecológico para a construção civil", 2004, Florianópolis. Anais... Florianópolis-SC: ICTR, 2004.

123 FREITAS, E. S. Caracterização da cinza do bagaço da cana-de-açúcar do município de Campos dos Goytacazes para uso na construção civil. 2005. 97 p. Dissertação (Mestrado) - Centro de Ciência e Tecnologia, da Universidade Estadual do Norte Fluminense Darcy Ribeiro - UENF, Rio de Janeiro, 2005.

124 RODRIGUES, J. A.; SANTOS, S. F. Brittle-ductile transition of alumina-glass castables. In: INTERNATIONAL COLLOQUIUM ON REFRACTORIES: REFRACTORIES FOR METALLURGY, 47., 2004, Aachen. Proceedings... Düsseldorf: Verlag Stahleisen GmbH. 2004. p. 81-84.

125 OLIVEIRA, I. R.; STUDART, A. R.; PILEGGI, R. G.; PANDOLFELLI, V. C. Dispersão e empacotamento de partículas: Principios e aplicações em processamento cerâmico. São Paulo/SP: Ed. Fazendo Arte, 2000. 224p.

126 OLIVEIRA, D. C. G. Avaliação do microclima interno de abrigos escamoteadores com diferentes tipos de pisos. 2010. 119f. Dissertação (Mestrado) - Faculdade de Zootecnia e Engenharia de Alimentos, Universidade de São Paulo, Pirassununga, 2010. 
127 SRINIVASAN, R.; DEFORD, D.; SHAH, P. S. The use of extrusion rheometry in the development of extrudate fiber-reinforced cement composites. Concrete Science and Engineering, v. 1, n.6, p.26-36, 1999.

128 BARBOSA, M. F.; LIMA, E.; PIRES SOBRINHO, C. W. A. Estudo de argamassas com adições de cinza de casca de arroz e cinza de cana-deaçúcar. In: ENCONTRO NACIONAL DE TECNOLOGIA DO AMBIENTE CONSTRUÍDO QUALIDADE NO PROCESSO CONSTRUTIVO, 7., 1998, Florianópolis. Anais... Florianópolis: UFSC/ANTAC, 1998. 5p.

129 BENTUR, A.; AKERS, S. A. S. The microstructure and aging of cellulose fibre reinforced cement composites cured in a normal environment. International Journal of Cement Composites and Lightweight Concrete. v. 11 n. 2, p. 99-109. 1989.

130 BATIC, O. R.; MILANESI, C. A.; MAIZA, P. J.; MARFIL, S. A. Secondary ettringite formation in concrete subjected to different curing conditions. Cement and Concrete Research. v. 30, n. 9, p. 1407-1412, 2000.

$131 \mathrm{MOHR}$, B. J.; NANKO, H.; KURTIS, K. E. Durability of kraft pulp fibre-cement composites to wet/dry cycling. Cement and Concrete Composites, v. 27, n. 4, p. 435-448, 2005. 


\section{APÊNDICE A}

Valores médios e desvios-padrão de módulo de ruptura (MOR), limite de proporcionalidade (LOP), módulo de elasticidade (MOE), tenacidade (TE), absorção de água (AA), densidade aparente (DA) e porosidade aparente (PA) dos compósitos reforçados com fibra e cinza de bagaço de cana-de-açúcar não-tratada e tratada. Compósitos testados após 28 dias de cura.

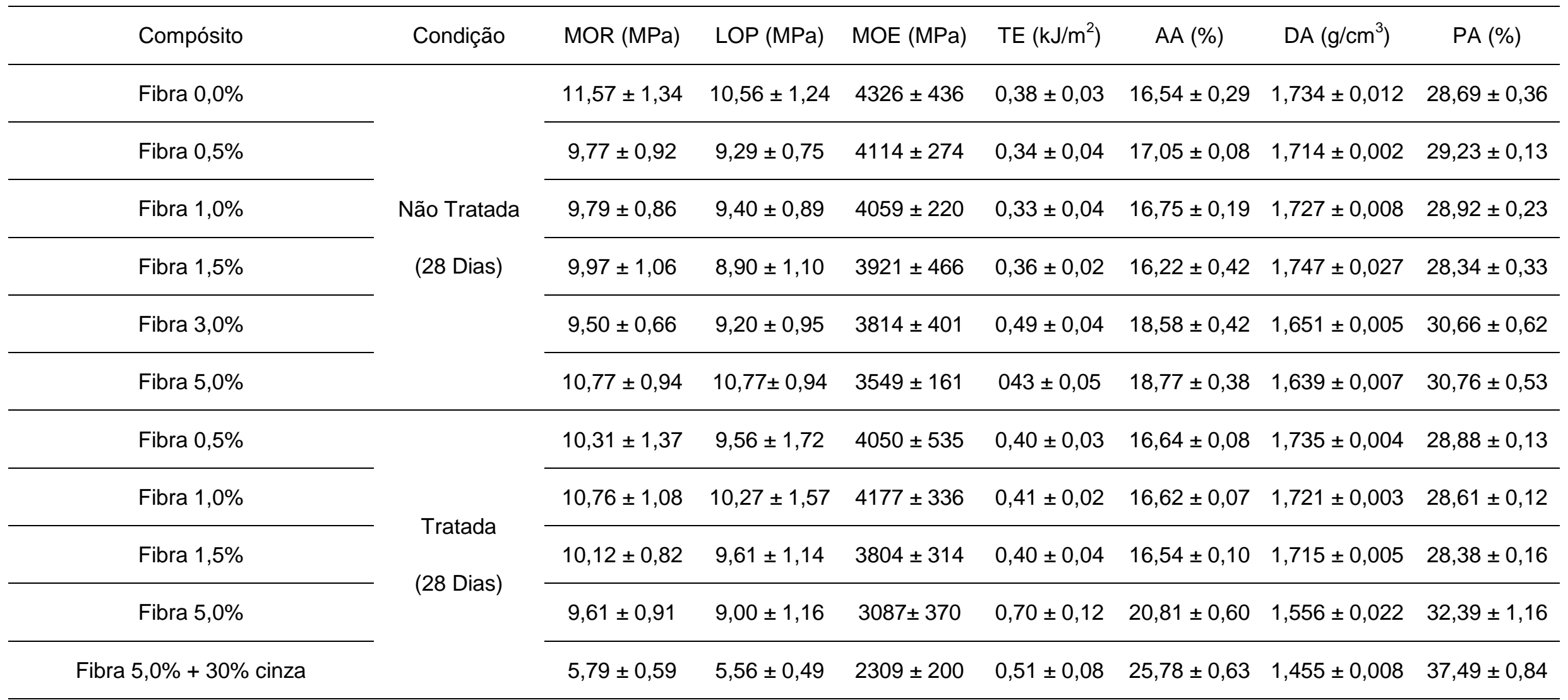




\section{APÊNDICE B}

Valores médios e desvios-padrão de módulo de ruptura (MOR), limite de proporcionalidade (LOP), módulo de elasticidade (MOE), tenacidade (TE), absorção de água (AA), densidade aparente (DA) e porosidade aparente (PA) dos compósitos reforçados com fibra e cinza de bagaço de cana-de-açúcar não-tratada e tratada. Compósitos testados após 200 ciclos de envelhecimento.

\begin{tabular}{|c|c|c|c|c|c|c|c|c|}
\hline Compósito & Condição & MOR (MPa) & LOP (MPa) & MOE (MPa) & $\mathrm{TE}\left(\mathrm{kJ} / \mathrm{m}^{2}\right)$ & $\mathrm{AA}(\%)$ & $\mathrm{DA}\left(\mathrm{g} / \mathrm{cm}^{3}\right)$ & PA (\%) \\
\hline Fibra 0,0\% & \multirow{6}{*}{$\begin{array}{l}\text { Não Tratada } \\
\text { (200 ciclos) }\end{array}$} & $14,84 \pm 4,26$ & $14,84 \pm 4,26$ & $9199 \pm 1508$ & $0,28 \pm 0,03$ & $11,65 \pm 0,77$ & $1,767 \pm 0,010$ & $20,57 \pm 1,27$ \\
\hline Fibra $0,5 \%$ & & $12,48 \pm 1,83$ & $12,48 \pm 1,83$ & $9248 \pm 1265$ & $0,26 \pm 0,03$ & $13,07 \pm 0,43$ & $1,737 \pm 0,002$ & $22,71 \pm 0,73$ \\
\hline Fibra 1,0\% & & $14,10 \pm 2,78$ & $14,10 \pm 2,78$ & $8879 \pm 1891$ & $0,38 \pm 0,02$ & $12,92 \pm 0,77$ & $1,754 \pm 0,010$ & $22,65 \pm 1,26$ \\
\hline Fibra 1,5\% & & $12,99 \pm 1,16$ & $12,30 \pm 1,18$ & $8370 \pm 1408$ & $0,36 \pm 0,02$ & $12,87 \pm 0,64$ & $1,794 \pm 0,029$ & $23,08 \pm 0,92$ \\
\hline Fibra 3,0\% & & $11,42 \pm 1,12$ & $11,42 \pm 1,12$ & $3922 \pm 300$ & $0,35 \pm 0,05$ & $13,84 \pm 0,27$ & $1,631 \pm 0,006$ & $23,26 \pm 0,48$ \\
\hline Fibra 5,0\% & & $12,29 \pm 1,26$ & $12,20 \pm 1,39$ & $3864 \pm 345$ & $0,40 \pm 0,06$ & $13,53 \pm 0,60$ & $1,659 \pm 0,006$ & $22,46 \pm 1,05$ \\
\hline Fibra $0,5 \%$ & \multirow{5}{*}{$\begin{array}{c}\text { Tratada } \\
\text { (200 ciclos) }\end{array}$} & $12,96 \pm 2,65$ & $12,68 \pm 2,63$ & $9269 \pm 1092$ & $0,22 \pm 0,07$ & $12,97 \pm 0,75$ & $1,766 \pm 0,006$ & $22,91 \pm 1,32$ \\
\hline Fibra 1,0\% & & $12,97 \pm 2,50$ & $12,97 \pm 2,50$ & $8139 \pm 1278$ & $0,23 \pm 0,05$ & $12,87 \pm 0,66$ & $1,742 \pm 0,004$ & $22,42 \pm 1,13$ \\
\hline Fibra 1,5\% & & $14,45 \pm 0,93$ & $14,11 \pm 0,60$ & $8277 \pm 1313$ & $0,33 \pm 0,10$ & $13,06 \pm 0,40$ & $1,742 \pm 0,004$ & $22,75 \pm 0,68$ \\
\hline Fibra 5,0\% & & $10,73 \pm 0,38$ & $10,43 \pm 0,54$ & $3819 \pm 335$ & $0,37 \pm 0,04$ & $21,08 \pm 0,25$ & $1,476 \pm 0,010$ & $31,12 \pm 0,52$ \\
\hline Fibra 5,0\% + 30\% cinza & & $8,35 \pm 0,56$ & $7,77 \pm 0,81$ & $3299 \pm 403$ & $0,37 \pm 0,04$ & $16,31 \pm 0,62$ & $1,610 \pm 0,006$ & $26,26 \pm 0,96$ \\
\hline
\end{tabular}

